SERVIÇO DE PÓS-GRADUAÇÃO DO ICMC-USP

Data de Depósito: 15.01.2004

Assinatura: Ana - Paula pampacio jrejon-

\title{
Uma estratégia para correção de uma característica de qualidade de uma peça devido à variação de temperatura
}

\author{
Paulo Leonardo Sirimarco Gomes
}

Orientador: Prof. Dr. Dorival Leão Pinto Júnior.

Dissertação apresentada ao Instituto de Ciências Matemáticas e de Computação - ICMC-USP, como parte dos requisitos para obtenção do título de Mestre em Ciências de Computação e Matemática Computacional

\author{
USP - São Carlos \\ Janeiro/2004
}


A Comissão Julgadora:

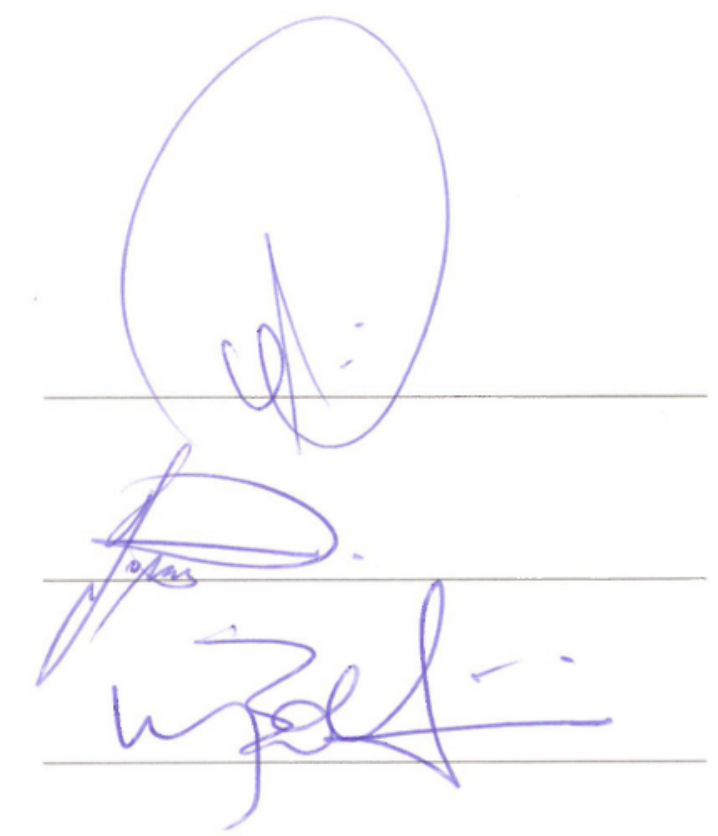


À minha familia e à minha noiva 


\section{Agradecimentos}

Neste momento, gostaria de agradecer as pessoas que, de alguma forma, contribuíram para a conchusão deste trabalho. Agradeço especialmente:

- Ao men orientador Prof. Dorival Leão pela dedicação, paciencia e por todo seu incentivo nos momentos de dívidas.

- À empresa KS Pistões pelo financiamento deste trabalho. Particularmente, aos senhores Ghïnter, Ednan e Juscelino pela cumplicidade e receptividade.

- Aos mens pais Panlo e Sônia r aos neus imaños Alessandro e Sabine pelo apoio e pela compreensão, principalmente nas horas mais difíccis.

- À minha noiva Glaucia por todo o amor, compreensão nas horas de nervosismo e pelos sonhos divididos.

- Ao instituto de ciências matemáticas e de computação da USP São Carlos pelos recursos oferecidos para o desenvolvimento deste trabalho.

- A Dens por permitir a conchusão deste trabalho.

Muito obrigado a todos! 


\section{Resumo}

Neste trabalho desenvolvemos um algoritmo para compensarmos as medições do diâmetro de una peça devido à variaşão de temperatura ambiente para sistemas de mediçăo que medem por comparação. Para isto, aplicamos os modelos de regressão com erros nas variáveis com o objetivo de determinar os coeficientes de correção no liânetro úteis no algoritmo. Numa primeira ctapa. realizamos dois experimentos, um utilizando da estufa para simular uma situação natural de variação de temperatura e assim obtermos informaçóes prévias do comportamento do diâmetro da peça cm função da temperatura. En um outro experimento onde a temperatura das peças foran obtidas em função da variação natural de temperatura do setor de realização do experimento. Numa segunda ctapa, apresentamos o modelo de rogressão lincar sen interecplo com cros nas variáveis para situação onde conheccmos a variância associada ao crro cometido pelo termometro utilizado para medir a temperatura das peças. Na terceira ctapa, propomos duas abordagens para tratar o problema, abordagem Bayesiana e Clássica. Numa quarta ctapa, comparamos as aproximações para as estimativas dos coeficientes do modelo de regressão com crros nas variáveis obtidos via algoritno de Gibbs e F.M. 


\begin{abstract}
In this work, we crcative an algorithm to compensate the measurement of the diameter of a pice clus to change of the enviromment temperature for systems of neasurement that measures by comparison. For this, we applind regression models with orrors in the variables in order to determine the coefficients of correction in the uschul dianneter in the algorithns. In a first step, we do two experiments, one using the thermal heating to simulate a natural situation of change the temperature and then we get prior information of diameter behavior of the piece in action of temperature. In another experiment the pieces temperature was get in function to natural change of tempcrature of the site of ruming experiment. In the second step, we present the linear regression model without interept with errors in variables to situation where we know the error variance conmit to themometer ased to measure the pieces temperature. In the thirst step, we propose two boards to treat the problem. Bayesian board and Classic. In the quarter step, wo compare the approach for the coefficients estimates of the regression model with crrors in variables got through Gibbs and EM algorithms.
\end{abstract}




\section{Conteúdo}

1 Introduçāo 1

1.1 Descrição da Peça o da Característica da Qualidade . . . . . . . . . . . 3

1.2 Célula de Medição e o procedimento de ajuste . . . . . . . . . 3

1.3 Equação de Medição . . . . . . . . . . . . . . . . . . . 5

1.4 Estratégia de Correção . . . . . . . . . . . . . . . . . . . 6

2 Delineamento Experimental 13

2.1 Experimento Preliminar . . . . . . . . . . . . . . . . . 14

2.2 Scyundo Exporinento . . . . . . . . . . . . . . . . . . . 20

3 Modelo de Regressão com erro nas variáveis intercepto nulo: Relação Ultraestrutural $\quad 27$

3.1 Notação Matricial . . . . . . . . . . . . . . . . . . . . . . . . 30

3.2 Introdução de Variáveis Latentes . . . . . . . . . . . . . . . 36

4 Estimador de Máxima Verossimilhança (EMV) 45

4.1 Algoritmo EM (Esperança c Maximização) . . . . . . . . . . . . 45

4.2 Matriz de Informação Esperada de Fisher . . . . . . . . . . . . . . . 48

5 Estimador de Bayes $\quad 53$

5.1 Métodos Baycsianos . . . . . . . . . . . . . . . . . 53

5.2 Análise Bavesiana e Algoritmo de Simulação . . . . . . . . . . . . . 54

6 Aplicação: Correção no Diâmetro do Furo do Pistão devido à Variação de Temperatura 59

6.1 Informaçós Iniciais . . . . . . . . . . . . . . . . . . . 59 
6.1.1 Ilipcrparânetros para análise Baycsiana . . . . . . . . . . (j0)

6.1 .2 Valores Iniciais . . . . . . . . . . . . . . . . . . . 63

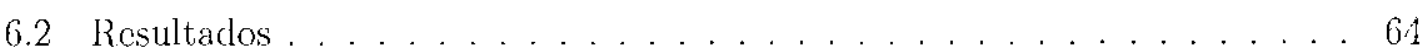

6.2 .1 Análise Clássica . . . . . . . . . . . . . . . . 64

6.2 .2 Análise Bayesiana . . . . . . . . . . . . . . . . . . . . . 68

6.3 Análise de Robustez . . . . . . . . . . . . . . . . . 74

6.3.1 Robustcz do Algoritmo EM . . . . . . . . . . . . . . . 74

6.3.2 Robustez das Estimativas Baycsianas . . . . . . . . . . . . 75

$\begin{array}{lll}7 & \text { Discussão } & 77\end{array}$

8 Propostas futuras $\quad 83$

9 Apêndices $\quad 85$

9.1 Certificarlo de calibração . . . . . . . . . . . . . . 85

9.2 Algoritmo de Gibbs Sampling . . . . . . . . . . . . . . 86

9.3 Critério de convergêneia de Gelman e Rubin . . . . . . . . . . . 88

9.4 Dados do Pré e segundo cxperimentos . . . . . . . . . . . . . . . . . 90

9.5 Dados da segunda fase da validaçäo . . . . . . . . . . . . . . . . . 97

$\begin{array}{ll}\text { Bibliografia } & 103\end{array}$ 


\section{Lista de Figuras}

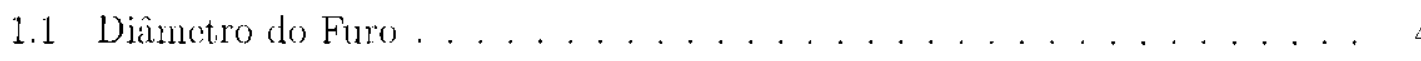

1.2 Procedimento de Medisão . . . . . . . . . . . . . . . . .

2.1 Termômetro de Contato . . . . . . . . . . . . . . . . 14

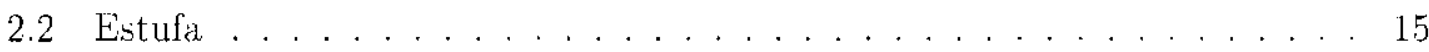

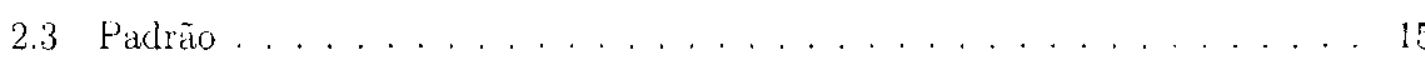

2.4 Scartcer Plot padräo . . . . . . . . . . . . . . . . 17

2.5 Scarter Plot poça . . . . . . . . . . . . . . . . . 17

2.6 bux-Plot padrão. . . . . . . . . . . . . . . . . . . . . 18

2.7 Box-Plot pega . . . . . . . . . . . . . . . . 18

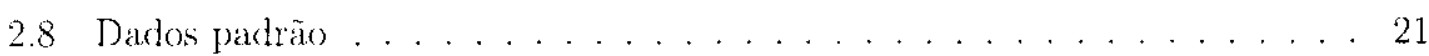

2.9 Dados pecia . . . . . . . . . . . . . . . . . . . 21

2.10 Dados transformados padrão . . . . . . . . . . . . . . . 22

2.11 Dados transformados peça . . . . . . . . . . . . . . . . . 23

6.1 Fqunação estimada - dados dos padrōes . . . . . . . . . . . . . 67

6.2 Equação estimada - dados dos pistõos . . . . . . . . . . . . . 67

6.3 Equlação estimada - dados dos padróes . . . . . . . . . . . . . 70

6.4 Equafáa estimada - dados dos pistóes . . . . . . . . . . . . . 70

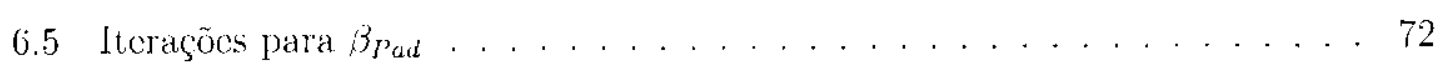

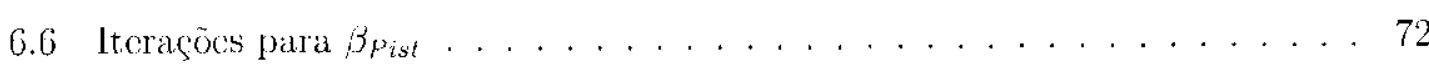

6.7 Aproximagào la densidade a posteriori marginal de $\beta_{p}$ ist . . . . . . . . 73



7.1 Erros de compensação térmica . . . . . . . . . . . . . . 80 


\section{Lista de Tabelas}

2.1 Sumarização dos dados de diânetro e temperatura para padrão. . . . . . . 19

2.2 Sumarização dos dados de diàmetro e temperatura para peça. . . . . . . 19

2.3 Sumarização dos dados do diâmetro e temperatura para padrão. . . . . . . 24

2.4 Sumarização dos dados de dianetro e temperatura para peça. . . . . . . 24

2.5 Sumarização dos dados transformados de diâmetro e temperatura para padrào. . . . . . . . . . . . . . . . . 25

2.6 Sumarização dos dados transformados de diânetro e temperatura para peça. 25

6.1 Informaçoos preliminares dos dos parânetros ß̧ e $\sigma^{2}$ para os dados dos padrōes. . . . . . . . . . . . . . . . . . . . . 61

6.2 Informaçós preliminares dos dos parâmetros $\beta$ e $\sigma^{2}$ para os dardos dos pistões. 61

6.3 Informações preliminares dos parâmetro $\sigma_{V}^{2}$ para os dados dos padrões e pistões. . . . . . . . . . . . . . . . . . . . 62 62

6.4 Resultados da análise clássica do modelo de regressão com erros para os dados para os padróes. . . . . . . . . . . . . . . . . . 65

6.5 Resultados da análise clássica do modelo de regressão com crros para os dados para os pistós. . . . . . . . . . . . . . . . . 65

6.6 Sumários a postcriori do modelo de regressão com crros para os dados para os padrö́cs. . . . . . . . . . . . . . . . . . . . . . . 68

6.7 Sumários a posteriori do modelo de regressão com erros para os dados para os pistoes. . . . . . . . . . . . . . . . . . . . . . . . 69

6.8 Estimativas Bayesianas para diferentes valores de $\sigma_{\delta}^{2} . \ldots \ldots 71$

6.9 Análise de Robustez do algoritmo EM para os dados dos padrões. . . . . . 74

6.10 Análise de Robustez do algoritno EM para os dados dos pistões. . . . . . . 75 
6.11 Análise de Robustez das aproximacões para as estimativas Bayesinas do modelo de regressão com crros para os dados dos padrócs. . . . . . . . . . 75

6.12 Análise de Robustez das aproximaçoes para as estimativas Bayesinas do modelo de regressão com crros para os dados dos pistões. . . . . . . . . . . 76

7.1 Valores de referencia obtidos a $20^{0} \mathrm{C} \ldots \ldots \ldots \ldots$

9.1 Dados referentes a Diàmetro do Furo dos Padrões - Pré-experimento. . . 90

9.2 Dados referentes ao Diâmetro do Furo dos Pistões (Peçass) - Prć-cxperimento. 92

9.3 Dados referentes ao Diâmetro do Furo dos Padröes - Segundo-experimento. 93

9.4 Dados referentes ao Diâmetro do Furo dos Pistốcs (Peças) - Segundocxperimento. . . . . . . . . . . . . . . . 95

9.5 Dados referentes ao Diâmetro do Furo e temperatura dos Padrões transformados - Segundo-cxperimento. . . . . . . . . . . . . . 96

9.6 Dados referentes ao Diâmetro do Furo dos Pistões Transformados (Peças) - Sogundo-experimento. . . . . . . . . . . . . . . 98 


\section{Capítulo 1}

\section{Introdução}

O desonvolvimento da indústria de manufatura tem exigido de sistemas de medição a garantia do medidas cadia ve mais oxatas. Atualmente, diversas empresas da área automobilística ten utilizado tolerâncias para algumas características de peças na escala do microns $\left(10^{-6}\right.$ metros). Infelizmente, on tal escalat, pequenas variaçoos na temperatura ambiente provocam alterações significativas nas características das peças. Neste trabalho, pretendemos desenvolver um algoritmo para a correção da característica da qualidade em funçäo da temperatura ambiente.

O comportamento das características das peças cm relação às variações da temperatura ambiente ó estudado noste trabalho via regressão com crros nas variáveis. Esta dasse de modelos tem sido aplicada en diversas situagõos onde o erro das medições é significativa, ver Fuller (1987) o Van Ness (1999). Aqui, vamos montar un experimento onde varianos a temperatura das pegas o medimos a sua comespondente característica. Como a temperatura é determinada por unn termômetro e a característica da clualidade por uma cólula automática, que medem com crro (como todo cyuipamento de medição), utilizamos os modolos de regressão com crros nas variáveis.

A preocupação de se estar medindo cometamente faz com que as mpresas dosenvolvam novas tócnicas para testar os scus sistemas de medição, pois este sistema ó um dos grandes medidores de qualidade de seus produtos. Caso o sistema de medição não seja confiável, não podemos confiar nos produtos que são aprovados ou reprovados por este sistema. Neste trabalho, o sistema cle mediça de interesse é a célula automática que 
mele o diâmetro do furo de $11 \mathrm{~m}$ pistião.

Este sistcma de medição ć responsável pela medição e classificação do pistôes a partir das características de interesse. $\Lambda \mathrm{KS}$ Jistôes a a maior produtora mundial do Pistõcs. Está produz peças com destino a motores à gasolina, álcool e diesel. A cstrutura da fáhrica ć dividida em quatro setores: Fundição, Lsinagcm, Tratamento Túrmico e Controle de Qualidade. Atualmente, as cólulas automáticas encontram-se na Usinageme no Controle de Qualiclade. Muitas divergêneias entre mediçöes realizadas entre estes dois setores e a alta variabilidade das medições dentro dos setores reforçaram a hipótese de que este sistema de modiçáo necessitava de molhoria.

Quando realizamos mediçõcs a partir da cólula autonnática no Controle do Qualidade ou na Usinagem, deparamos com muitas influências que geram erros nos resultados obtidos, de modo que não exista medição perfeita, ou scja, sem erros. Aspectos tecnológicos forçam que qualquer sistema de medição construído resulte imperfeito: suas dimensocs, forma geométrica, material, propricdades elétrica, pneumática, ot,e, não correspondem exatamente ao ideal. As leis e princípios físices que regem o funcionamento da cólula automática nem sempre são perfeitamente lincares como uma análise simplista. poderia supor. Podendo também ocorrer desgaste e deterioração do partes do equipamento, agravando ainda mais a qualidade do sistena de modição.

Pertubaçócs externas como condiçôs ambicntais podem provocar crros, alterando diretamente o sistema de medição o fazendo com que o comportamento do sistema do medição se afaste ainda mais do ideal. Neste trabalho estamos preocupados com as variações ambientais, no Controle de Qualidade e na Usinagem, que chegam a variar durante um mosino dia em $15^{\circ} \mathrm{C}$.

$\Lambda$ preocupação principal com a variação térmica ć o fato de que os limites de especificação associados às características da qualidade foram projetados para a temperatura $20^{\circ} \mathrm{C}$. Porém, a temperatura ambiente pode variar entre $10^{\circ} \mathrm{C}$ e $35^{\circ} \mathrm{C}$.

Diante deste problena, propomos um algoritmo para realizarmos correçōes nas características de cualidade para a temperatura de referência de $20^{\circ} \mathrm{C}$. Com isto, precisamos corrigir todas as leituras para a temperatura de referencia de $20^{\circ} \mathrm{C}$. Enbora a 
temperatura ambiente possa variar entre $10^{\circ} \mathrm{C}$ o $35^{\prime \prime} \mathrm{C}$ no dia-d-dia de trabalho.

\subsection{Descrição da Peça e da Característica da Quali- dade}

Neste trabalho o produto de interesse é o pistão para carros. Quando se produz um pistão deve-se ter en mente quais são as propriedades finais que este deve possuir para (lesempenhar suas funções adequadamente. Uma das características de interesse do pistão ć o diâmetro do furo. Isto decorre do fato que o pistão deve encaixar perfeitamente ao pino que scgura a bicla. Caso isto não ocorra, o bom funcionamento do motor pode ser comprometido, podendo até ocasionar a quebra do motor.

Dentre os vários tipos de pistões fabricados pela KS Pistões, estudamos o pistão do tipo $P B 086144$, que é utilizado em carros con motores de gasolina com motores 1.6 . Este pistão quando fabricado deve atender às especificaçôes associadas à característica do diametro do furo. As especificaçoes de projeto são:

- Limitc Inferior de Especificação: 20007,0 nicrons

- Valor Nominal de Desenho: 20004,5 microns

- Limite Superior de Especificaşão: 20002,0 microns

Deve-se salientar que os limites de especificação associados ao diâmetro do furo são valores projetados para $20^{\circ} \mathrm{C}$. $\Lambda$ figura 1.1 representa uma unidade do produto pistão $P B 086144$ e sua respectiva característica de qualidade (diâmetro do furo) indicada apropriadamonte.

\subsection{Célula de Medição e o procedimento de ajuste}

A cólula de medição realiza suas medições sob princípio de um relógio comparador. Medir o diâmetro de uma peça por comparação é determinar a diferença do diâmetro exis- 


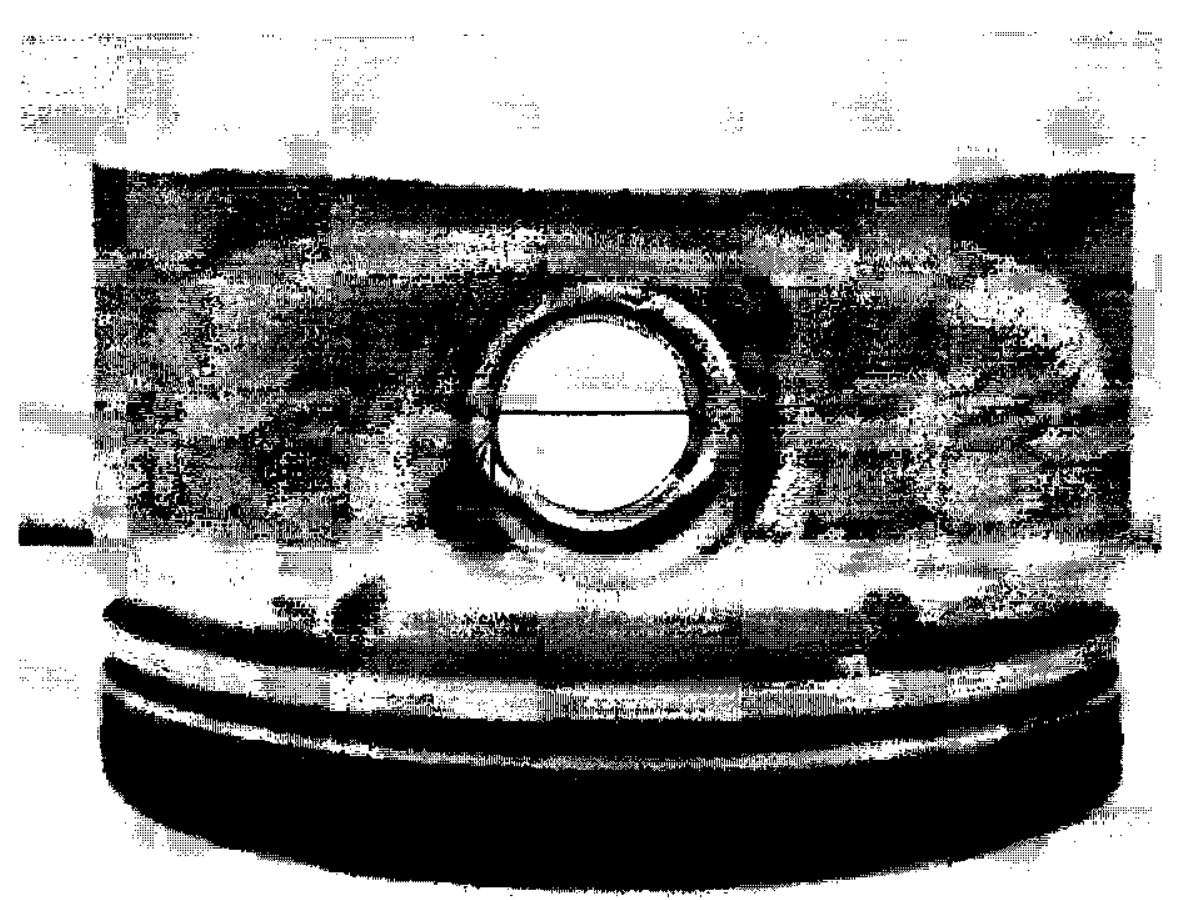

Figura 1.1: Diâmetro do Furo

tonte ontre ela c o padrão calibrado. No cuntanto, a cólula de medição ao contrário do relógio comparador connum de funcjonamento mecánico, realiza suas mediçôs de forma cletrônica. Isto possibilita uma leitura rápida, indicando instantancamente a medida no display cm microns.

Antes cue a Cólula de Medição comece a medir e classificar os pistōos, ela deve passar por unn procedimento do ajuste. Esto procedimento consisto cm: ajustar os vários parâmetros da cólula de medição (pressão de saidà trimplot, cte) o a realizar o zeramento do equipamento de medição.

Para molhor comprecensão do esquema de medição o posteriormente do algoritmo de correcão, inscrimos o conceito de zcramento. Este consiste cm passar o padrão na célula e informar o seu respectivo valor calibrado à $20^{\circ} \mathrm{C}$. O padrão possui un papel inportante na realização das mediçoócs por possuir valor "conhecido"à $20^{\circ} \mathrm{C}$. () padrão é calibrado por um laboratório de metrologia e consequentemente, o laboratório determila o valor do padrão a $20^{\circ} \mathrm{C}$ o seu respectivo desvio padrão (incerteza). No ́́tenu a seguir: mostramos que o esquema de medição da célula depence do valor do padrão à $20^{\circ} \mathrm{C}$, 
tornando as mediçós realizadas pela cólula rastreáveis em relação a un padrão nacional (INMHTRO).

\subsection{Equação de Medição}

Para propor o algoritmo de correção, precisamos conhecer o esquema de medição da célula. Ela realiza mediçōes segundo o princípio de un relógio comparador. Desde que a cólula é zerada por um padrão e informado o valor do padrão à $20^{\circ} \mathrm{C}$, o esquema matemático de medição da cólula funciona da seguinte forma:

$$
D_{C T}=D_{\text {rad201": }}+\Delta_{\text {Desiocamento }}
$$

onde

- $D_{C T}$ : representa o diâmetro do furo na temperatura $T$ medirlo pela célula;

- $D_{\text {Pada20 }} 0^{0}$ representia o valor do padrão detcrminado por calibração à $20^{0} \mathrm{C}$;

- $\Delta_{\text {Deslocamento }}$ representa a diferença entre o diâmetro do pistão e do padrão na temperatura $T$.

A cólula apenas mede a diferença entre o diànetro do pistão e pacluão na temperatura ambiente e cntĩo, somamos através de soltware o valor do paclrão à $20^{\circ} \mathrm{C}$. A rigura 1.2 nos mostra um operador realizando a medição do 11 pistão na cólula.

Conforme Figura 1.2, peça é alocada no espigão, onde a pressão exercida pola peça é transformada en tensão clétrica por um princípio físico denominado Piezoclétrico. Fsta. tensão clétrica é medida por um sensor e cligitalizada. O valor da tensão é transformado cun milínetros por um modelo de regressão inversa, definido na fase do ajuste da cólula.

Devemos salientar que a diferença de comportamento térmico entre o pistão co padrão ó consequencia do pistão ser de alumínio o o padrão ser de aço. Conhecinentos a 


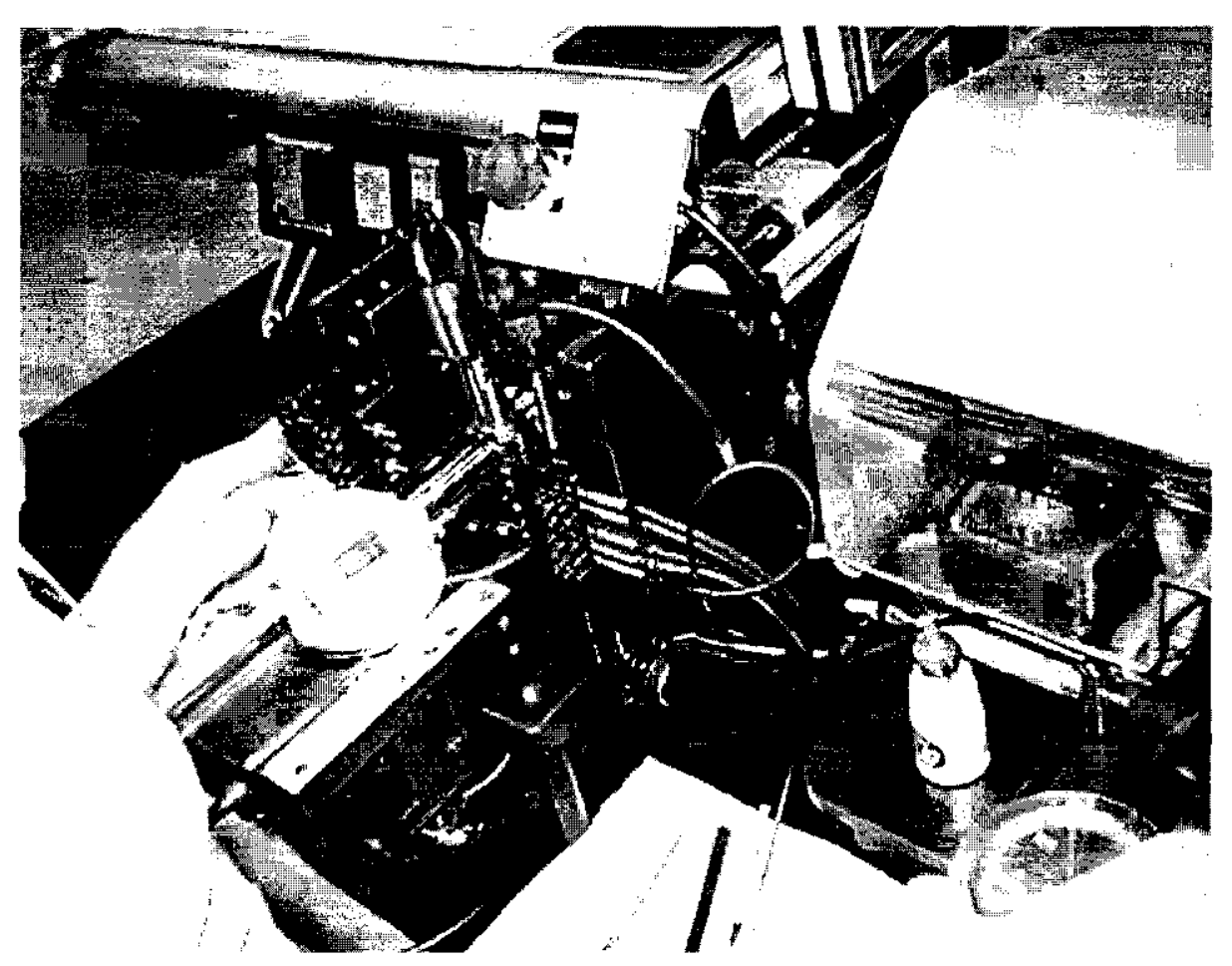

Figura 1.2: Procedimento de Mediçăo

priori da física nos garantem que o alumínio dilata mais do que o aço quando submeticlos a. mesma temperatura.

\subsection{Estratégia de Correção}

Para entender o problema existente neste esquema de medição e motivar a cstratćgia de correçäo para o esquema de medição $\mathrm{cm}$ 1.1, vamos considerar una ilıstraçầo munériça. Consideramos uma peça onde conhecemos o seu diâmetro do furo à $20^{\circ} \mathrm{C}$ e diâmetro do furo do padrão também à $20^{n} \mathrm{C}$. Além disso, sabemos que o diâmetro do furo para o pistão aumenta 2 microns $/{ }^{\circ} \mathrm{C}$ enquanto que para o padrão aumenta 1 micron $/{ }^{\circ} \mathrm{C}$.

A scguir apresentamos o valor diâmetro do furo para pistào e o padrão à $20^{\prime \prime} \mathrm{C}$, para ilustrar a cstratégia de ajuste.

- Pistãdo: 18998 microns

- Padrão: 19000 microns 
Utilizando a equação de melição da cólula em 1.1, temos analiticamente que

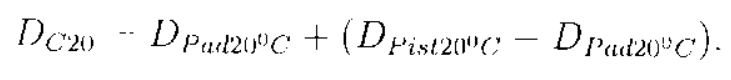

Assim, o resultado final da medição do diâmetro do furo para cada pistão cm $20^{\circ} \mathrm{C}$ a partir da cólula é

- $19000+(18998-19000)=18998$.

Podemos notar que a célula apenas mede a difcrença entre a peça e o padrão o adiciona ao valor do padrão à $20^{\circ} \mathrm{C}$. Esta situação climática de $20^{\circ} \mathrm{C}$ é a ideal, pois obtemos a medição clo diâmetro do furo do pistão na mesma tempcratura en que os limites de cspecificação foram projetados. Além dissso, o esquema de medição cm 1.1 preserva os verdadeiros valores do furo. Ou scja, para a temperatura de referência de $20^{n} \mathrm{C}$ o esquema de medição da célula não necessita de uma estrutura de correção.

Agora, supomos que pistão c padrão estcjam ambos a $15^{\circ} \mathrm{C}$. Vamos simular como o esquema de medição em 1.1 realiza suas medições. Primciro, calculamos quanto o diâmetro cla peça e do padrão contraíram com a queda de temperatura de $20^{\circ} \mathrm{C}$ para $15^{\circ} \mathrm{C}$. Para isto, conlıccimentos à priori sobre a relação cla clilatação do diêmetro do furo $\mathrm{cm}$ função da temperatura garantem que esta relação pode ser aproximada de forma linear. A relação lincar para pistão e padrão são apresentados a scguir.

$$
D_{P^{\prime} i s t T}=D_{P i s t 200^{\circ} \mathrm{C}}+\beta_{\text {Pist }} *(T-20)
$$

oncle,

- D Pisty $_{1}$ : representa o diâmetro do furo do pistão na temperatura $T$;

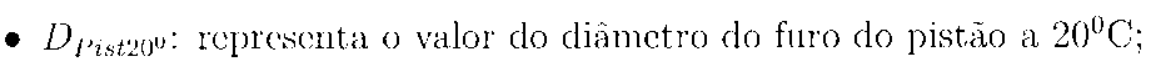

- $\beta_{P i s t}$ : representa a taxa de mudança do diâmetro do furo do pistão quando ocorre a mudança de unia unidade na temperatura. 
Similarmonts, para n diàmetro do fumo do padrão, temons:

$$
D_{\Gamma^{\prime} a d T^{2}}=-D_{P a d 20^{0} \mathrm{C}}+\beta_{P a d} *(T-20)
$$

onde,

- $D_{P a d T}$ representa o diàmetro do furo do padrão na temperatura $T$;

- $D_{P a d 20^{0} \mathrm{C}}$ : represchta o valor do diâmetro do furo para o padrão a $20^{\circ} \mathrm{C}$;

- $\beta_{P a d}$ representa a taxa de mudança do diâmetro do furo do padrão quando ocorre a mudança de una unidade na temperatura.

Para cste excmplo cstamos assumindo que $\beta_{P i . s t}=2$ e $\beta_{P a d}=1$. Assim, os diannetros da peça c padrão são dados por:

- P'stãn: $18998+2 *(15-20) \cdot 18988$.

- Padrão: $19000+1 *(15-20)-18995$

Através da Equação 1.1, temos que

$$
D_{C 15}-D_{P a d 20^{12} C}+\left(D_{P i s t 15^{0} C^{\prime}}-D_{P a d 15^{11} C^{*}}\right)
$$

onde,

- DCis: representa o diânetro obtido pela cólula na temperatura $T=15^{\circ} \mathrm{C}$.

Utilizando as Equaçóes 1.4 e 1.3, obtemos que

$$
D_{C T}=D_{P a d t 0^{\prime \prime C}}+\left(D_{P_{i s t} 0^{\prime \prime} C}-D_{P^{\prime} a d 20^{\prime \prime} C}\right)-\beta_{P a d} *(15-20)+\beta_{F^{\prime} i s t} *(15-20) .
$$

Assim, o diâmetro da peça obtido pela cólula automáticá na temperatura de $15^{\circ} \mathrm{C}$ c dado por: 
- Pistão: $19000+(18988-18995)=18993=19000+(18998-19000)+(-10+5)-1900()-2-5$

Note que nesta situação climática de $T=15^{\circ} \mathrm{C}$ menor que a situaçào de interesse do $T=20^{\circ} \mathrm{C}$, o esquena de medição em 1.1 não foi capaz de preservar o verdadeiro valor do diâmetro do furo conhecido à $20^{\circ} \mathrm{C}$, on seja, o esquema de medição para este caso necessita de una estrutura de correção.

Além disso: a cquação de medição em 1.6 quando realizado mediçós na temperat ura de $15^{\circ} \mathrm{C}$, a diferença de medição do diânetro do furo entre peça e padrão é decomposta con duas parcelas: diferença do pistão para o padrão à $20^{\circ} \mathrm{C}$ mais a diferença de contração do pistão para o padrão de $20^{\circ} \mathrm{C}$ para $15^{\circ} \mathrm{C}$. Com isto, se rcalizamos uma correção na medição no diâmetro do furo do pistão realizada pela cólula à $15^{\circ} \mathrm{C}$ de $\beta_{P a d} *(T-20)-\beta_{P i s t} *(T-20)$ ć possível resgatar o verdadeiro valor do diâmetro do furo medido pela célula na temperatura ambiente de $20^{\circ} \mathrm{C}$.

Uma estratćgia de correção no esquema de medição para Equação 1.1 se faz necessária principalnente porque no dia-a-dia de trabalho da KS Pistões nos sctores da Csinagem e Controle de Qualidade como mencionado anteriormente, a temperatura ambiental chega a variar em até $15^{\circ} \mathrm{C}$, e raramente atinge à temperatura de interesse de $20^{\circ} \mathrm{C}$. Como visto anteriormente através da simulação numórica, o esquena de medição da cólula necessita de uma estratégia de correcão para temperaturas diferentes de $20^{\circ} \mathrm{C}$.

A estratégia de correção para Equação 1.1 tornaria desnecessária sc o material, a geometria c a massa do pistão fossem os mesmos do padrão. Na realidade, cles tem o mesmo comportamento se a peça for um "clone" do padrão. Porćn, a empresa opera com o padrão e peça não atendendo a estas exigências.

Por outro lado, a estratégia adotada para resolver o problema existente no esquema de medição jara Equação 1.1 é realizar a correção do $\beta_{P a d} *(T \quad 20)-\beta_{\text {Pist }} *(T-20)$ no diâmetro do furo do pistão obtido pela cólula. No cntanto, para que esta se torne viável, é necessário estimar os valores de $\beta_{P i s t}$ e $\beta_{\text {Pad }}$ através de experimentos. Para isto, plancjamos um experimento para pistão c padrão en que basicamente variamos a temperatura deles e medimos seus respectivos diâmetros do luro. P’ara estimar $\beta_{\text {pad }} \mathrm{e}$ 
$B_{\text {Past }}$ adequadamente, propomos um modelo de regressão com crros nas variáveis para o diâmetro do furo da peça c do padrão cm funçâa da temperatura ambicnte.

En linhas gerais, a estratégia de correção proposta neste trabalho consiste en olbter uma medição cm temperatura ambiente pola célula funcionando como relógio comparador

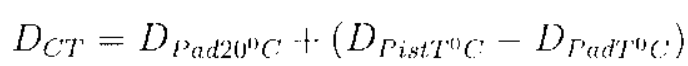

e, realizar a correção $\mathrm{cm} D_{C T}$ da seguinte forma:

$$
D_{C o r r 20}=D_{C T}-\beta_{P_{i s t}} *(T-20)+\beta_{P a d} *(T-20)
$$

O trabalho foi organizado cm 5 capítulos, conforme descrito abaixo:

No capítulo 2, apresentamos os matcriais e o procedimento cxperimental empregado para obter informaçoes anostrais sobre o comportamento do dianetro do furo do pistão e do padrão em função da temperatura a partir de dois cxperimcntos. Análise exeploratória das informaçoes de ambos os experimentos são apresentados.

No capítulo 3, descrovemos um modelo do regressão com crros nas variáveis scm intercepto: relação ultraestrutural para modelar a dilatação tóminica.

No capítulo 4 á descrito um procedimento de estimação via abordagen Clássica para os parâmetros de interesse $\beta_{p i s t}$ e $\beta_{P a d}$. Alćm, obtemos a matriz de informação do Fisher esperada.

No capítulo 5 un procedinento de estimaşa via abordagem Bayosiana para os parâmetros de intercssse $\beta_{P_{i, s t}}$ e $\beta_{P_{u d}}$.

No capítulo 6 aprescentanos aproximaçoos das estinuativas dos cocficientes utilizando abordagens Clássica e Bayesiana.

No capítulo 7 realizamos uma discussão sobre os ganhos proporcionados pela motodologia descnvolvida. Analisamos a redução do crro sistenático devido a uma má correçầo e diminuição na taxa de refugo. 
No capítulo 8 apresentamos as perspectivas de continuidade deste trabalho. 


\section{Capítulo 2}

\section{Delineamento Experimental}

Neste capítulo, aprescntamos detalhes sobre o planejamento experimental empregado para a coleta de obscrvações referentes ao diâmetro do furo cm função da variação de temperatura, tanto para peça e padrão.

Nos primoiros experimentos, chegamos a utilizar uma caixa de papelão com uma lâmpada para aquecer as peças e os padròs $\mathrm{cm} 15$ minutos de estabilização em cada patamar. Os resultados obtidos foram considcrados inadequados. A partir daí, uma cstufa passou a scr utilizada nos experimentos.

Ainda assim, foi necessário realizar outros experinnentos para determinar um tempo adequado para a estabilização da temperatura. Após alguns experimentos pilotos, que scrviram para ajustar e conlhecer variáveis não controladas, seguindo princípio Interativo de Aprendizagem, ver Box o Drapper (1987), determinamos o temıjo de estabilização nos patamares de temperatura. Após vários pré-cxperimentos, propomos um tempo de estabilização de 2 horas para os pistões c de 3 horas para o padrão em cada patamar de temperatura.

$\Lambda$ utilização da estufa permitiu em curto prazo de tempo o levantanento de dados sobre o comportamento do diâmetro cm função da temperatura. Se por um lado a utilização da estufa permite a realização do experimento de forma rápida, por outro cria uma situação artificial de variação da tempcratura das peças o padrōes. Assim, realizamos un segundo experimento onde observamos o diàmetro do furo a partir da variaçãa natural da 
temperatura do setor de realização do experimento e utilização do sistema de medição.

\subsection{Expcrimento Preliminar}

Un primciro experimento foi realizado para obter informaçôes à priori sobre os parâmetros do modelo de regressão com crros nas variáveis descrito com detalhes no próximo capítulo. Para obtermos as várias condições de temperatura, neste experimento utilizamos auxílio da cstufa, enquanto que no outro utilizamos da própria variação da temperatura ambiente.

$\Lambda$ seguir, o procedimento experimental c os equipamentos utilizados para a realização do experimento são descritos

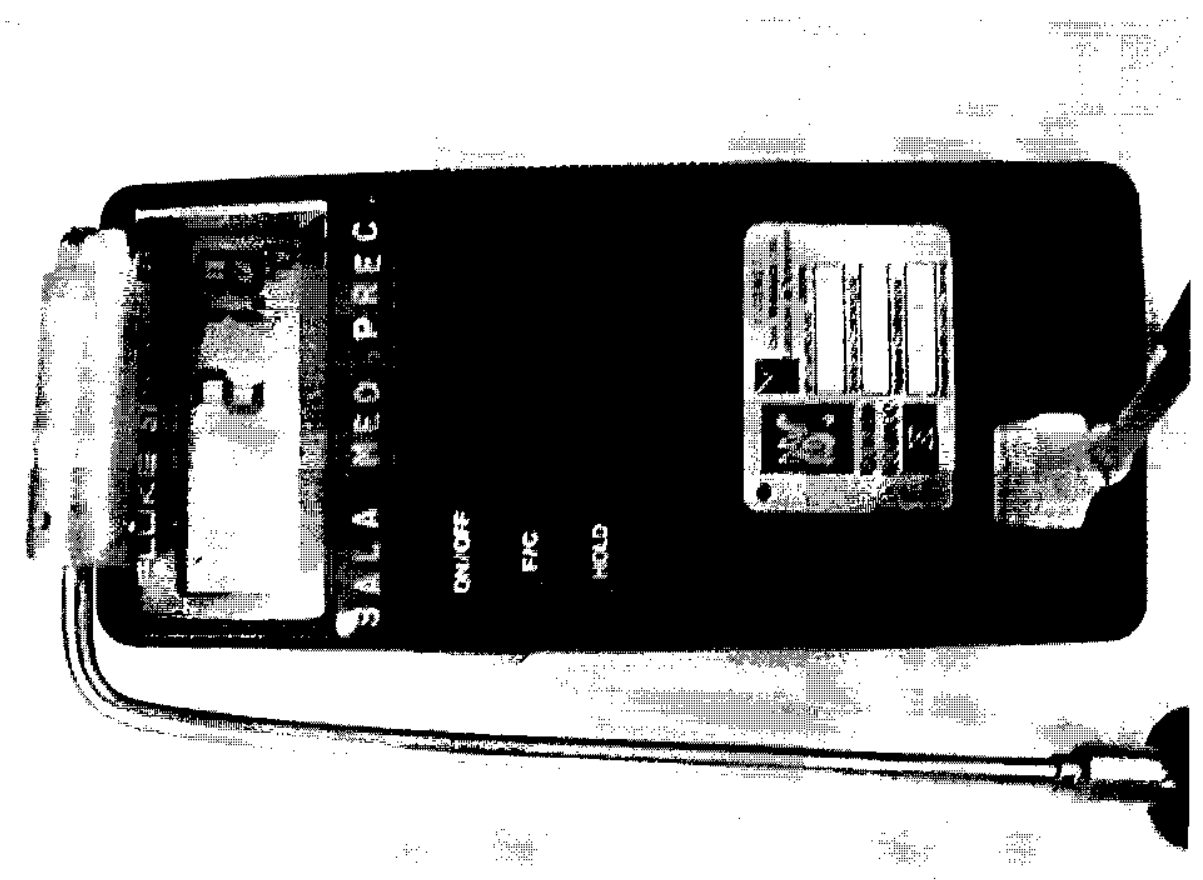

I

Figura 2.1: Termometro de Contato 


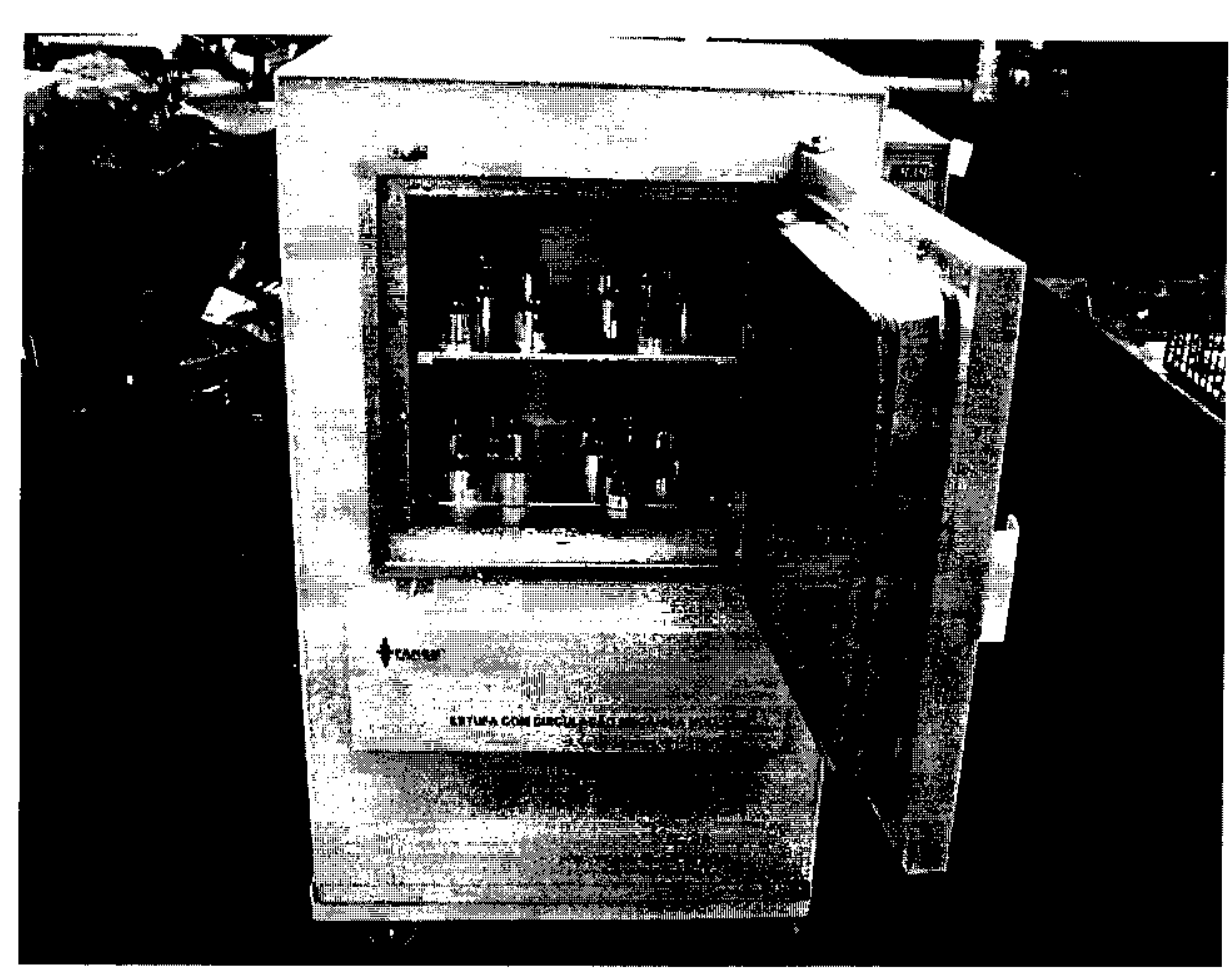

Figura 2.2: Estufa



Figura 2.3: Padrão 
O termômetro Fluke tem resolıção de $0,1^{0} \mathrm{C}$ com certificado de calibração emitido pelo laboratório da Rede Brasilcira de Calibração. Este equipamento realiza as mediçōes via o contato de sua hastc com a peça ou padrão.

O procedimento experimental empregado para os pistões ć apresentado abaixo:

1. Sclecionar 10 pistǒes:

2. Considerar uma faixa experimental de temperatura de $200^{\circ} \mathrm{C}$ a $60^{\circ} \mathrm{C}$;

3. $\Lambda$ estufa ć limita a operar de $30^{\circ} \mathrm{C}$ a $550^{\circ} \mathrm{C}$. Diante disto, se no início do experimento a temperatura ambiente é menor que $30^{\circ} \mathrm{C}$, realizar uma primeira tomada de temperatura sem a utiliazação da cstufa.

4. Regular a estufa para $30^{\circ} \mathrm{C}$, inscrir os pistões no scu interior c aguardar um tempo de estabilização de 2 horas (Figura 2.2):

5. Após o processo de estabilização, cada pistão foi retirado da estufa (um a um após cada medição), o imediatamente a temperatura do pistão foi tomada com termômctro FLUKE (Figura 2.1);

6. Na sequencia, a peça foi introduzida na célula de medição para realização da medição do diâmetro do furo (Figura 1.2);

7. O scgundo passo foi repetido incrementando-se de $5 \mathrm{~cm} 5$ graus até que se atingisse 60. Consequentemente, tambóm os passos 3,4 e 5 foram repetidos sem alteraçôs.

De forma análoga, o procedimento empregado para coleta de dados associado ao padrão foi o mesmo utilizado para os pistõcs. Devemos frisar que nestc experimento utilizou-se as mesmas peças nos vários patamares de temperatura. Isto ocorreu porque os pistões são vistos como unidades experimentais heterogêneas. Apesar de perecercm iguais visivelmente, cles possuem uma série de características distintas uma das outras (não existe 2 peças iguais). Com isso, a necessidade de se realizar um esquema experimental de medidas repetidas.

Un primciro passo foi análise gráfica do comportamonto do diametro do furo cm função da tempcratura para cada padrão c peça. 


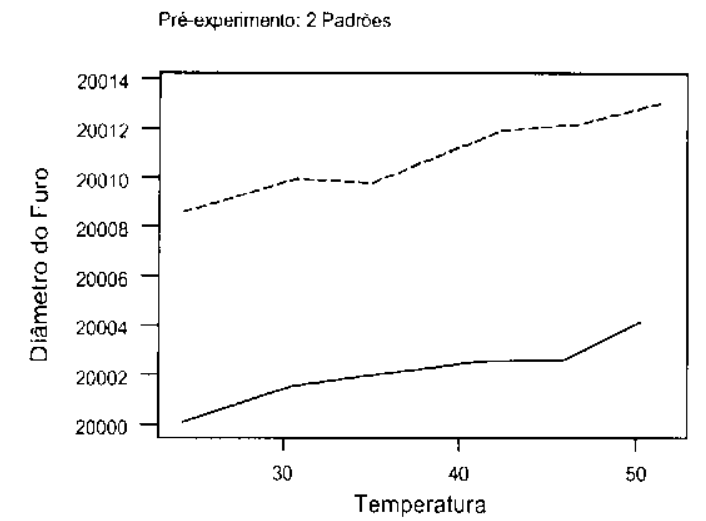

Figura 2.4: Scartter Plot padrão

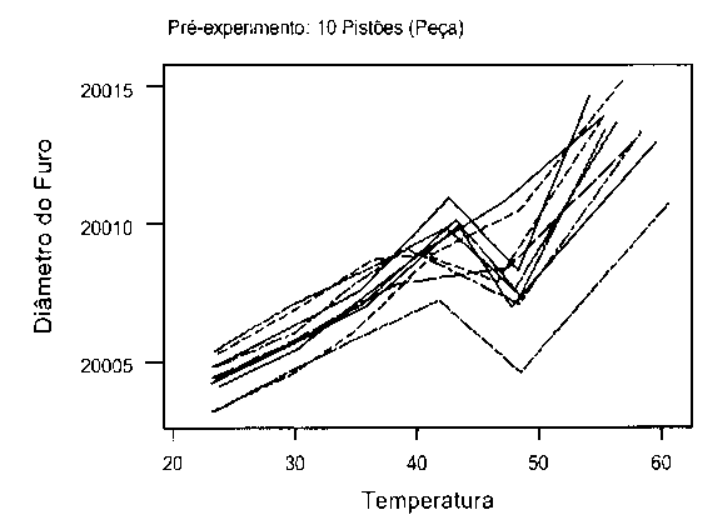

Figura 2.5: Scartter Plot peça 
A partir dos gráficos acima, tianto para peça como para o padrão, notamos uma relaçäo lincar do diâmetro do furo cm função da temperatura. Além disso, notanos um ammento na variabilidado das medições do diâmetro para patamares de temperatura a a ima de $30^{\circ} \mathrm{C}$, para peça c padrão.

Para avaliarmos a varibilidade das mediçós da temperatura para cada patanar: apresentamos Gráficos Box-Plots para padrão e peça:

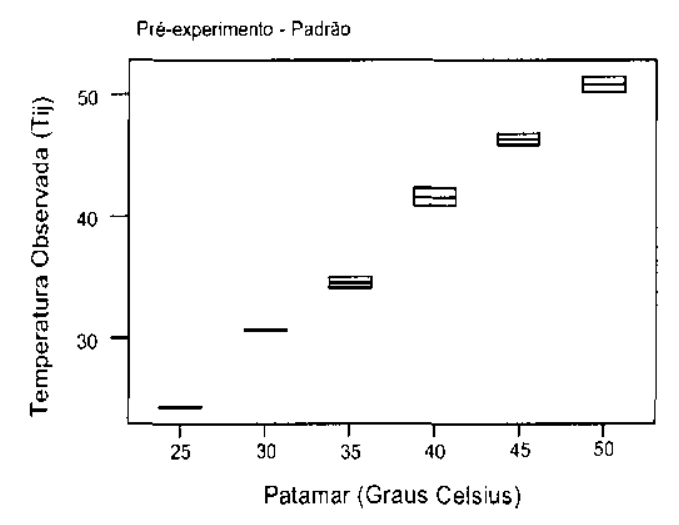

Figura 2.6: Box-Plot padrão

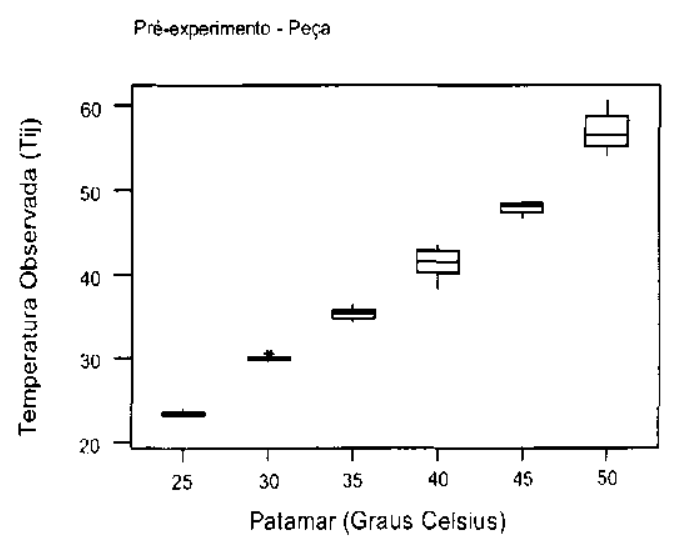

Figura 2.7: Box-Plot peça 
Como nas medições do diâmetro, a variabilidade nas medições da temperatura também almmentia quando o patamar é maior que $30^{\circ} \mathrm{C}$. Lsto ocorre, devido a troca intensa de calor contre uma pega retirada da cstufa e o meio onde é realizado o experimento. A seguir, as Tabclas 2.1 c 2.2 sumarizam as observaçoes associadas ao diâmetro e a temperatura obscrvada cm cada patamar de temperatura, para padrão o peça.

\begin{tabular}{|c|c||c|c|c|}
\hline Patamiar & Diânetro & & Temperatura & \\
\hline Patanlar & Média & Desvio Padrão & Média & Desvio Padrão \\
\hline 25 & 200001,3 & 6,01041 & 24,3 & 0 \\
\hline 30 & 20005,8 & 5,9397 & 30,65 & 0,070711 \\
\hline 35 & 20005,8 & $5,5861 \cdot 1$ & 34,55 & 0,636396 \\
\hline 40 & 20007,2 & 6,64182 & 41,6 & 0,989949 \\
\hline 45 & 20007,4 & 6,80423 & 46,35 & 0,636396 \\
\hline 50 & 20008,6 & 6,32749 & 50,85 & 0,919239 \\
\hline
\end{tabular}

Tabela 2.1: Sumarização dos dados de diâmetro e temperatura para padrão.

\begin{tabular}{|c|c||c|c||c|}
\hline Patamar & Diametro & & Temperatura & \\
\hline Patamà & Média & Desvio Padrão & Média & Dosvio P'adrão \\
\hline 25 & 20004,4 & 0,75542 & 23,39 & 0,22828 \\
\hline 30 & 20005,8 & 0,8135 & 29,92 & 0,25298 \\
\hline 35 & 20007,3 & 0,86929 & 35,41 & 0,65056 \\
\hline 40 & 20009,2 & 1,10179 & 41,40 & 1,64722 \\
\hline 45 & 20008,0 & 1,77975 & 47,92 & 0,66131 \\
\hline 50 & 20013,5 & 1,20904 & 56,98 & 2,073 \\
\hline
\end{tabular}

'Tabola 2.2: Sumarizaça dos dados de diâmetro e temporatura para peça. 
Devidos a problemas como a troca intensa de calor após a retirada da peca da estufa até a medição, optamos pela realização de um segundo expcrimento onde a variação de temperatura é dado pelo próprio meio ambiente. Nestc caso, o tempo de cxocução do cxpcrimento é bem maior que o primeiro experimento, porém com uma confiabilidade neslhor na medição da temperatura.

A seguir apresentamos detalhes do experimento e das observações coletadas no segundo experimento.

\subsection{Segundo Expcrimento}

Neste cxpcrimento amostramos informações do diâmetro do furo cm vários níveis de tcmperatura utilizando da própria variação natural da temperatura no ambiente de atuação das células (Usinagem e Controle). Os dados referentes a este expcrimento encontran-se no apendice.

Fm especial, temos que neste experimento obtemos mediçōes do furo dentre os vários patandares de temperatura, inchusive na condição de $20^{\circ}$ Celsins. Isto permite realizar uma transformação nas variávcis do diâmetro e da tompcratura do forma a possibilitar estabclecer um nodelo sem intercepto, visto que na Equação (1.8) necessitamos apenas do cocficiente angular e não do intercepto.

A transformação é dada subtraindo-se o diâmetro da j-ésima peça obtida no iésimo patamar de temperatura do diâmetro da j-ésima peça obtida a $20^{\circ} \mathrm{C}$. Fstes dados transformados são utilizados para ilustrar a metodologia descnvolvida no Capítulo 3.

Para ilustrar esta idéia, apresentamos gráficos referentes às observações dos padrões c dos pistõos scm a transformação 




Figura 2.8: Dados padrão

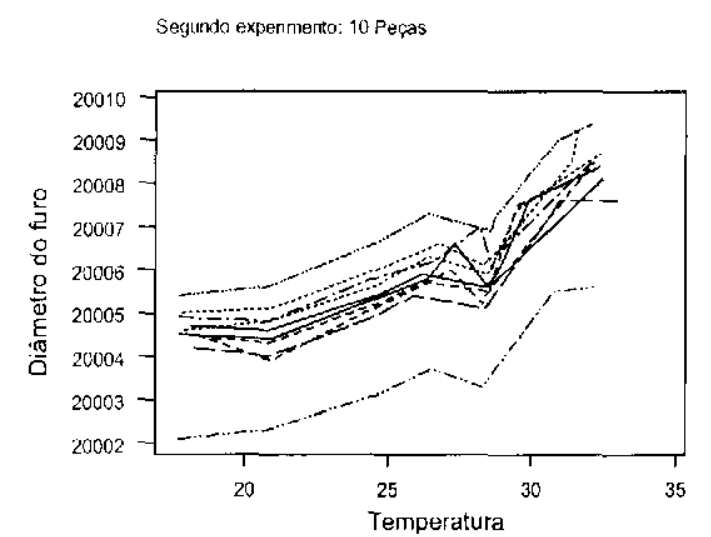

Figura 2.9: Dados peça

Visivelnıcnte uma relaçào lincar com intercepto poderia ser cstabclecida. Diante disto, realizamos uma transformação nos dados subtraindo o valor do cliametro e temperatura com rolação à $20^{\circ} \mathrm{C}$. Para ilustrar a transformação, tomanos os dados de um dos padrões (dados completos localizados nas tabelas nas tabclas 9.3 c 9.5 no apêndice), para o qual a transformaça 


\begin{tabular}{|c|c|c|c|}
\hline Temperatura & Diâmetro & Temperalura Tramsfomada & Diâmetro Tramsformado \\
\hline 20,9 & 20000 & $20,9-20,9=0$ & $20000-20000=0$ \\
\hline 33,2 & 20001,5 & $33,2-20,9=12,3$ & $20001,5-200000=1,5$ \\
\hline 24,6 & 20000,1 & $24,6-20,9=3,7$ & $20000,1-20000=0,1$ \\
\hline 28,9 & 20000 & $28,9-20,9=8$ & $20000-20000=0$ \\
\hline 28,1 & 20000,8 & $28,1-20,9=7,2$ & $20000,8-20000=0,8$ \\
\hline 17,1 & 19999,9 & $17,1-20,9=-3,8$ & $19999,9-20000=-0,4$ \\
\hline 25,9 & 20000,4 & $25,9-20,9=5$ & $20000,4-20000=0,4$ \\
\hline 27 & 20000,5 & $27-20,9=6,1$ & $20000,5-200000=0,5$ \\
\hline
\end{tabular}

Como podemos observar, tomamos o patamar de temperatura mais próximo a $20^{\circ} \mathrm{C}$ c subtrámos as temperaturas e seus respectivos diannetros com relação a este patamar.

Apresentamos os gráficos de dispersão para os padrós e pistõos após a transformação:

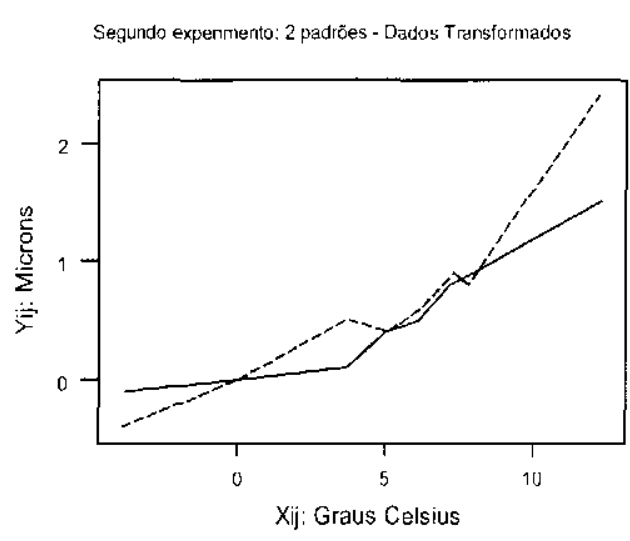

Figura 2.10: Dados transformados padrão 


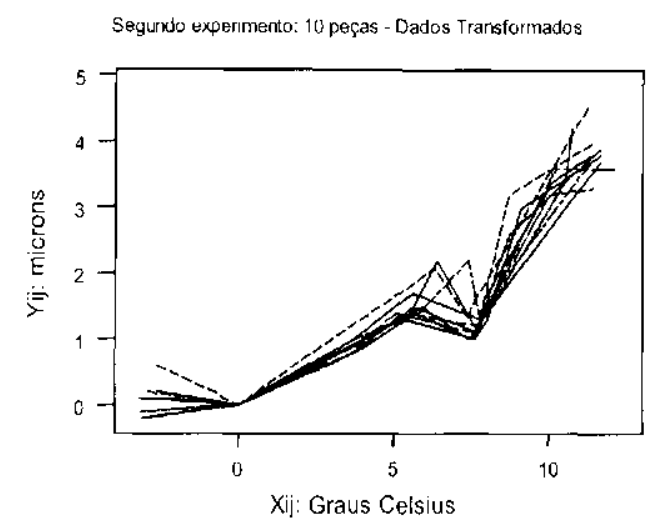

Figura 2.11: Dados transformados peca

Note que a transformação conserva a relação linear cntre o diâmetro c a temperatura porém passando pela origem do plano. Alćm disto, a transformação reduziu nos patamares a variabilidade das medições entro peças e padrões.

Obscrve que mesmo com temperatura abaixo de $20^{\circ} \mathrm{C}$, alguns desvios são maiores que zero (ver gráfico 2.11). Este comportamento é conscquencia dos erros de medição ocorridos na medição da temperatura pelo termômetro Fluke e do diâmetro realizado pela Célula de medição. Isto reflete a necessidade de utilizarmus modelos com crros nas variáveis.

Utilizando apenas da variação natural da temperatura ambiente do local de realização do experimento, a variabilidade das medições foram menores e mais estávcis do que aquelas utilizando a estufa. Esta estratégia contorna problemas de troca intensa de calor entre uma peça retirada da estufa o o meio onde ó realizado o experimento.

Nas Tabelas abaixo, as médias e os desvios padrão são conados de 10 peças para as tabelas 2.3 e 2.5 × 2 padrões para as tabelas 2.4 c 2.6 referentes aos padrões. Os dados completos estão no apêndlice 


\begin{tabular}{|c|c||c|c||c|}
\hline & Diâmetro & & Temperatura & \\
\cline { 1 - 1 } Patamar & Média & Desvio Padrão & Média & Desvio Padrão \\
\hline 1 & 20004,5 & 6,43467 & 20,9 & 0 \\
\hline 2 & 20006,5 & 7,07107 & 33,15 & 0,07071 \\
\hline 3 & 20004,8 & 6,71751 & 24,6 & 0 \\
\hline 4 & 20004,8 & 6,78823 & 28,8 & 0,14142 \\
\hline 5 & 20005,4 & 6,50538 & 28,20 & 0,141421 \\
\hline 6 & 20004,2 & 6,43467 & 17,05 & 0,070711 \\
\hline 7 & 20005,0 & 6,43467 & 25,95 & 0,070711 \\
\hline 8 & 20005,1 & 6,50538 & 27,05 & 0,070711 \\
\hline
\end{tabular}

Tabcla 2.3: Sumarização dos dados de diânetro e tompcratura para padrão.

\begin{tabular}{|c|c||c|c||c|}
\hline Patamar & Diâmetro & $D_{i j}$ & Temperatura & $T_{i, j}$ \\
\hline Patamar & Média & Desvio Padrão & Média & Desvio Padrão \\
\hline 1 & 20004,4 & 0,88919 & 20,83 & 0,0483 \\
\hline 2 & 20008,2 & 1,06687 & 32,27 & 0,35606 \\
\hline 3 & 20005,4 & 0,94334 & 25,38 & 1,77689 \\
\hline 4 & 20005,7 & 0,95661 & 27,85 & 1,74436 \\
\hline 5 & 20005,5 & 0,9331 & 28,44 & 0,11738 \\
\hline 6 & 20004,4 & 0,88719 & 17,9 & 0,22608 \\
\hline 7 & 20006 & 1,04992 & 26,7 & 1,01215 \\
\hline 8 & 20007,2 & 1,09869 & 29,26 & 1,84162 \\
\hline
\end{tabular}

Tabela 2.4: Sumarização dos dados de diâmetro c temperatura para peça.

Na sequencia a sumarização das observações após a transformação. 


\begin{tabular}{|c|c||c|c|c|}
\hline Patamar & Diâunctro & $Y_{i j}$ & Tomperatura & $X_{i j}$ \\
\cline { 2 - 5 } Patanar & Média & Desvio Padrão & Médlia & Desvio Padrão \\
\hline 1 & 0 & 0 & 0 & 0 \\
\hline 2 & 1,95 & 0,63364 & 12,25 & 0,07071 \\
\hline 3 & 0,3 & 0,28284 & 3,7 & 0 \\
\hline 4 & 0.25 & 0,35355 & 7,9 & 0,14142 \\
\hline 5 & 0,85 & 0,070711 & 7,25 & 0,070711 \\
\hline 6 & $-0,25$ & 0,212132 & $-3,85$ & 0,070711 \\
\hline 7 & 0,4 & 0,0000 & 3,7 & 0,070711 \\
\hline 8 & 0,55 & 0,070711 & 6,15 & 0,070711 \\
\hline
\end{tabular}

Tabcla 2.5: Sumnarização dos dados lamsformados de diâmetro e temperatura para padrão.

\begin{tabular}{|c|c||c|c||c|}
\hline Patamar & Diâmetro & $Y_{i j}$ & Temperatura & $X_{i j}$ \\
\hline Pattamar & Média & Desvio Padrão & Média & Desvio Padrão \\
\hline 1 & 0 & 0 & 0 & 0 \\
\hline 2 & 3,86 & 0,353396 & 11,41 & 0,37476 \\
\hline 3 & 1,01 & 0,191195 & 4,55 & 1,76714 \\
\hline 4 & 1,34 & 0,279682 & 7,02 & 1,75613 \\
\hline 5 & $1,1 \cdot 1$ & 0,117379 & 7,61 & 0,14491 \\
\hline 6 & 0,06 & 0,250333 & $-2,93$ & 0,22632 \\
\hline 7 & 1,59 & 0,387155 & 5,87 & 1,01877 \\
\hline 8 & 2,78 & 0,716163 & 8,43 & 1,85356 \\
\hline
\end{tabular}

Tabcla 2.6: Sumarizaça dos dados transformados de diâmetro e temperatura para peça.

No próximo capítulo, propomos un1 modelo de regressão com crros nas variáveis com intercepto nulo para nodelar os dados deste segundo experimento. 


\section{Capítulo 3}

\section{Modelo de Regressão com erro nas variáveis intercepto nulo: Relação Ultraestrutural}

Nesta segão, proponos um modelo de regressão com crros nas variáveis para modelar a dilataça ténuica da pega e do padrão cm função da temporatura ambiente.

No capítulo 1 propomos uma estratégía de correção para o escquema de medição $\mathrm{cm} 1.1$ para que a cólula de medição (no dia-a-dia de trabalho) realize correçöes no valor do diâmetro do furo. Para isso, precisamos conhecer os coeficientes de correção térmica do diâmetro do furo para peça e padrão.

No capítnlo 2, apresentanos dois delineanentos experimentais, um utilizando cstufa e outra a variaçăo natural da temperatura ambiente, onde para diferentes temperaturas da pega e clo padrĩo medimos seus respectivos dianctros do furo. Porém, estas duas variáveis saio mediclas por equipamentos de mediçáa, o termômetro de contato na modição da temperatura e a cémla de medição na medição do diâmetro do furo. Como todo equipamento de medição, cólula e termômetro, ambos medem com erro, vamos considerar morlelos com crros nas variáveis. Neste traballo, temos o conhecimento à priori da variabilidade associada ao erro aleatório cometido pelo termônetro de contato. A variância do cro do temónetro é obtido a partir do certificado de calibraçãa emitido 
por $11 \mathrm{~m}$ laboratório de calibração (ver apôndice). Darqui para frente vamos considerar o modelo para o diâmetro da peça cm relação à temperatura. Um modelo sirnilar será. lisado para o padrāo. Noste contexto, propomos um modelo de regressão com crros nas variáveis, com o intercepto nulo, da seguinte forma:

$$
Y_{i j}=\beta V_{i j}+\varepsilon_{i j}
$$

onde;

- $Y_{i j}$ : Diâmetro da j-ćsima peça obtida no i-ćsimo patamar de temperatura subtraída do diânetro da j-ćsima pexa obtida a $20^{\circ} \mathrm{C}$.

- $V_{i j}$ : Vordadeiro valor da temperatura da j-ćsima peça no i-ćsimo patamar de temperatura subtraído de $20^{\circ} \mathrm{C}$

- $\beta$ : Coeficiente de dilatigão da peça

- $\varepsilon_{i j}$ : Erro de medição do diàmetro do furo obtida na j-ćsima peça no i-ésimo patamal de temperatiura.

No entanto, o diâmetro do furo possui comportamento lincar apenas cm função do verdadeiro valor da temperatura, que não ć diretamente observado. Neste tipo de modelagem, observamos a temperatura, porém medida com erro como apresentado a seguir:

$$
X_{i j}=V_{i j}+\delta_{i j}
$$

onde;

- $X_{i j}$ : Temperatura observada da j-ćsima peça no i-ésimo patamar de temperatura subtraída de $20^{\circ} \mathrm{C}$. Medição obtida a partir do termòmetro de contato Fluke.

- $V_{i}$ : Verdadeiro valor da temperatura da j-ésima peça no i-ésimo patamar do temperatura subtraído de $20^{\circ} \mathrm{C}$. 
- $\delta_{i j}$ : Variável aleatória correspondendo ao crro de medição de temperatura, cuja variância foi previamente estimada no processo de calibraçäo (ver apêndice).

Aqui, faremos as seguintes hipóteses:

1. $\varepsilon_{i j} \sim N\left(0, \sigma^{2}\right)$ com $\sigma^{2}$ desconhecido.

2. $\delta_{i j} \sim N\left(0, \sigma_{\delta}^{2}\right)$ com $\sigma_{\delta}^{2}$ conhecido.

3. $V_{i j} \sim N\left(\mu_{i}, \sigma_{V}^{2}\right)$. com $\mu_{i}$ e $\sigma_{V}^{2}$ desconliecidos.

4. $\varepsilon_{i j}$ são independentes $\delta_{i j}$ para todo i c $\mathrm{j}$.

5. $\varepsilon_{i^{\prime} j}$ são independentes $\varepsilon_{i j}$, $\varepsilon_{i j^{\prime}}$ são independentes $\varepsilon_{i j}$, $\delta_{i^{\prime} j}$ são independentes $\delta_{i j}, \delta_{i j^{\prime}}$ são independentes $\delta_{i j}$, $V_{i^{\prime} j}$ são independentes $V_{i j}$ e $V_{i j^{\prime}}$ são independentes $V_{i j}$, para todo $i=1, \ldots, n \subset j=1, \ldots, k$.

Neste conjunto de suposiçóes, assumimos que o erro conctido pela cólula na medição do diâmetro é independente do crro cometido pelo termômetro de contato na medição de temperatura, independente do pistão e do patamar de temperatura. Com relação aos crros cometidos na medição da variável resposta e na mediçào da variável independente, assumiremos que estes são independentes do pistão e do patannar de temperatural. Com estas suposições, a esperança de $Y_{i j}$ e $X_{i j}$ são:

- $E\left[Y_{i j}\right]=E\left[\beta V_{i j}+\varepsilon_{i j}\right]=\beta \mu_{i}$

- $F_{i}\left[X_{i j}\right]=E\left[V_{i j}+\delta_{i j}\right]-\mu_{i}$

c a variância de $Y_{i j}$ c $X_{i j}$ são

- $\operatorname{Var}\left[Y_{i j}\right]=\operatorname{Var}\left[\beta V_{i j}+\varepsilon_{i j}\right]=\beta^{2} \sigma_{V}^{2}+\sigma^{2}$

- $\operatorname{Var}\left[X_{i j}\right]=\operatorname{Var} V_{i j}+\delta_{i j} ?=\sigma_{V}^{2}+\sigma_{\delta}^{2}$

Alóm disso, a estrutura de covariância, para pistões j e j' do mosmo patamar i do tompcratura ć dada por: 
- $\operatorname{Cov}\left[Y_{i j}, Y_{i j^{\prime}}\right]=\operatorname{Cov}\left[\beta V_{i j}+\varepsilon_{i j}, \beta V_{i j^{\prime}}+\varepsilon_{i j^{\prime}}:=0\right.$

- $\left.\operatorname{Cov}\left[X_{i j}, X_{i j^{\prime}}\right]-\operatorname{Cov} V_{i j}+\delta_{i j}, V_{i j^{\prime}}+\delta_{i j^{\prime}}\right]=\operatorname{Con}\left[V_{i j}, V_{i j^{\prime}}\right]+\operatorname{Cov}\left[V_{i j}, \delta_{i j^{\prime}}{ }^{i}+\operatorname{Cov}\left[\delta_{i j}, V_{i j^{\prime}}\right]+\right.$ $\operatorname{Cov}\left[\delta_{i j}, \delta_{i j^{\prime}},=0\right.$,

- $\operatorname{Cov}\left[Y_{i j}, X_{i j}=\operatorname{Cov}\left[\beta V_{i j}+\varepsilon_{i j}, V_{i j}+\delta_{i j}{ }_{i}=\operatorname{Cov}\left[\beta V_{i j}, V_{i j}\right]+\operatorname{Cov}\left[\beta V_{i j}, \delta_{i j}\right]+\operatorname{Cov}\left[\varepsilon_{i j}, V_{i j}{ }^{\prime}+\right.\right.\right.$ $\operatorname{Cov}\left[\varsigma_{i j}, \delta_{i j}\right]=\beta \sigma_{V}^{2}$,

- $\left.\left.\operatorname{Cov}_{i}^{\prime} Y_{i j}, X_{i j^{\prime}}\right]=\operatorname{Cov}\left[\beta V_{i j}+\varepsilon_{i j}, V_{i j^{\prime}}+\delta_{i j^{\prime}}\right]=\operatorname{Cov}\left[\beta V_{i j}, V_{i j^{\prime}}\right]+\operatorname{Cov}^{\prime} \beta V_{i j}, \delta_{i j^{\prime}}\right]+\operatorname{Cov}_{i}^{\prime} \varepsilon_{i j}, V_{i j^{\prime}}{ }^{\prime}+$ $\left.\operatorname{Cov} \varepsilon_{i j}, \delta_{i j^{\prime}}\right]=0$,

- $\operatorname{Cov}\left[V_{i j}, X_{i j}\right]=\operatorname{Cov}\left[V_{i j}, V_{i j}+\delta_{i j}\right]-\operatorname{Cov}\left[V_{i j}, V_{i j}\right]+\operatorname{Cov}\left[V_{i j}, \delta_{i j}\right]=\sigma_{V}^{2}$

- $\operatorname{Cov}\left[V_{i j}, X_{i j^{\prime}}\right]=\operatorname{Cov}\left[V_{i j}, V_{i j^{\prime}}+\delta_{i j^{\prime}}\right]=\operatorname{Cot}\left[V_{i j}, V_{i j^{\prime}}\right]+\operatorname{Con}\left[\left[V_{i j}, \delta_{i j^{\prime}}\right]=0\right.$,

- $\operatorname{Cov}\left[V_{i j}, Y_{i j}\right]=\operatorname{Cov}\left[V_{i j}, \beta V_{i j}+\varepsilon_{i j}\right]=\operatorname{Cov}\left[V_{i j}, \beta V_{i j}\right]+C o v\left[V_{i j}, \varepsilon_{i j}\right]=\beta \sigma_{V}^{2}$,

- $\operatorname{Cov}\left[V_{i j}, Y_{i j^{\prime}}\right]=\operatorname{Cov}\left[V_{i j}, 3 V_{i j^{\prime}}+\varepsilon_{i j^{\prime}}\right]-\operatorname{Cov}\left[V_{i j}, 3 V_{i j^{\prime}}+\operatorname{Cov} V_{i j}, \varepsilon_{i j^{\prime}}{ }^{\prime}=0\right.$

De forma análoga, para patamares i c i' considerando o mesmo pistão j tcmos a mesma estrutura de covariância anterior. Quando cste modelo é adotado, o interesse principal está en estinar $\beta, \mu, \sigma^{2}$ e $\sigma_{V}^{2}$ respectivamente ou uma função doles.

\subsection{Notação Matricial}

Para simplificar a notaşão, vamos tratar as obscrvaçócs de forma matricial. P’ara isso, tomamos 


$$
\underline{Z_{i}}=\left(\begin{array}{c}
Y_{i 1} \\
Y_{i 2} \\
\cdot \\
\cdot \\
\cdot \\
Y_{i k} \\
X_{i 1} \\
X_{i 2} \\
\cdot \\
\cdot \\
\cdot \\
X_{i k}
\end{array}\right)_{2 k \times 1}\left(\begin{array}{c}
\frac{Z_{1}}{\underline{Z}} \\
\underline{Z} \\
\cdot \\
\cdot \\
\underline{Z_{n}}
\end{array}\right)_{n \times 1}
$$

Vamos admitir que o vetor aleatório $\underline{Z_{i}}$ tem distribuição normal $2 k$-multivariada, nat forma

$$
\underline{Z_{i}} \sim N_{2 k}\left(\underline{\mu_{i}}, \Sigma\right)
$$

onde $\mu_{i}$ ć o vetor de médias de dimensão $2 k \times 1 ; \sum$ e a matriz de covariância. Aqui, tenos como vetor de médias e a matriz de covariâncias respectivamente. 


$$
\underline{\mu_{i}}=\left(\begin{array}{c}
\beta \mu_{i} \\
\beta \mu_{i} \\
\cdot \\
\cdot \\
\beta \\
\mu_{i} \\
\mu_{i} \\
\mu_{i} \\
\cdot \\
\cdot \\
\mu_{i}
\end{array}\right)_{2 k \times 1} ; \Sigma-\left(\begin{array}{cc}
B_{11} & B_{12} \\
B_{21} & B_{22}
\end{array}\right)_{2 k \times 2 k}
$$

onde

$$
\begin{gathered}
B_{11}\left(\begin{array}{ccccc}
\beta^{2} \sigma_{V}^{2}+\sigma^{2} & 0 & \cdots & 0 \\
0 & \beta^{2} \sigma_{V}^{2}+\sigma^{2} & \cdots & 0 \\
\cdot & \cdot & \cdots & \cdot \\
\cdot & \cdot & \cdots & \cdot \\
\cdot & & \cdot & \cdots & \cdot \\
0 & & 0 & \cdots & \beta^{2} \sigma_{V}^{2}+\sigma^{2}
\end{array}\right) \\
B_{12}=\left(\begin{array}{cccc}
\beta \sigma_{V}^{2} & 0 & \cdots & 0 \\
0 & \beta \sigma_{V}^{2} & \cdots & 0 \\
\cdot & \cdot & \cdots & \cdot \\
\cdot & \cdot & \cdots & \cdot \\
\cdot & \cdot & \cdots & \cdot \\
0 & 0 & \cdots & \beta \sigma_{V}^{2}
\end{array}\right)=B_{21}
\end{gathered}
$$




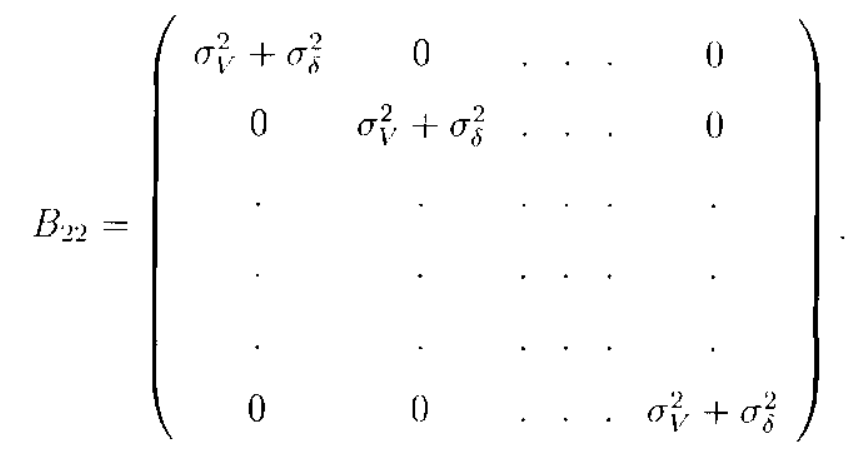

Assim, a função de distribuição conjunta do vetor $\underline{Z}_{i}$ é dada por:

$$
f\left(\underline{Z_{i}}\right)=\frac{1}{\sqrt{(2 \pi)^{2 k}|\Sigma|}} \exp \left(-\frac{1}{2}\left(\underline{Z_{i}}-\underline{\mu_{i}}\right)^{\prime} \Sigma^{-1}\left(\underline{Z_{i}}-\underline{\mu_{i}}\right)\right)
$$

No cutanto, precisamos calcular a inversa e o determinante da matriz de covariâncias $\Sigma$. Para o calculo da inversa c do detcrminante, utilizamos resultados para inversas de matrizes apresentados por Graybill (Teorema 8.3.3,1983,pag 189). Estas estratégials consistem basicamente $\mathrm{em}$ considerar a matriz do covariâncias constituída de blocos. Para o calculo da inversal, considerenos a matriz da seguinte forma:

$$
\Sigma=\left(\begin{array}{ll}
B_{11} & B_{12} \\
B_{21} & B_{22}
\end{array}\right)_{2 k \times 2 k}
$$

Com isto, a inversa da matriz ć dada por [Graybill (1983), Tcorema 8.3.3, pg.189]

$$
\Sigma^{-1}=\left(\begin{array}{cc}
{\left[B_{11}-B_{12} B_{22}^{-1} B_{21}\right]^{-1}} & -B_{11}^{-1} B_{12}\left\{B_{22}-B_{21} B_{11}^{-1} B_{12 \vdots}^{-1}\right. \\
-B_{22}^{-1} B_{21}\left[B_{11}-B_{12} B_{22}^{-1} B_{21}\right]^{-1} & {\left[B_{22}-B_{21} B_{11}^{-1} B_{12}\right]^{-1}}
\end{array}\right)_{2 k \times 2 k}
$$

o o determinante da matriz é dada por [Graybill,(1983), Teorema 8.2.1,item 2, pag. 184

$$
\left|\Sigma_{2 k \times 2 k}\right|=\left|B_{22}\right|\left|B_{11}-B_{12} B_{22}^{-1} B_{21}\right| .
$$


Primeiro efetuamos o caleulo da inversa da matriz do covariâncias. Consideramos esta matriz formada por blocos da seguinte forma: $\Sigma_{11}^{-1}, \Sigma_{12}^{-1}, \Sigma_{21}^{-1}$ e $\Sigma_{22}^{-1}$. Calculamos cada bloco passo a passo.

1. $\Sigma_{11}^{-1}=\left[B_{11}-B_{12} B_{22}^{-1} B_{21}\right]^{-1}$

2. $B_{11}=\left(\beta^{2} \sigma_{V}^{2}+\sigma^{2}\right) I_{k \times k}$

3. $B_{12} B_{22}^{-1} B_{21}=\left(\beta \sigma_{V}^{2}\right)\left(I_{k \times k}\right)\left(\frac{1}{\sigma_{V}^{2}+\sigma_{\delta}^{2}}\right)\left(I_{k \times k}\right)\left(\beta \sigma_{V}^{2}\right)\left(I_{k \times k}\right)=\left(\frac{\beta^{2} \sigma_{V}^{4}}{\sigma_{V}^{2}+\sigma_{\delta}^{2}}\right)\left(I_{k \times k}\right)$.

4. $B_{11}-B_{12} B_{22}^{-1} B_{21}=\left(\frac{\beta^{2} \sigma_{V}^{2} \sigma_{\delta}^{2}+\sigma^{2} \sigma_{Y}^{2}+\sigma^{2} \sigma_{\hat{\sigma}}^{2}}{\sigma_{V}^{2}+\sigma_{\delta}^{2}}\right)\left(I_{k \times k}\right)$

5. $\Sigma_{11}^{-1}-\left[B_{11}-B_{12} B_{22}^{-1} B_{21}\right]^{-1}=\left(\frac{\sigma_{V}^{2}+\sigma_{\delta}^{2}}{\beta^{2} \sigma_{1}^{2} \sigma_{\delta}^{2}+\sigma^{2} \sigma_{v}^{2}-\sigma^{2} \sigma_{\delta}^{2}}\right)\left(I_{k \times k}\right)$.

A seguir, calculamos $\Sigma_{22}^{-1}$

1. $\Sigma_{22}^{-1}=\left[B_{22}-B_{21} B_{11}^{-1} B_{12}\right]^{-1}$

2. $B_{22}-\left(\sigma_{V}^{2}+\sigma_{\tilde{\delta}}^{2}\right) I_{k \times k}$

3. $B_{21} B_{11}^{-1} B_{12}=\left(\beta \sigma_{V}^{2}\right)\left(I_{k \times k}\right)\left(\frac{1}{\beta^{2} \sigma_{V}^{2}+\sigma^{2}}\right)\left(I_{k \times k}\right)\left(\beta \sigma_{V}^{2}\right)\left(I_{k \times k}\right)=\left(\frac{\beta^{2} \sigma_{V}^{4}}{\beta^{2} \sigma_{V}^{2}+\sigma^{2}}\right)\left(I_{k \times k}\right)$

4. $B_{22}-B_{21} B_{11}^{-1} B_{12} \cdots\left(\frac{\beta^{2} \sigma_{v}^{2} \cdot \sigma_{1}^{2} \mid \sigma^{2} \sigma_{r}^{2}+\sigma^{2} \sigma_{S}^{2}}{\beta^{2} \sigma_{V}^{2}+\sigma^{2}}\right)\left(I_{k \times k}\right)$

5. $\Sigma_{22}^{-1}=\left[B_{22}-B_{21} B_{11}^{-1} B_{12}\right]^{-1}=\left(\frac{\beta^{2} \sigma_{1}^{2}+\sigma^{2}}{\beta^{2} \sigma_{k}^{2} \cdot \sigma_{\delta}^{2}+\sigma^{2} \sigma_{k}^{2}+\sigma^{2} \sigma_{\xi}^{2}}\right)\left(I_{k \times k}\right)$.

Finalmente, calculamos $\sum_{21}^{-1}$

1. $\left[-B_{22}^{-1} B_{21}\right]=\left(-\frac{i \beta \sigma_{k}^{2}}{\sigma_{k}^{2}+\sigma_{\dot{\alpha}}^{2}}\right)\left(I_{k \times k}\right)$

2. $\Sigma_{21}^{-1}=\left[-B_{22}^{-1} B_{21}\right]\left[B_{11}-\left.B_{12} B_{22}^{-1} B_{21}\right|^{-1}=\left(-\frac{\beta \sigma_{V}^{2}}{\beta^{2} \sigma_{V}^{2} \sigma_{\delta}^{2}+\sigma^{2} \sigma_{V}^{2}+\sigma^{2} \sigma_{k}^{2}}\right)\left(I_{k \times k}\right)\right.$

$\Sigma_{12}^{-1}$

1. $\left.-B_{11}^{-1} B_{12}\right]=\left(-\frac{\beta \sigma_{k}^{2}}{\beta^{2} \sigma_{v}^{2}+\sigma^{2}}\right)\left(I_{k \times k}\right)$

2. $\Sigma_{12}^{-1}=\left[-B_{11}^{-1} B_{12}\left[B_{22}-B_{21} B_{11}^{-1} B_{12}\right]^{-1}-\left(-\frac{\beta \sigma_{i}^{2}}{\beta^{2} \sigma_{V}^{2} \sigma_{\delta}^{2}+\sigma^{2} \sigma_{V}^{2}+\sigma^{2} \sigma_{\delta}^{2}}\right)\left(I_{k \times k}\right)\right.$. 
Desta forma, obtemos

$$
\begin{aligned}
& \Sigma_{2 k \times 2 k}^{-1}-\left(\frac{1}{\beta^{2} \sigma_{V}^{2} \sigma_{\delta}^{2}+\sigma^{2} \sigma_{V}^{2}+\sigma^{2} \sigma_{\delta}^{2}}\right)
\end{aligned}
$$

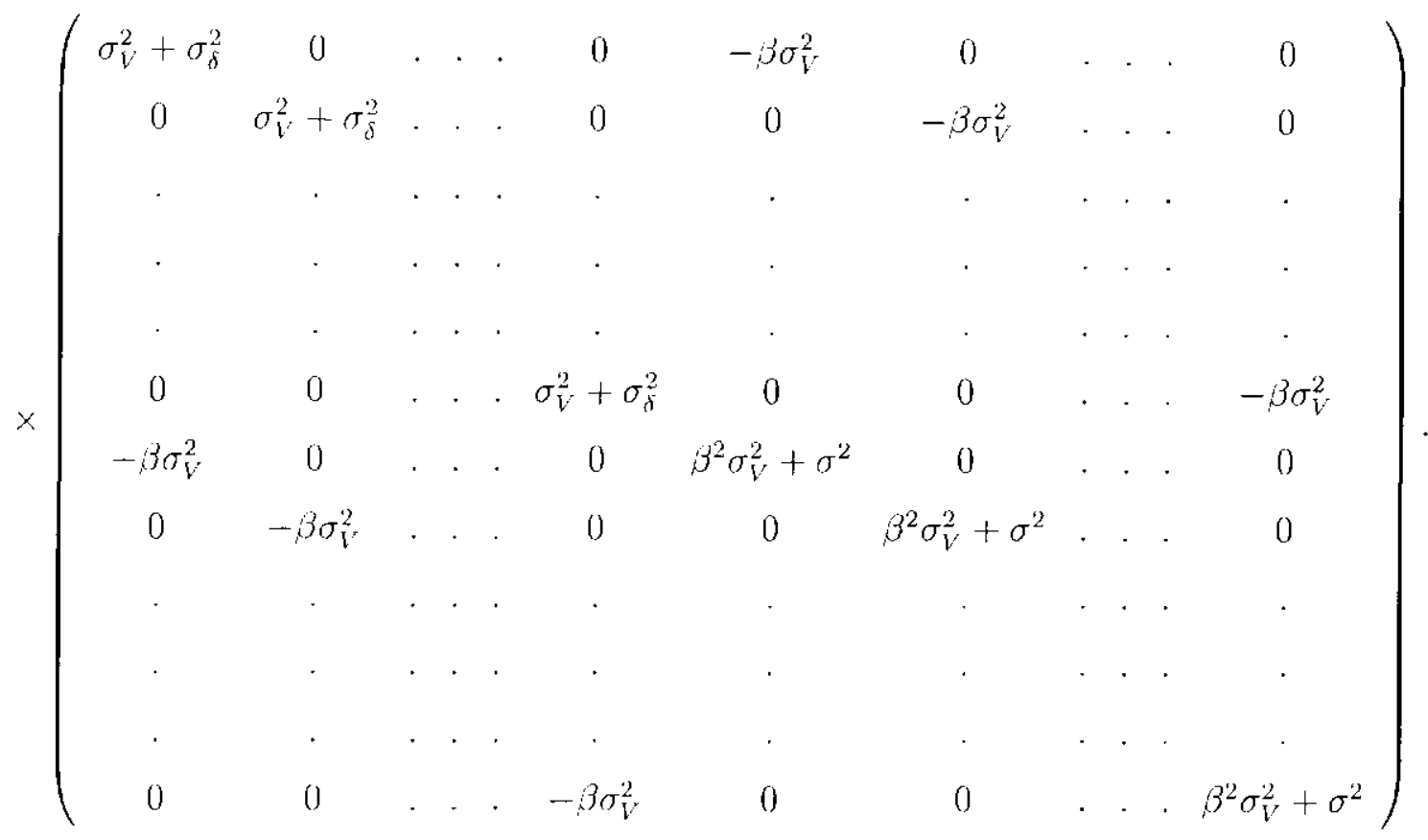

Após calculo da inversa da matriz de covariâncias, o próximo passo co o calculo do seu determinante.

1. $\left|B_{11}-B_{12} B_{22}^{-1} B_{21}\right|=\left(\frac{\beta^{2} \sigma_{v}^{2} \sigma_{s}^{2}+\sigma^{2} \sigma_{v}^{2}+\sigma^{2} \sigma_{\dot{b}}^{2}}{\sigma_{V}^{2}+\sigma_{s}^{2}}\right)^{k}$

2. $\left|B_{22}\right|=\left(\sigma_{V}^{2}+\sigma_{i}^{2}\right)^{k}$

3. $\left|\Sigma_{2 k \times 2 k}\right|=\left(\sigma_{V}^{2}+\sigma_{\delta}^{2}\right)^{k}\left(\frac{\beta^{2} \sigma_{V}^{2} \sigma_{\dot{\alpha}}^{2} \mid \sigma^{2} \sigma_{V}^{2}+\sigma^{2} \sigma_{s}^{2}}{\sigma_{V}^{2} \cdot \sigma_{s}^{2}}\right)^{k}$

A partir da inversa o do detcrminante da matriz de covariâncias, obtemos a função distribuição conjunta de $\underline{Z_{i}}$. Após manipulações algébricas, conchuímos que,:

$$
f(\underline{Z})=\prod_{i=1}^{n} f\left(\underline{Z_{i}}\right)
$$

$f\left(Z_{1}, \underline{Z_{2}}, \ldots, \underline{Z_{n}}\right) \propto\left(\beta^{2} \sigma_{V}^{2} \sigma_{\delta}^{2}+\sigma^{2} \sigma_{V}^{2}+\sigma^{2} \sigma_{\delta}^{2}\right)^{n k / 2} \operatorname{cxp}\left(-\frac{1}{2} h_{1}\left(\beta, \mu_{1}, \ldots, \mu_{n}, \sigma_{V}^{2}, V_{i j}, Y_{i j}, X_{i j}\right)\right)$ 


$$
\begin{aligned}
& h_{1}-\left(\frac{\beta \sigma_{V}^{2}}{\beta^{2} \sigma_{V}^{2} \sigma_{\delta}^{2}+\sigma^{2} \sigma_{V}^{2}+\sigma^{2} \sigma_{\delta}^{2}}\right)\left(\sum_{i=1}^{n} \sum_{j=1}^{k} Y_{i j} X_{i j}-\sum_{i=1}^{n} \mu_{i} \sum_{j=1}^{k} Y_{i j}-\beta \sum_{i=1}^{n} \mu_{i} \sum_{j=1}^{k} X_{i j}+k \beta \sum_{i=1}^{n} \mu_{i}^{2}\right) \\
& -\left(\frac{1}{\beta^{2} \sigma_{V}^{2} \sigma_{\delta}^{2}+2 \sigma^{2} \sigma_{V}^{2}+2 \sigma^{2} \sigma_{\delta}^{2}}\right)\left(\beta \sigma_{V}^{2} \sum_{i=1}^{n} \sum_{j=1}^{k} X_{i j}^{2}-2 \beta \sigma_{V^{\prime}}^{2} \sum_{i=1}^{n} \mu_{i} \sum_{j=1}^{r} X_{i, j}+k \beta \sigma_{V}^{2} \sum_{i=1}^{n} \mu_{i}^{2}\right) \\
& -\left(\frac{1}{\beta^{2} \sigma_{V}^{2} \sigma_{\delta}^{2}+2 \sigma^{2} \sigma_{V}^{2}+2 \sigma^{2} \sigma_{j}^{2}}\right)\left(\sigma^{2} \sum_{i=1}^{n} \sum_{j=1}^{k} X_{i}^{2}-2 \sigma^{2} \sum_{i=1}^{n} \mu_{i} \sum_{j=1}^{k} X_{i j}+k \sigma^{2} \sum_{i=1}^{n} \mu_{i}^{2}\right) \\
& -\left(\frac{1}{\beta^{2} \sigma_{V}^{2} \sigma_{\delta}^{2}+2} \cdot \frac{1}{\sigma^{2} \sigma_{V}^{2}+2 \sigma^{2}} \sigma_{\delta}^{2}\right)\left(\sigma_{V}^{2} \sum_{i=1}^{n} \sum_{j-1}^{k} Y_{i j}^{\prime 2}-2 \beta \sigma_{V}^{2} \sum_{i=1}^{n} \mu_{i} \sum_{j=1}^{k} X_{i j}+k \beta \sigma_{V}^{2} \sum_{i=1}^{n} \mu_{i}^{2}\right) \\
& -\left(\frac{1}{\beta^{2} \sigma_{V}^{2} \sigma_{\delta}^{2}+2 \frac{\sigma^{2} \sigma_{V}^{2}+2 \sigma^{2} \sigma_{\delta}^{2}}{\delta}}\right)\left(\sigma_{\delta}^{2} \sum_{i=1}^{n} \sum_{j=1}^{k} Y_{i j}^{2} \cdots 2 \sigma_{j}^{2} \beta \sum_{i=1}^{n} \mu_{i} \sum_{j=1}^{k} Y_{\eta,}+k \sigma_{i j}^{2} \beta^{2} \sum_{i=1}^{n} \mu_{i}^{2}\right)
\end{aligned}
$$

Como a função conjunta acima ć complexa (observe que $\beta$ e $\sigma_{v}^{2}$ estão juutos no denominador), não conseguimos obter explicitanonte o estimador do máxima verosimilhança. Diante deste problena, recorremos a estratégia de buscal estimativas de máxima verossimillança via algoritmo FN (Esperança c Maximização)

O algoritmo E.M [ver Dempster L Laird and Rubin (1977) ć usado na cstimação do máxima vorossimilhança na presença de dados faltantes (ou perdidos), porćm a verossimilliança dada om (3.5) não cnvolve variávois não observáveis. Neste contexto introduzimos as variáveis latentes $V_{i j}$

\subsection{Introdução de Variáveis Latentes}

Como podemos observar, a função de verossimilhança dada cm 3.5, apesar de cnglobar Ioda informação da amostra, é bastante complexa. Este fato, na análise clássica acaba dificultando a obtenção de expressóses fechadas para os estimadores de máxima verossimilhança. 
Introduzinos no modelo variáveis não observáveis $V_{i j},(i-1, \ldots, n$ e j $-1, \ldots, k)$, também channadas de variáveis latentes que permitem a ubtenção de estimadores mediante a utilização do algoritmo EM (Estimação e Maximização). Fsta variável pode ser considerada uma variável latente adequada, pois ao introduzimmos a variável latente $V_{l j}$ quebranos a estrutura de covariância, deixando apenas os crros.

Com a introdução das variáveis latentes: o novo vetor de observaçós denotado por $\underline{W_{i}}$ tornd-se

$$
\underline{W_{i}}=\left(\begin{array}{c}
Y_{i 1} \\
Y_{i 2} \\
\cdot \\
\cdot \\
Y_{i k} \\
X_{i 1} \\
X_{i 2} \\
\cdot \\
\cdot \\
X_{i k} \\
V_{i 1} \\
V_{i 2} \\
\cdot \\
\cdot \\
\cdot \\
V_{i k}
\end{array}\right)_{3 k \times 1}\left(\begin{array}{c}
\underline{W_{1}} \\
\underline{W_{2}} \\
\cdot \\
\underline{W_{n}}
\end{array}\right)_{3 n k \times 1}
$$

Vamos admitir que a distribuição conjunta de $\underline{W_{i}}$ é norma multivariada, na forma

$$
\underline{W_{i}} \sim N_{3 k}\left(\underline{\mu_{i}^{*}}, 2 * *\right)
$$

onde $\mu^{*}$ é u vetor de médias de dimensão $3 k \times 1 ; \Sigma^{*}$ e a matriz de covariância 


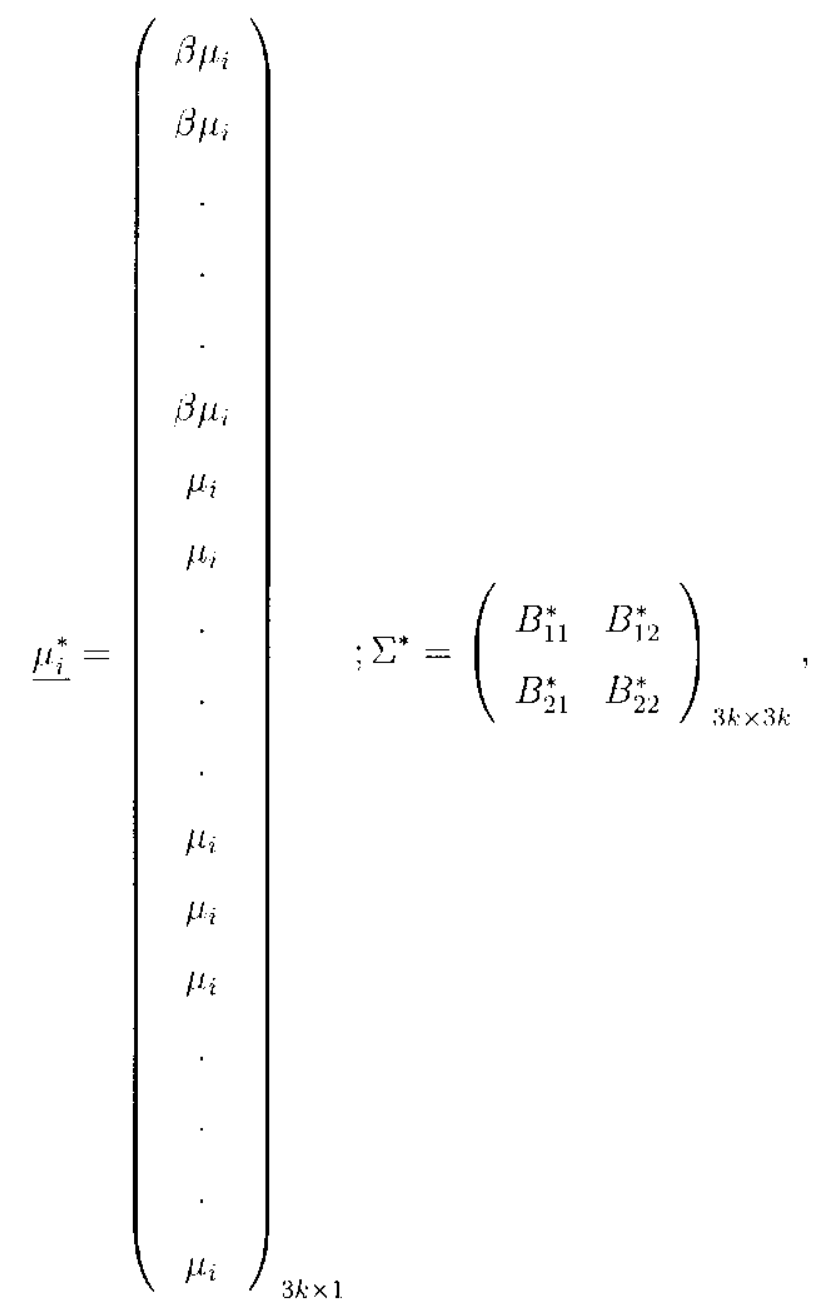

onde

$$
B_{11}^{*}=\Sigma_{2 k \times 2 k}
$$




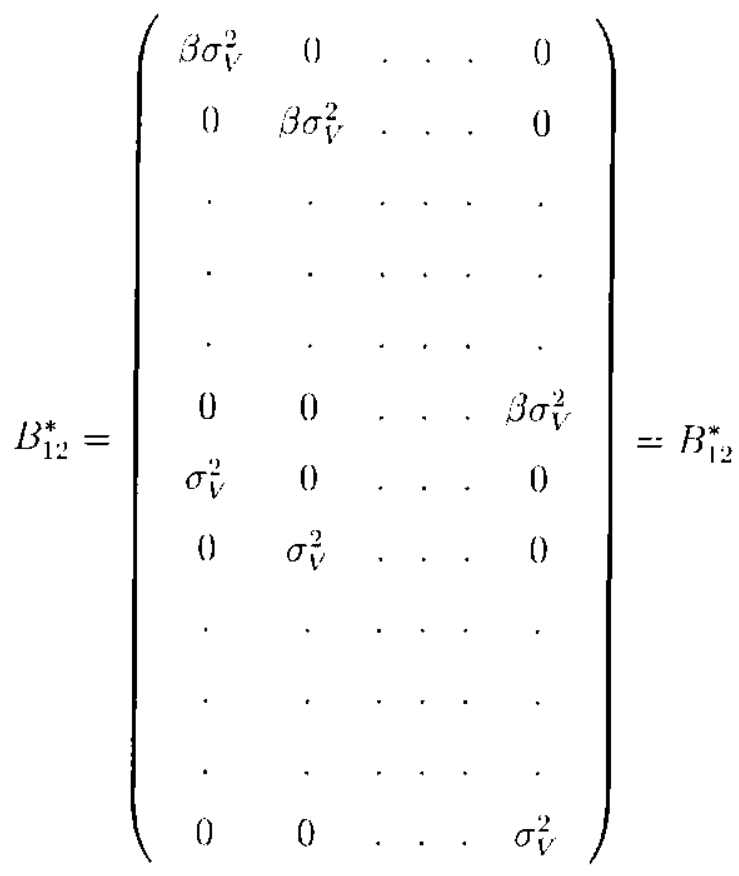

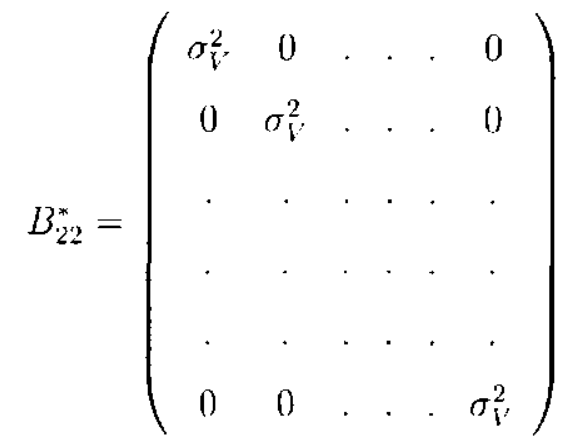

Assime a função de distribuição conjunta on a função de verossinnilhança do vetor Ẃ ć dada por

$$
f(\underline{\underline{W}})-\prod_{i=1}^{n} \frac{1}{\sqrt{(2 \pi)^{3 k}\left|2^{*}\right|}}=\exp \left(-\frac{1}{2}\left(\underline{W_{i}}-\underline{\mu_{i}^{*}}\right)^{\prime} \Sigma^{*-1}\left(\underline{W_{i}}-\underline{\mu_{i}^{*}}\right)\right) .
$$

No cutanto, novamente precisamos calcular a inversa e o determinante da matri\%

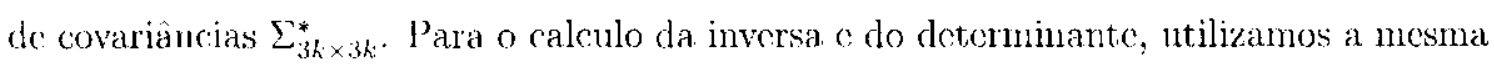
estraténia da seção 3. Consideramos a matriz covariâncias, ampliada com a entrada da variável latente, constituída de blocos. Para o calculo da inversa, consideramos a matriz da seguinte forma: 


$$
\Sigma^{*} \cdots\left(\begin{array}{ll}
B_{11}^{*} & B_{12}^{*} \\
B_{21}^{*} & B_{22}^{*}
\end{array}\right)_{3 k \times 3 k}
$$

Com isto, a inversa da matriz ć dada por [Gaybill (1983), Teoroma 8.3.3, pg.189]

$$
\Sigma^{*-1}=\left(\begin{array}{cc}
{\left[B_{11}^{*}-B_{12}^{*}\left[B_{22}^{*}{ }^{1} B_{21}^{*}\right]^{1}\right.} & -B_{11}^{*-1} B_{12}^{*}\left[B_{22}^{*}-\left.B_{21}^{*} B_{11}^{*-1} B_{12}^{*}\right|^{-1}\right. \\
-B_{22}^{*-1} B_{21}^{*}\left[B_{11}^{*}-B_{12}^{*} B_{22}^{*-1} B_{21}^{*}\right]^{-1} & \left.B_{22}^{*}-B_{21}^{*} B_{11}^{*-1} B_{12}^{*}\right]^{-1}
\end{array}\right)_{2 k \times 2 k}
$$

c o determinante da matriz ó dada por 'Graybill,(1983), T'oorema 8.2.1, itom 2, pag. 184]

$$
|2 * \cdots 13 k \times 3 k|-\left|B_{22}^{*}\right|\left|B_{11}^{*}-B_{12}^{*} B_{22}^{*} \cdot 1 B_{21}^{*}\right|
$$

Primeiro efetuanos o cálenlo da inversa da nova matri\% de covariandeias. Consideramos csta matriz formada por blocos da seguinte forma: $\Sigma_{11}^{*-1}, \Sigma_{12}^{*-1}, \Sigma_{21}^{*-1}$ e $\Sigma_{22}^{*-1}$. Calculamos cada bloco a seguir.

1. $\Sigma_{11}^{*-1}=\left[B_{11}^{*}-B_{12}^{*} B_{22}^{*}{ }^{1} B_{21}^{*}\right\}^{\prime}=$

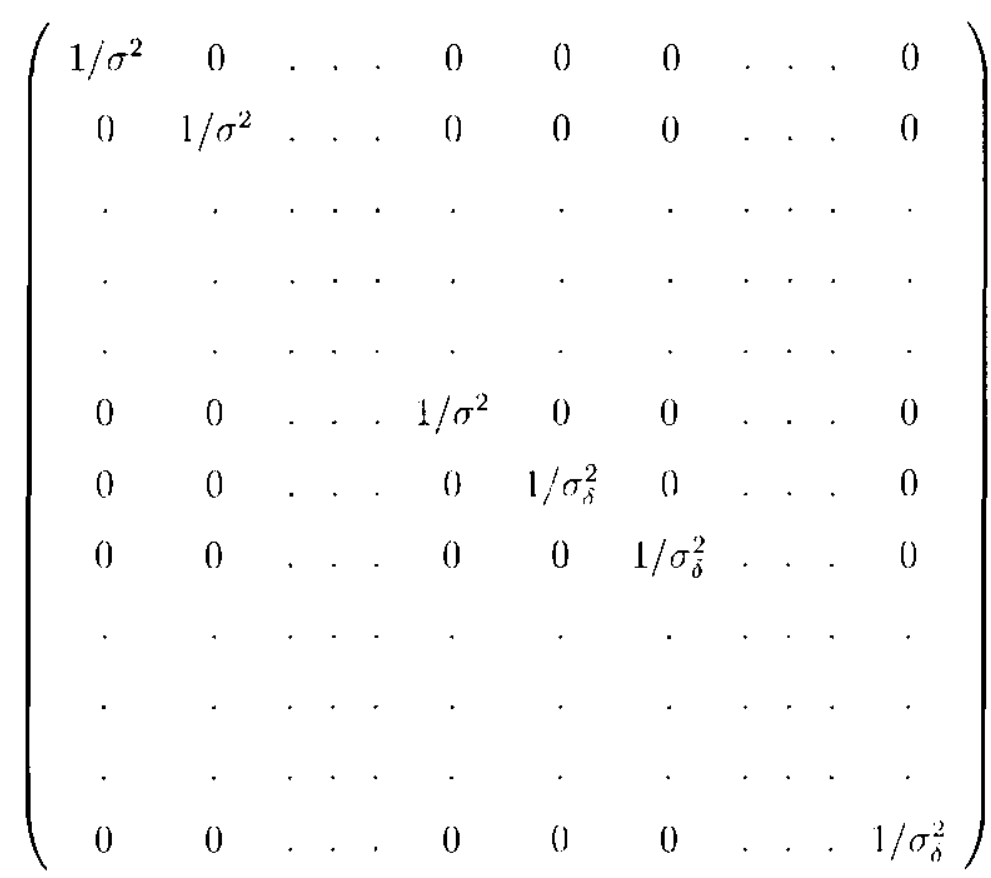


2. $\Sigma_{22}^{*-1}=\left[B_{22}^{*}-B_{21}^{*} B_{11}^{*-1} B_{12}^{*}\right]^{-1}=$

$$
\left(\begin{array}{ccccc}
\psi / \sigma_{V}^{2} \sigma^{2} \sigma_{\delta}^{2} & 0 & . & . & 0 \\
0 & \psi / \sigma_{V}^{2} \sigma^{2} \sigma_{\delta}^{2} & \cdot & \cdot & 0 \\
\cdot & \cdot & \cdot & \cdot & \cdot \\
\cdot & \cdot & \cdot & \cdot & \cdot \\
\cdot & \cdot & \cdot & \cdot & \cdot \\
0 & 0 & \cdot & \cdot & \psi / \sigma_{V}^{2} \sigma^{2} \sigma_{\delta}^{2}
\end{array}\right)
$$

onde

$$
\psi=\beta^{2} \sigma_{V}^{2} \sigma_{\delta}^{2}+\sigma_{V}^{2} \sigma^{2}+\sigma_{\delta}^{2} \sigma^{2}
$$

3. $\Sigma_{21}^{*-1}-\left[-B_{22}^{*-1} B_{21}^{*}\right]\left[B_{11}^{*}-B_{12}^{*} B_{22}^{*-1} B_{12}^{*}\right]^{-1}=$

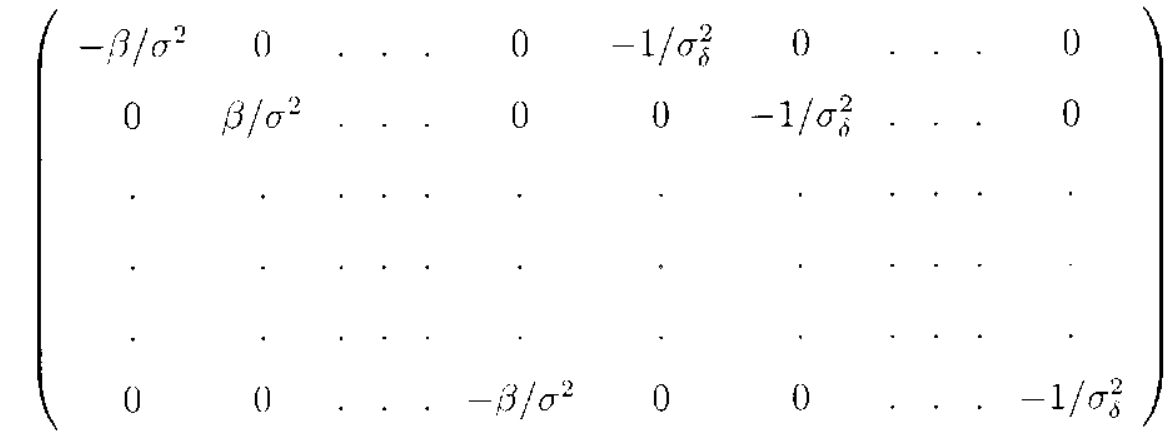


4. $\Sigma_{12}^{*-1}=\left[-B_{11}^{*-1} B_{12}^{*}\right]\left[B_{22}^{*}-B_{21}^{*} B_{11}^{*-1} B_{121}^{*} i^{i-1}\right.$

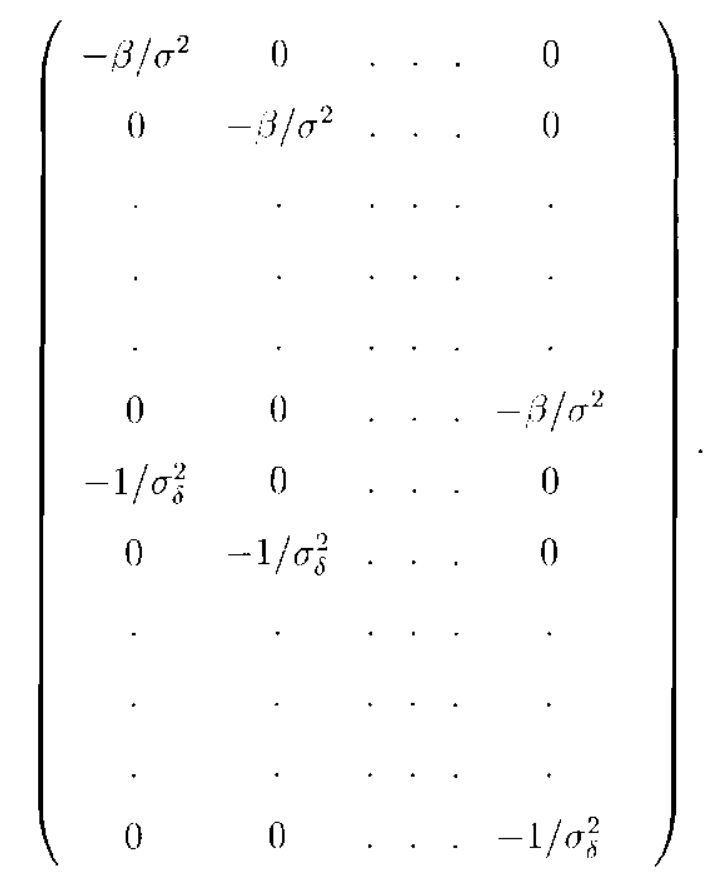

Após calculo da inversa da matriz de covariâncias, o próximo passo é o calculo do scu detcrminante.

$$
\left|B_{11}^{*}-B_{12}^{*} B_{22}^{*-1} B_{21}^{*}\right|=\left(\sigma_{V}^{2}\right)^{k}\left(\sigma^{2}\right)^{k}\left(\sigma_{\delta}^{2}\right)^{k}
$$

Observe que o determinante da matriz de covariancias ficon mais simples con a introducão da variável latente. A partir da inversa o do detcrminante da matriz de covariancias, podemos desenvolver a Equação (3.6) com mais detallues. Após manipulaçõos algébricas, obtemos

$f\left(\underline{W} / \beta, \mu_{1}, \ldots, \mu_{m}, \sigma_{V}^{2}, \sigma^{2}\right) \propto\left(\sigma_{V}^{2}\right)^{-n k / 2}\left(\sigma^{2}\right)^{-n k / 2} \operatorname{cxp}\left(-\frac{1}{2} h_{2}\left(\beta, \mu_{1}, \ldots, \mu_{n}, \sigma_{V}^{2}, V_{i j}, Y_{i j}, X_{i j}\right)\right)$

onde

$$
h_{2}\left(\beta, \mu_{1}, \ldots, \mu_{u}, \sigma_{V}^{2}, V_{i j}, Y_{i, j}, X_{i, j}\right)=\frac{1}{\sigma^{2}} \sum_{i=1}^{n} \sum_{j=1}^{k} Y_{i j}^{2}-\frac{2 \beta}{\sigma^{2}} \sum_{i=1}^{n} \sum_{j=1}^{k} Y_{i j} V_{i j}+\frac{1}{\sigma_{j}^{2}} \sum_{i=1}^{n} \sum_{j=1}^{k} X_{i j}^{2}
$$


$-\frac{2}{\sigma_{\delta}^{2}} \sum_{i=1}^{n} \sum_{j=1}^{k} X_{i j} V_{i j}+\frac{\beta^{2}}{\sigma^{2}} \sum_{i=1}^{n} \sum_{j=1}^{k} V_{i j}^{2}+\frac{1}{\sigma_{\delta}^{2}} \sum_{i=1}^{n} \sum_{j=1}^{k} V_{i j}^{2}+\frac{1}{\sigma_{V}^{2}} \sum_{i=1}^{n} \sum_{j=1}^{k} V_{i j}^{2}-\frac{2}{\sigma_{V}^{2}} \sum_{i=1}^{n} \sum_{j=1}^{k} V_{i j} \mu_{i}+\frac{k}{\sigma_{V}^{2}} \sum_{i=1}^{n} \mu_{i}^{2}$.

Obscrve que esta expressãa apresenta uma grande simplificação cm relação a expressão em 3.5. Nlóm disso, cnvolve as varjáveis não obscrváveis $V_{i j}$. 


\section{Capítulo 4}

\section{Estimador de Máxima Verossimilhança (EMV)}

Neste capítulo, utilizanos do algoritmo EM para obtenção de aproximações para os cstimadores de Máxima Verossimilhança para os parânctros envolvidos no modelo de regressão com crros proposto no Capítulo 3. Além disto, vamos utilizar a tcoria assintótica para detcrminarmos a variância assintólica dos estimadores c construirmos intervalos de. confiança..

\subsection{Algoritmo EM (Esperança e Maximização)}

A técnica conhecida como algoritmo EM, fomalizado por Dempster; Laird e Rubin em 1977, tornou-se um algoritmo numćrico para obtenção de aproximações para as estimativas de máxima verossimilhnaça. O algoritmo EM (cxpectation and maximization) tornou muitos problemas de inferência, atć então sem solução, possiveis de serem solucionados se abordados sob o ponto de vista de um problema onde estivesse faltando dados. Na etapa E estimamos os valores das variáveis latentes via o valor esperado condicional destas variáveis dado os dados c os valores iniciais para os parâmetros. Para executarmos a etapa M, maximizamos a função de verossimilhança do modelo com as variáveis latentes (cquaçào 3.6$)$ 
Para isto, derivando o logaritmo da função de verossimilhança (equação 3.8) com respcito aos parâmetros: $\beta, \mu_{i}, \sigma_{V}^{2} \mathrm{c} \sigma^{2}$, temos

$$
\begin{gathered}
\hat{\beta}=\frac{\sum_{i=1}^{n} \sum_{j=1}^{k} Y_{i j} V_{i j}}{\sum_{i=1}^{n} \sum_{j=1}^{k} V_{i j}^{2}} \\
\hat{\mu}_{i}=\frac{\sum_{j=1}^{k} V_{i j}}{k} \\
\hat{\sigma_{V}^{2}}=\frac{\sum_{i=1}^{n} \sum_{j=1}^{k}\left(V_{i j}-\hat{\mu}_{i}\right)^{2}}{n k} \\
\hat{\sigma^{2}}=\frac{\sum_{i=1}^{n} \sum_{j-1}^{k}\left(Y_{i j}-\hat{\beta} V_{i j}\right)^{2}}{n k}
\end{gathered}
$$

onde $V_{i, j}$ para $i=1, \ldots, n$ o $j=1, \ldots, k$ serão cstimados na ctapa E do algoritmo EM. Com a inclusão das variáveis latentes, foi possívol obter expressões fechadas para cada um dos parâmetros, porém, envolvendo as variáveis latentes. As equaçôes $(4.1),(1.2)$ e (4.3) e (4.4) definem o passo M do algoritmo EM.

No passo E necessitamos calcular as esperanças condlicionais das variávcis latentes. dado $\underline{Y_{i}}, \underline{X_{i}}, \underline{\mu_{i}}, \sigma_{V}^{2} \odot \sigma^{2}$. Note que as expressões obtidas $\mathrm{cm}(4.1),(4.2)$ e (4.3) $\odot(4.4)$ a partir da verossimilhança aumentada dependem de funçoes do verdadeiro valor da temperatura, $\left(V_{i j}\right.$ c $\left.V_{i j}^{2}\right)$. Porém estes não são obscrvados dirctamente. $\Lambda$ ssim. precisamos cstimar estas funçôes dos verdadeiros valores da temperatura fazendo uso da clistribuiçào conjunta de $\underline{Y_{i}}: \underline{X_{i}} \circ \underline{V_{i}}$.

Utilizando a distribuição conjunta dada pela cquação (3.6), estas csperanças podem ser facilmente obtidas através do seguinte resultado. Considere $\underline{t}=\left(\underline{t_{1}}, \underline{t_{2}}\right)^{\prime}$ um vetor aleatório tal que



Então 


$$
\underline{l_{1}} / \underline{t_{2}} \sim N\left[\underline{\mu_{1}}+T_{12} T_{22}^{-1}\left(\underline{t_{22}}-\underline{\mu 2}\right), T_{11}-T_{12} T_{22}^{-1} T_{21}\right]
$$

conforme apresentado por 'Graybill,(1976), Teorema 3.6.1, pag.106]. Então, as csperanças condicionais são dadas por

$$
E\left[V_{i} / \underline{Y_{i}}: \underline{X_{i}}, \sigma_{V}^{2}, \sigma^{2}, \underline{\mu_{i}}\right]=\underline{\mu_{i}}+A \underline{d_{i}}
$$

onde

$$
\begin{aligned}
& \underline{d_{i}}=\left(\underline{Z_{i}}-\underline{\mu_{i}}\right)_{2 k \times 1} e
\end{aligned}
$$

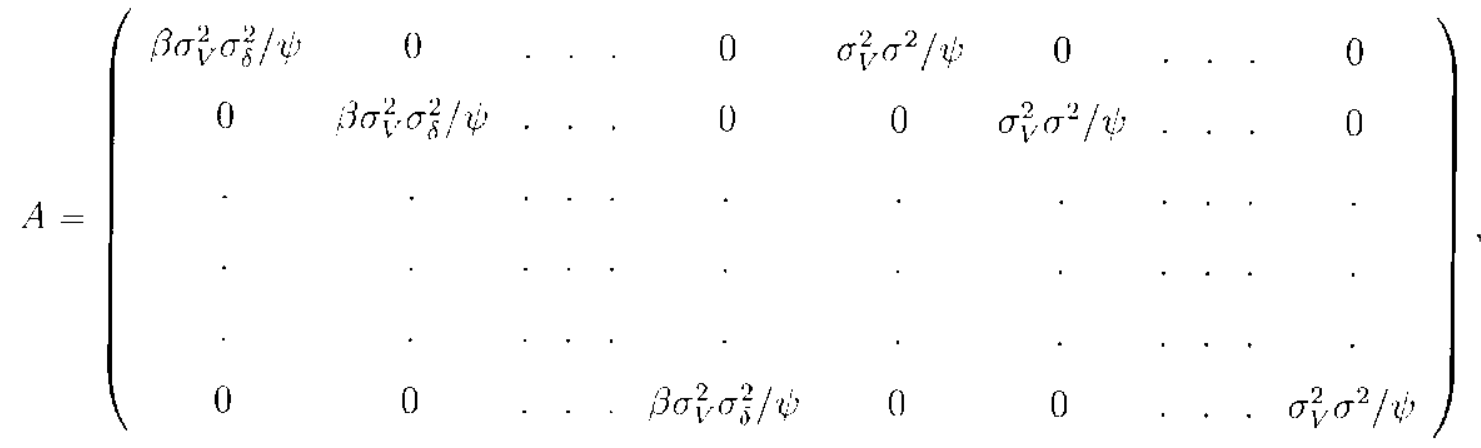

$$
\begin{aligned}
& \text { c. } \\
& \psi=\beta^{2} \sigma_{V}^{2} \sigma_{\delta}^{2}+\sigma^{2} \sigma_{V}^{2}+\sigma^{2} \sigma_{\delta}^{2}
\end{aligned}
$$

Alćm disso,

$$
\left.E \underline{V_{i}^{2}} / \underline{Y_{i}}, \underline{X_{i}}, \sigma_{V}^{2}, \sigma^{2}, \underline{\mu_{i}}\right]=\operatorname{Var}\left[\underline{V_{i}} / \underline{Y_{i}}, \underline{X_{i}}, \sigma_{V}^{2}, \sigma^{2}, \underline{\mu_{i}},+E^{2}\left[\underline{V_{i}} / \underline{Y_{i}}, \underline{X_{i}}: \sigma_{V}^{2}, \sigma^{2}, \underline{\mu_{i}}\right]\right.
$$

onde

$$
E\left[\underline{V_{i}} / \underline{Y_{i}}: \underline{Y_{i}}, \sigma_{V}^{2}, \sigma^{2}, \underline{\mu_{2}} .\right.
$$

foi definida anteriormente c 


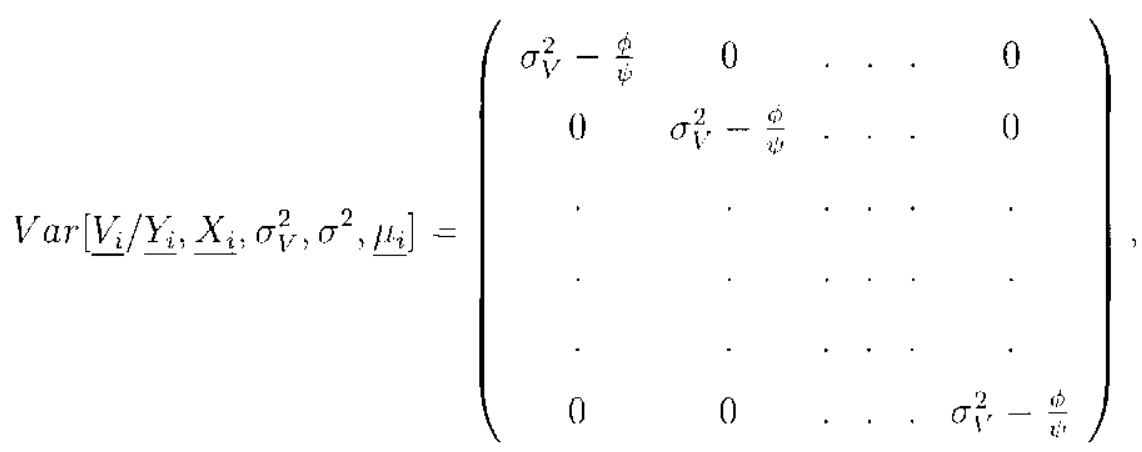

onde

$$
\phi=\beta^{2} \sigma_{V}^{4} \sigma_{\delta}^{2}+\sigma_{V}^{4} \sigma^{2}
$$

O algoritmo computacional para obtcrmos aproximaçoes para as estimativas de máxima verossimilhança dos parâmetros $\beta, \sigma_{V}^{2}, \sigma^{2} \odot \mu_{i}$ ć estabclecido da scguinte forma:

(i) Tomar os valores iniciais de $\beta^{(0)}, \sigma_{V}^{(0) 2}, \sigma^{(0) 2}, \mu_{i}^{(0)}$.

(ii) Na ctapa $\mathbf{E}$, calcular $\hat{V_{i j}}$ \& $\hat{V}_{i j}^{2}$ através das cquaçoces em (4.5) o (4.6).

(iii) Na ctapa $\mathbf{M}$, obter o valor de $\beta^{(1)}, \mu_{i}^{(1)}, \sigma_{V}^{2(1)}$ o $\sigma^{2(1)}$, usando as expluacoes em $(4.1),(4.2),(4.3)$ e (4.4)

(iii) Verificar a convergêneia

(iv) Incrementar cm 1 unidade o contador se não há convergência

\subsection{Matriz de Informação Esperada de Fisher}

$\mathrm{Na}$ seção antcrior, propomos $111 \mathrm{~m}$ algoritmo para obtcr aproximaçõcs para cstimativas dos EMVs para os parâmetros cnvolviclos no modelos de regressĩo com crros. $\Lambda$ gora, cstamos interessados em encontrar a distribuição assintútica dos cstimadores.

$\operatorname{Seja}, \underline{\zeta}_{(1 \times n+3)}=\left(\beta, \sigma_{V}^{2}, \sigma^{2}, \mu_{1}, \ldots, \mu_{n}\right)$ o vetor com os verladciros valores dos parâmetros, c $\hat{\zeta}$ o vetor de estimadorcs de Máxima Verossimithança. Como o modolo satisfaz as condições de regularidade apresentados cm Scn e Singer, 1993 [teorcma 5.2.2, página 209], concluímos que $(\underline{\zeta}-\underline{\widehat{\zeta}})$ converge cm distribuição para $N_{u+3}(\underline{0}, \Gamma(\underline{\zeta}))$, isto ć 


$$
\left(\begin{array}{c}
\hat{\beta}-\beta \\
\hat{\sigma_{V}^{2}}-\sigma_{V}^{2} \\
\hat{\sigma^{2}}-\sigma^{2} \\
\cdot \\
\cdot \\
\cdot \\
\hat{\mu}_{n}-\mu_{n}
\end{array}\right) \longrightarrow N_{n+3}(\underline{0}, \underline{\Gamma})
$$

onde $\Gamma(\zeta)$ é estimado pela inversa da matriz de informação de Fisher Esperada para a função de verossimilhança em (3.5).

Denotamos por $I_{(\underline{\zeta})}$ a matriz de informação de Fisher Esperada dos parâmetros a serem estimados, obtida a partir da esporança das segundas derivadas do logaritmo da função de verossimilhança (equação (3.5)) em relação ao vetor de parânetros $\zeta$. Devido a complexidade do logaritmo da verossintilhança expressa em (3.5), utilizamos teorema [seção 3.1 na página $44 \mathrm{~cm}$ Dolby, 1976, para calcular a matriz de informação de Fishor esperada. Cada clemento da matriz de Informação Esperadá de dimensão $((n+3) \times(n+3))$ ó dado por

$$
-E\left[\frac{\partial^{2} \log L}{\partial \psi \partial \omega}\right]-k *\left[\operatorname{tr}\left(P^{1} P^{2} P^{-1} P_{\omega}\right)+d_{\psi}^{\prime} P^{-1} d_{\omega}\right] .
$$

Aqui. temos que

$$
\begin{gathered}
P_{2 n k \times \underline{2} n k}=\left(\begin{array}{cc}
\left(\beta^{2} \sigma_{V}^{2}+\sigma^{2}\right) I & \left(\beta \sigma_{V}^{2}\right) I \\
\left(\beta \sigma_{V}^{2}\right) I & \left(\sigma_{V}^{2}+\sigma_{\delta}^{2}\right) I
\end{array}\right), \\
P_{2 n k \times 2 n k}^{-1}=\left(\begin{array}{cc}
\left(\sigma_{V}^{2}+\sigma_{\delta}^{2}\right) I & \left(-\beta \sigma_{V}^{2}\right) I \\
\left(-\beta \sigma_{V}^{2}\right) I & \left(\beta^{2} \sigma_{V}^{2}+\sigma^{2}\right) I
\end{array}\right) \times \frac{1}{\psi}, \\
d_{2 n k \times 1}=\left(\begin{array}{c}
\underline{Y_{i}}-\beta \underline{\mu} \\
\underline{X_{i}}-\underline{\mu}
\end{array}\right) .
\end{gathered}
$$


e I é uma matriz identidade.

$$
n k \times n k
$$

Denotamos por $P_{\omega}$ e $d_{\omega}$ as dorivadas clemento à elemento da matrizes $P$ o $d$ com relação a um parâmetro arbitrário $\omega$ pertenconto ao conjunto $\underline{\zeta}_{(1 \times n+3)}-\left(\beta, \sigma_{V}^{2}, \sigma^{2}, \mu_{1}, \ldots, \mu_{n}\right)$ A seguir, calculamos cada elemento da matriz do informação esperada. Primeiro, as variâlıciass e na sequencia as covarianncias

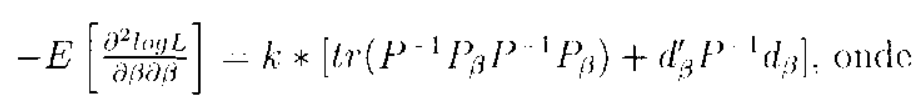

1. $P_{\beta}=\left(\begin{array}{cc}\left(2 \beta \sigma_{V}^{2}\right) I & \left(\sigma_{V}^{2}\right) I \\ \left(\sigma_{V}^{2}\right) I & (0) I\end{array}\right)$

2. $d_{\beta(1 \times 2 n k)}^{\prime}=\left(\underline{\mu^{\prime}} \underline{0}\right)$

3. $\operatorname{lr}\left(P^{-1} P_{\beta} P^{-1} P_{\beta}\right)-\frac{n k}{\psi^{2}}\left(\left(\sigma_{V}^{4}+\sigma_{\delta}^{2} \sigma_{V}^{2}\right)\left(\sigma^{2} \sigma_{V}^{2}-\beta^{2} \sigma_{V}^{4}\right)\left(\left(\beta \sigma^{4}+2 \beta \sigma_{V}^{2} \sigma_{\delta}^{2}\right)^{2}+\beta^{2} \sigma^{8}\right)\right)$.

4. $d_{\beta}^{\prime} P^{-1} d_{\beta}-\frac{k \cdot\left(\sigma_{V}^{2}+\sigma_{j}^{2}\right)\left(\sum_{i=1}^{n} \mu_{i}^{2}\right)}{\psi}$

$$
-E\left[\frac{\partial^{2} \log L}{\partial \sigma_{V}^{2} \partial \sigma_{V}^{2}}\right]=k *\left[\operatorname{tr}\left(P^{-1} P_{\sigma_{V}^{2}} P^{-1} P_{\sigma_{V}^{2}}\right)+d_{\sigma_{V}^{2}}^{\prime} P^{-1} d_{\sigma_{V}^{2}}\right], \text { onde }
$$

1. $P_{\sigma_{V}^{2}}=\left(\begin{array}{ll}\left(\beta^{2}\right) I & (\beta) I \\ (\beta) I & (0) I\end{array}\right)$

2. $d_{\sigma_{V}^{2}(1 \times 2 n k)}^{\prime}=0$

3. $\operatorname{tr}\left(P^{-1} P_{\sigma_{V}^{2}} P^{-1} P_{\sigma_{V}^{2}}\right)=\frac{n k}{\psi^{2}}\left(\beta^{4} \sigma_{\delta}^{4}+2 \xi^{2} \sigma^{2} \sigma_{\delta}^{2}+\sigma^{4}\right)$

4. $d_{\sigma_{v}^{2}}^{\prime} P^{-1} d_{\sigma_{V}^{2}}=0$

$$
-E\left[\frac{\partial^{2} \log l}{\partial \sigma^{2} \partial \sigma^{2}}\right]-k *\left[\operatorname{lr}\left(P^{-1} P_{\sigma^{2}} P^{-1} P_{\sigma^{2}}^{2}\right)+d_{\sigma^{2}}^{\prime} P^{-1} d_{\sigma^{2}}\right]: \text { ondo }
$$

1. $P_{\sigma^{2}}=\left(\begin{array}{ll}(1) I & (0) I \\ (0) I & (0) I\end{array}\right)$

2. $d_{\sigma^{2}(1 \times 2 n k)}^{\prime}=0$

3. $\operatorname{tr}\left(P^{-1} P_{\sigma^{2}} P^{-1} P_{\sigma^{2}}\right)=\frac{n k}{\psi^{2} \cdot}\left(\sigma_{V}^{2}+\sigma_{b}^{2}\right)^{2}$ 
4. $d_{\sigma^{2}}^{\prime} P^{-1} d_{\sigma^{2}}=0$

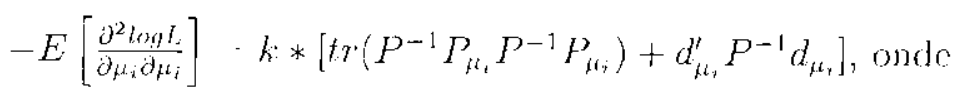

1. $P_{\mu_{t}}=\left(\begin{array}{ll}(0) I & (0) I \\ (0) I & (0) I\end{array}\right)$

2. $d_{\mu,(1 \times 2 n k)}^{\prime}=((-\beta \ldots-\beta)(0 \ldots 0)(-1 \ldots-1)(0 \ldots 0))$

3. $\operatorname{tr}\left(P^{-1} P_{h_{i}} P^{-1} P_{\mu_{i}}\right)=0$

4. $d_{\mu_{t}}^{\prime \prime} P^{-1} d_{\mu_{1}}=\frac{k}{\psi}\left(\beta^{2} \sigma_{\delta}^{2}+\sigma^{2}\right)$

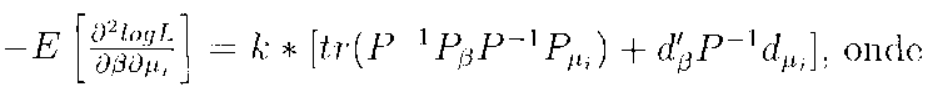

1. $\operatorname{tr}\left(P^{-1} P_{\beta} P^{-1} P_{\mu_{2}}\right)=0$.

2. $d_{\beta}^{\prime} P^{-1} d_{\mu_{i}}=\frac{k ; \beta \sigma_{i}^{2} \mu_{i}}{\psi}$

$-E\left[\frac{\partial^{2} \log L}{\partial \beta \partial \sigma_{v}^{2}}\right]=k *\left[\operatorname{tr}\left(P^{-1} P_{\beta} P^{-1} P_{\sigma_{v}^{2}}\right)+d_{\beta}^{\prime} P^{-1} d_{\sigma_{v}^{2}}\right]$, ondo

1. $\operatorname{tr}\left(P^{-1} P_{\beta} P^{-1} P_{\sigma_{V}^{2}}\right)=\frac{2 n k}{v^{2}}\left(\beta^{3} \sigma_{V}^{2} \sigma_{\delta}^{2}+\beta \sigma^{2} \sigma_{V}^{2} \sigma_{\delta}^{2}\right)$.

2. $d_{\beta 3}^{\prime} P^{1} d_{\sigma_{\psi^{\prime}}^{2}}=0$

$-E\left[\frac{\partial^{2} l_{o g} L}{\partial \beta \partial \sigma^{2}}\right]=k *\left[t r\left(P^{-1} P_{\beta} P^{-1} P_{\sigma^{2}}\right)+d_{\beta}^{\prime} P^{-1} d_{\sigma^{2}}\right]$, onde

1. $\operatorname{tr}\left(P^{-1} P_{\beta \beta} P^{-1} P_{\sigma^{2}}\right)=\frac{2 n k}{\psi^{2}}\left(\beta \sigma_{V}^{4} \sigma_{\delta}^{2}+\beta \sigma_{V}^{2} \sigma_{\delta}^{1}\right)$.

2. $d_{\beta}^{\prime} P^{\cdot 1} d_{\sigma^{2}}=0$

$-E\left[\frac{\partial^{2} \operatorname{tog} L}{\partial \mu_{1}, \partial_{\mu_{i}}}\right]=k *\left[\operatorname{ltr}\left(P^{1}{ }^{1} P_{\mu_{i}} P^{-1} P_{\mu_{1}}\right)+d_{\mu,}^{\prime} P^{-1} d_{\mu_{i},}\right]$, onde

1. $\operatorname{tr}\left(P^{-1} P_{\mu_{i}} P^{-1} P_{\mu_{i^{\prime}}}\right)=0$.

2. $d_{\mu i}^{\prime} P^{-1} d_{\mu_{i} i^{\prime}}=0$

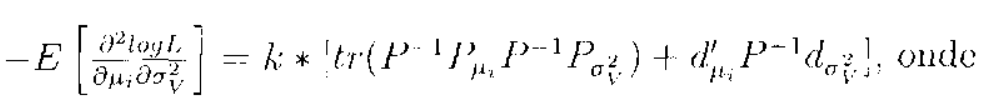

1. $\operatorname{tr}\left(P^{-1} P_{\mu_{i}} P^{-1} P_{\sigma_{v}^{2}}\right)=0$. 
2. $d_{\mu i}^{\prime} P^{-1} d_{\sigma_{!^{\prime}}^{\prime}}=0$

$$
-E\left[\frac{\partial^{2} \log L_{L}}{\partial \mu_{i} \partial \sigma^{2}}\right]=k *\left[\operatorname{tr}\left(P^{-1} P_{\mu_{i}} P^{-1} P_{\sigma^{2}}\right)+d_{\mu_{i}}^{\prime} P^{-1} d_{\sigma^{2}}\right], \text { onde }
$$

1. $\operatorname{tr}\left(P^{\cdot 1} P_{\mu_{i}} P^{-1} P_{\sigma^{2}}\right)=0$.

2. $d_{\mu_{i}}^{\prime \prime} P^{-1} d_{\sigma^{2}}-0$

$$
-E\left[\frac{\partial^{2} l o g L}{\partial \sigma_{V}^{2} \cdot \partial \sigma^{2}}\right]=k *\left[\operatorname{tr}\left(P^{-1} P_{\sigma_{V}^{2}} P^{-1} P_{\sigma^{2}}\right)+d_{\sigma_{V}^{2}}^{\prime} P^{-1} d_{\sigma^{2}}\right] \text {, ondo }
$$

1. $\operatorname{tr}\left(P^{-1} P_{\sigma_{v}^{2}} P^{-1} P_{\sigma^{2}}\right)=\frac{n k}{v^{2}}\left(\beta \sigma_{\hat{\delta}}^{2}\right)^{2}$.

2. $d_{\sigma_{V}^{2}}^{\prime} P^{-1} d_{\sigma^{2}}=0$

Assim, compomos a matriz de informação esperada de dimensão $((n+3) \times(n+3))$

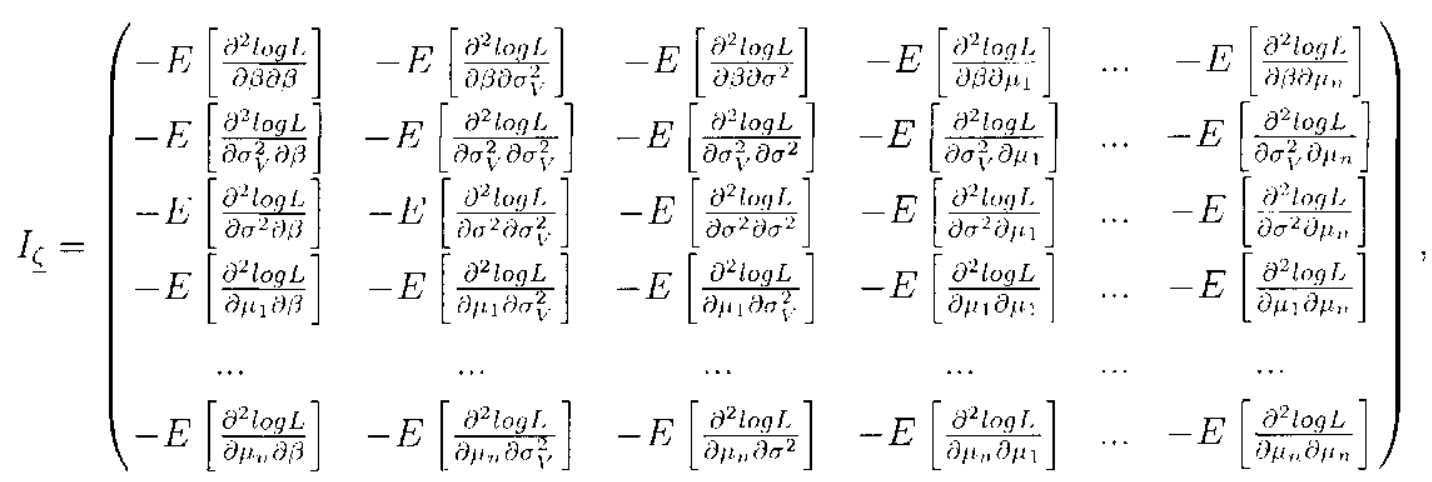

onde parte dos elementos foram calculados devido à propriedade de simetria da matriz esperada. Na prática, a partir das estimativas de máxima verossimilhança dos parâmetros c os dados calculamos a matriz esperada no ponto das aproximações das estimativas de máxima verossinuilhança e posteriormente calculamos sua inversa de forma numérica. Desta forma, calculamos intervalos de confiança para os parâmetros cnvolvidos.

No próximo capítulo apresentamos análise estatística do modelo de regressão com crros nas variáveis em (3.1) e (3.2) utilizando métodos Bayesianos. 


\section{Capítulo 5}

\section{Estimador de Bayes}

\subsection{Métodos Bayesianos}

Wétodos Baycsianos são métodos infercuciais alternativos aos méiodos tradicionais que. podem melhorar a precisâo dos resultados. A principal diferenģa entre os mélodos Clássicos e Bayesianos ó que os métodos Bayesianos permiten incorporar ao modelo informaçóes prévias a respeito dos parâmetros de interesse para a análise. Ao contrário da inferência Clássica, a inferencia bayesiana considera os parâmetros como variaveis aleatórias com dis tribuições de probabilidade chamalas de distribuiçoos a priori, disponíveis para melhorar a precisão da inferencia. $\Lambda$ escolla de uma distribuição a priori adequada é fundamental para garantir a qualidade da inforencia Bayesiana. Após estipular as distribuições a priori para os parânetros do nodelo, combinamos estas distribuiçoes com a função do verossimilhança c através da fómula de Baycs cncontramos a distribuição a posterior conjunta para os parânetros. Na análise Baycsiana toda a inferência de interesse será bascarla nesta distribuição.

O algoritno Gibbs Sampling ó um mótodo de simulação via cadcias do Markov, quo obtém anostras de una distribuiçäo de interesse, bascada nas disl ribuiçós condicionais a posteriori dos parânetros. Este algoritmo é utilizadlo quando as distribueções condicionais apresentaun a forma de distribuição conhecida.

Un tópico de grande importanncia ó o diagnóstico de convergôncia das cadcias 
de Markov. Fxistem vários mótodos para verificação da convergência e um dos mais utilizados é o método de Gelman e Rubin (ver Gelman o Rubin, 1992). A idéia deste método é cue iniciando com diferentes pontos iniciais, as trajetórias de várias cadeias devem ser sinnilares se convergirem para uma distribuição estacionária. Gelman o Rubin (1992) formalizam essas idéias através do uso das técnicas de análise de variância (ver apêndice B). Neste trabalho, utilizamos este método para a verificação da convergência no modelo de regressão com crros.

Como no algoritmo EM, aqui tambóm introduzimos no modolo variáveis não observáveis $V_{i j},(i=1, \ldots, n \circ j=1, \ldots, h)$ visto a complexidade da verossimilhança cm (3.3). Estas variáveis simplificam o algoritmo de simulação dos métodos MCNC [ver Tanner and Wong (1987)], favorecendo a utilização do algoritmo de Gibbs Sampling. Na próxima seção apresentamos análise bayesiana do modolo de regressão com erros nas variáveis já com a inclusão das variáveis latentes.

\subsection{Análise Bayesiana e Algoritmo de Simulação}

Descnvolverros uma análise Baycsiana para o modelo de regressão com erros nas variáveis assumindo as scguintes distribuições a priori para os parâmotros:

1. $\beta \sim N\left(a_{0}, b_{0}^{2}\right)$ para $a_{0}$ c $b_{01}^{2}$ conhecidos.

2. $\mu_{i} \sim N\left(a_{1 i}, b_{1 i}^{2}\right)$ para $a_{1 i} \mathrm{e} b_{1 i}^{2}$ conhecidos, para $i=1, \ldots, n$.

3. $\sigma_{V}^{2} \sim I G\left(a_{2}, b_{2}\right)$ para $a_{2}$ e $b_{2}$ conhocidos.

4. $\sigma^{2} \sim I G\left(a_{3}, b_{3}\right)$ para $a_{3}$ c $b_{3}$ conhecidos.

Onde os todos hiperparânetros são obtidos a partir das informaçoos prévias obtidas pelo experimento preliminar. Conforme modelo proposto, temos que

$V_{i j} \sim N\left(\mu_{i}, \sigma_{V}^{2}\right)$ para $\mu_{i}$ c $\sigma_{V}^{2}$ desconhecidos. 
Assumindo que as distribuições a priori para os parânetros $\sigma_{V}^{2}, \sigma^{2}, \mu_{i}, \beta$ e $V_{i j}$ são independentes, a função densidade a priori conjunta para esses parânetros é dada por,

$$
\begin{array}{r}
g\left(\sigma_{V}^{2}, \sigma^{2}, \mu_{i}, \beta, V_{i j}\right) \propto \exp \left(-\frac{1}{2 b_{0}^{2}}\left(\beta-a_{0}\right)^{2}\right) \prod_{i=1}^{n} \exp \left(-\frac{1}{2 b_{1 i}^{2}}\left(\mu_{i}-a_{1 i}\right)^{2}\right) \\
\prod_{i=1}^{n} \prod_{j=1}^{k} \operatorname{cxp}\left(-\frac{1}{2 \sigma_{V}^{2}}\left(V_{i j}-\mu_{i}\right)^{2}\right)\left(\sigma^{2}\right)^{-\left(a_{3}+1\right)} \exp \left(-\frac{b_{3}}{\sigma^{2}}\right)\left(\sigma_{V}^{2}\right)^{-\left(a_{2}+1\right)} \exp \left(-\frac{b_{2}}{\sigma_{V}^{2}}\right)
\end{array}
$$

Combinando a expressão (5.2) com a lunção de verossimilhança com as variávei latentes dada $\mathrm{cm}(3.8)$, cncontramos a densidade a postcriori conjunta para $\sigma_{V}^{2}, \sigma^{2}, \mu_{i}, \beta$ c. $V_{i j}$ dada por

$$
\begin{gathered}
g\left(\sigma_{V}^{2}, \mu_{i}, \beta / V_{i j}, X_{i j}, Y_{i j}\right) \propto \exp \left(-\frac{1}{2 b_{0}^{2}}\left(\beta-a_{0}\right)^{2}\right) \prod_{i=1}^{n} \operatorname{cxp}\left(-\frac{1}{2 b_{1 i}^{2}} \cdot\left(\mu_{i}-a_{1 i}\right)^{2}\right) \\
\prod_{i=1}^{n} \prod_{j=1}^{k} \exp \left(-\frac{1}{2 \sigma_{V}^{2}}\left(V_{i j}-\mu_{i}\right)^{2}\right)\left(\sigma_{V}^{2}\right)^{-\left(a_{2}+1\right)} \exp \left(-\frac{b_{2}}{\sigma_{V}^{2}}\right) \\
\left(\sigma^{2}\right)^{-\left(a_{i j}+1\right)} \exp \left(-\frac{b_{3}}{\sigma^{2}}\right)\left(\sigma^{2}\right)^{-n k / 2}\left(\sigma_{V}^{2}\right)^{-n k / 2} \exp \left(-\frac{1}{2} h\left(\beta, \mu_{1}, \ldots, \mu_{n}, \sigma_{V}^{2}, V_{i j}, Y_{i j}, X_{i j}\right)\right)
\end{gathered}
$$

Portanto, as distribuiçōes condicionais neccssárias para o uso dos mótodos MCMC são dadas por,

$$
\begin{aligned}
& (i) g\left(\beta / Y_{i j}, X_{i j}, \mu_{i}, \sigma_{V}^{2}, \sigma^{2}, V_{i j}\right) \times \operatorname{cxp}\left\{\frac{-1}{2\left(\frac{b_{0}^{2} \sigma^{2}}{\sigma^{2}+b_{0}^{2} \sum_{i-1}^{n} \sum_{j=1}^{k} V_{i j}^{2}}\right)}\left(\beta-\frac{a_{0} \sigma^{2}+b_{0}^{2} \sum_{i=1}^{n} \sum_{j=1}^{k} Y_{i j} V_{i j}}{\sigma^{2}+b_{0}^{2} \sum_{i=1}^{n} \sum_{j=1}^{k} V_{i j}^{2}}\right)^{2}\right\} \\
& \text { (ii) } g\left(\mu_{i} / Y_{i j}, X_{i j}, \beta, \sigma_{V}^{2}, \sigma^{2}, V_{i j}\right) \propto \exp \left\{\frac{-1}{2\left(\frac{b_{1 i}^{2} \sigma_{V}^{2}}{\sigma_{V}^{2}+2 k b_{i j}^{2}}\right)}\left(\mu_{i}-\frac{a_{1 i} \sigma_{V}^{2}+2 b_{1 i}^{2} \sum_{i=1}^{n} \sum_{j=1}^{k} V_{i j}}{\sigma_{V}^{2}+2 k b_{1 i}^{2}}\right)^{2}\right\}
\end{aligned}
$$




$$
\begin{aligned}
& \text { (iii) } g\left(V_{i j} / Y_{i j}, X_{i j}, \mu_{i}, \sigma_{V}^{2}, \sigma^{2}, \beta\right) \propto \\
& \exp \left\{\frac{-1}{2\left(\frac{\sigma^{2} \sigma_{\delta}^{2} \sigma_{V}^{2}}{2 \sigma^{2} \sigma_{\delta}^{2}+\sigma_{V}^{2} \cdot \sigma^{2}+\sigma_{V}^{2} \sigma_{\delta}^{2}}\right)}\left(V_{i j}-\frac{\beta Y_{i j} \sigma_{V}^{2} \sigma_{\delta}^{2}+X_{i j} \sigma_{V}^{2} \sigma^{2}+2 \mu_{i} \sigma^{2} \sigma_{\delta}^{2}}{2 \sigma^{2} \sigma_{\delta}^{2}+\sigma_{V}^{2} \sigma^{2}+\sigma_{V}^{2} \sigma_{\delta}^{2}}\right)^{2}\right\} \\
& \text { (iv) } g\left(\sigma_{V}^{2} / Y_{i j}, X_{i j}, \mu_{i}, V_{i j}, \sigma^{2}, \beta\right) \propto \\
& \left(\sigma_{V}^{2}\right)^{\left(a_{2}+\frac{\mu k}{2}+1\right)} \operatorname{cxp}\left\{\frac{-1}{\sigma_{V}^{2}}\left(b_{2}+\sum_{i=1}^{n} \sum_{j=1}^{k} V_{i j}^{2}-2 \sum_{i=1}^{n} \sum_{j=1}^{k} \mu_{i} V_{i j}+k \sum_{i=1}^{n} \mu_{i}^{2}\right)\right\} \\
& (v) g\left(\sigma^{2} / Y_{i j}, X_{i j}, \mu_{i}: V_{i j}, \sigma_{V}^{2}, \beta\right) \propto \\
& \left(\sigma^{2}\right)^{-\left(a_{3}+\frac{\eta k k}{2}+1\right)} \operatorname{cxp}\left\{\frac{-1}{\sigma^{2}}\left(b_{3}+\frac{\left(\beta^{2}+1\right) \sum_{i=1}^{n} \sum_{j=1}^{k} V_{i j}^{2}}{2}-\beta \sum_{i=1}^{n} \sum_{j=1}^{k} Y_{i j} V_{i j}\right)\right\}
\end{aligned}
$$

Como as distribuições condicionais para os parânıctros $\beta, \sigma_{V^{\prime}}^{2}, \sigma^{2}, \mu_{i} \circ V_{i j}$ para $i=1, \ldots, n$ apresentam formas de distribuiçoes Normais e Inversa Gáma, utilizamos o algoritmo Gibbs Sampling para realizar a simulaçào dos parámetros e fazcr as inferchncias descjadas. $O$ algoritmo computacional para gerar amostras dos parâmotros $\beta, \sigma_{V}^{2}, \sigma^{2}$ c $\mu_{i}$, bascado na introdução do variáveis latentes, ć dado pelas seguintes ctapas:

(i) Dados os valores iniciais $\beta^{(0)}, \sigma_{V}^{(0) 2}, \sigma^{(0) 2} \odot \mu_{i}^{(0)}$. gerar unia amostra $\left(V_{11}, V_{12}, \ldots, V_{n k}\right)$ da distribuição Normal para $V_{i j}$ definido no item (iii) das Eq11ações em (5.4)

(ii) Gerar $\mu_{i}^{(1)}$ a partir da distribuição Normal no itcm (ii) das Equações cm (5.4)

(iii) Gerar $\beta^{(1)}$ a partir da distribuição Normal no itcm (i) das Equações em (5.4)

(iv) Gerar $\sigma_{V}^{(0) 2}$ a partir da distribuição Inversa Gama no item (iv)das Equaçōos cm (5.4)

(v) Gerar $\sigma^{(0) 2}$ a partir da distribujção Inversa Ganıa no itom (v)das Equações em (5.4) 
Repetir (i)-(v) até gerar uma amostra de tamanho S. 


\title{
Capítulo 6
}

\section{Aplicação: Correção no Diâmetro do Furo do Pistão devido à Variação de Temperatura}

\begin{abstract}
Neste capítulo, consideramos os dados obtidos a partir do segundo experimento do Capítulo 2 realizado na Fábrica de Pistões - LS Pistóes (Nova Odessia/SP). Primciro, utilizamos as informaçoes adicionais do experinnento prelininar do Capítulo 2 para anxiliar os procedimentos clássico e bayesiano de estimação na escollha dos valores incciais e hiperparâmetros. Na sequencia, os resultados são aprescutados para ambas estratígias de estimação. Por último, a análise de robustez dos mótodos de estimação.
\end{abstract}

\subsection{Informações Iniciais}

Nesta secão, tratamos para os Algoritmos Eil de Gibbs Sampling a atribuição de valores iniciais para os parámetros c a cespecificação dos liperparâmetros referentes às densidades informativas a priori. Para isto, utilizamos os dados obtidos atravós do experimento preliminar localizados no Apendice. Na análise proliminar realizada para obtermos os hiperparânotros ajustamos uma regressão linear para cada peça o cada padrão referentes aos clados do P’éé-experimento descutido no Capítulo 2. 
Outra informação fornecida nesta seção ó sobre a variabilidade $\left(\sigma_{\delta}^{2}\right)$ do orro de medição do temômetro Fluke. Esta pode ser obtida pelo certificado de calibração emitido pelo Laboratório de Termonetria Latermo (ver apêndice). No entanto, o certificado ofercce o desvio padrão em cada ponto de temperatura multiplicado pelo fator de abrangencia 2. Desta forma, precisamos calcular,

$$
\sigma_{\delta}^{2}=\left(\frac{1,5}{2}\right)^{2}=0,5625
$$

Este valor foi adotado tanto para análise dos dados para as peças como para os padrónes.

\subsubsection{Hiperparâmetros para análise Bayesiana}

Quando utilizamos do Pré-experimento em nossa análise, no enfoque Bayesiano, estamos considerando como informação a priori sobre os parâmetros cnvolvidos no modelo de regressão com crros. Em outros problcmas práticos poderíamos questionar o especialista da área sobre o valor da módia c da variância de um específico parânectro.

Neste contexto, primeiramente, o procedimento prático usual para obtenção dos hiperparâmetros em (5.1) é explorar os dados do Pré-experimento (ver apêndice tabelas (9.1) e (9.2)) sobre o valor da média c da variância.

Utilizamos a Regressão Lincar Simples com intercepto para os dados do Préexperimento para os padrócs e pistões para obtenção dos estimadores preliminares para os parâmetros $\beta$ e $\sigma^{2}$, detalhes ver (Drapper e Smith, 1998). A seguir apresentamos os resultados referentes aos padrões e depois das peças. 


\begin{tabular}{|c|c|c|}
\hline Padrão & $\widehat{\beta}$ & $\widehat{\sigma^{2}}$ \\
\hline 1 & 0,13013 & 0,1942 \\
\hline 2 & 0,16478 & 0,135 \\
\hline Mécia & 0,1474 & 0,1646 \\
\hline Variância & 0,06 & 0,01752 \\
\hline
\end{tabular}

Tabela 6.1: Informações preliminares dos dos parâmetros $\beta \mathrm{e} \sigma^{2}$ para os dados dos padrões.

\begin{tabular}{|c|c|c|}
\hline Pistão & $\widehat{\beta}$ & $\widehat{\sigma^{2}}$ \\
\hline 1 & 0,31435 & 0,093 \\
\hline 2 & 0,27386 & 0,988 \\
\hline 3 & 0,20368 & 2,792 \\
\hline 4 & 0,20456 & 2,288 \\
\hline 5 & 0,1644 & 2,781 \\
\hline 6 & 0,27168 & 3,481 \\
\hline 7 & 0,23120 & 0,678 \\
\hline 8 & 0,21764 & 2,252 \\
\hline 9 & 0,31135 & 1,620 \\
\hline 10 & 0,24167 & 2,955 \\
\hline Viédia & 0,2434 & 1,9931 \\
\hline Variância & 0,024 & 1,2273 \\
\hline
\end{tabular}

Tabcla 6.2: Informações preliminares dos dos parâmetros 3 e $\sigma^{2}$ para os dados dos pistöcs

Na sequencia, aprescntamos os resultados preliminares para as peças c os padrões referentes ao parâmetro $\sigma_{V}^{2}$. Para este parâmctro, calculamos a variância amostral da temperatura observada em cada patamar de icmperatura, utilizando os mesmos dados localizados nas tabclas $(9.1)$ ○ (9.2)[Apcndicc]: 


\begin{tabular}{|c|c|c|}
\hline Patamar & $\widehat{\sigma_{V}^{2}}$ (Padrão) & $\widehat{\sigma_{V}^{2}}$ (Pistão) \\
\hline 1 & 0,0 & 0,05211 \\
\hline 2 & 0,005 & 0,064 \\
\hline 3 & 0,405 & 0,4232 \\
\hline 4 & 0,980 & 0,029 \\
\hline 5 & 0,405 & 0,43733 \\
\hline 6 & 0,845 & 4,29733 \\
\hline Módia & 0,44 & 0,8831 \\
\hline Variância & 0,1681 & 2,8323 \\
\hline
\end{tabular}

Tabcla 6.3: Informaçõos preliminares dos parâmetro $\sigma_{V}^{2}$ para os dados dos padrões c pistões.

Na obtenção de informações preliminares para os parâmetros $\mu_{i}$ adotamos $\mathrm{cm}$ anotar o valor da temperatura ambiente no início das medições na realização do scgundo cxperimento. As informações a priori sobre a temperatura foram obtidos através de um termômetro de mercúrio instalado na área. Este procedimento possibilitou a utilização destes valores na especificação das médias a priori $a_{1 i}$. Na especificação das variâncias $b_{1 i}^{2}$ utilizamos o desvio padrão do termônetro de mercúrio $(0,1)$ muliplicado por 10 . Esto procedimento foi adotado para os dados das peças c dos padrōes.

Portanto, para obtermos os hipcrparâmetros, iniciamos com as densidades a priori dos parâmetros $\sigma_{V}^{2}$ e $\sigma^{2}$ utilizando as informações proliminares das tabelas (6.1), (6.2) c ((j.3). Ilustramos os cálculos para os dados do padrão, de forma similar poderia ser estendido para os dados dos pistões. Fntão, primeiro o parâmetro $\sigma_{V}^{2}$, resolvemos o sistema de duas equações envolvendo os hiperparâmetros $a_{2}$ c $b_{2}$,

$$
\left\{\begin{array}{c}
0,44=\frac{b_{2}}{a_{2}-1} \\
0,1681-\frac{b_{2}^{2}}{\left(a_{2} \cdot 1\right)^{2}\left(a_{2}-2\right)}
\end{array}\right.
$$

c obtemos $a_{2}-3,15$ e $b_{2}-0,94$. Para obtenção dos hiperparâmotros $a_{3}$ e $b_{3}$ da distribuição a priori do parânetro $\sigma^{2}$, realizamos o mesmo procedinnento anterior, 


$$
\left\{\begin{array}{c}
0,1646=\frac{b_{3}}{a_{3}-1} \\
0,01752=\frac{b_{3}^{2}}{\left(a_{3}-1\right)^{2}\left(a_{3}-2\right)}
\end{array}\right.
$$

e obtemos $a_{3}=3,54 \mathrm{e} b_{3}=0,42$.

Para os parâmetros $\beta$, obtemos $0,1474=a_{0}$ o $0,06=b_{0}^{2}$. Finalmente, relativo aos parametros $\mu_{4}$ olstemos para $i=1, \ldots, n$,

$$
a_{11}=1 \mathrm{e} b_{12}^{2}=1, a_{12}=14 \mathrm{c} b_{12}^{2}=1, a_{13}=5 \circ b_{13}^{2}=1, a_{14}=9 \mathrm{e} b_{14}^{2}=1, a_{15}=9 \mathrm{c}
$$

$b_{1 ;}^{2}=1, a_{16}=-2 \circ b_{16}^{2}=1, a_{17}=7 \circ b_{17}^{2}=1, a_{18}-8 \subset b_{18}^{2}=1$.

De mancira análoga, repetimos os cálculos anteriores para os didos dos pistōes

$a_{0} \cdots 0,256044, b_{01}^{2}=0,01797, a_{11} \therefore 1 \mathrm{c} b_{12}^{2}-1, a_{12}=14 \mathrm{c} b_{12}^{2}=1, a_{13}=5 \mathrm{c}$ $b_{13}^{2}=1, a_{14}=9 \mathrm{e} b_{14}^{2}=1, a_{15}=9 \mathrm{c} b_{15}^{2}=1, a_{16}=-2 \circ b_{16}^{2}=1, a_{17}=7 \mathrm{c} b_{17}^{2}-1, a_{18}=8$ c $b_{18}^{2}-1, a_{2}=2,27, b_{2}=1,126, a_{3}=5,23, b_{3}=8,44$

Muito cmbora a prática de considerarnos informação a priori scja muito difundida cm várias áreas, problemas adicionais podem aparecer, uma vez que essa informação podo mudar substancialmentc a resposta a postcriori. Idcalmente, almejamos obter uma priori de tal sorte que, mesmo uma informação a priori totalmente conflitante com os dados não provoque mudança substancial na resposta a postcriori, o que caracteriza o problema de robustes Bayesiana. Detalhes sobre robustez Baycsianla pode ser visto em (Pericchi o Smith, 1992)

\subsubsection{Valores Iniciais}

A atribuição de valores iniciais aos parâmetros para cada cadcia simulada ć de fundamental inportancia para uma convergência adequada nos algoritmos. Para ambos os algoritmos adotamos os nuesmos valores iniciajs. A partir disto, variamos estes valores iniciais permitindo gerar várias cadeias referentes ao algoritmo de Gibbs ou várias exccuções do algoritmo E.M. A seguir apresentamos para cada parâmetro os três valores iniciais adotados: 
$\beta_{r^{\prime} u d}-[0,1 ; 0,14 ; 5], \sigma_{V}^{2}-[0,1 ; 0,44 ; 5], \sigma^{2}=[0,01 ; 0,1646 ; 5], \mu_{1}=[-5 ; 1: 5]$, $\mu_{2}-[7 ; 14 ; 15], \mu_{3}=[1 ; 5 ; 6], \mu_{4}=[4 ; 9 ; 10], \mu_{5}=[4 ; 9 ; 10], \mu_{6}=[-6 ;-2 ; 0] \mu_{7}-0 ; 7 ; 9 ;$ $\mu_{8}=[3 ; 8: 10]$ e para os pistôcs

$\left.\beta_{\text {Pist }}=0,01 ; 0,24 ; 5\right], \sigma_{V}^{2}=[0,01 ; 0 ; 88 ; 5], \mu_{1}=[-5 ; 1 ; 5], \mu_{2}=[7 ; 14 ; 15], \mu_{3}=$ $[1 ; 5 ; 6], \mu_{4}=[4 ; 9 ; 10], \mu_{5}-[4 ; 9 ; 10], \mu_{6}-\left[-6 ;-2 ; 0 ; \mu_{7}=[0 ; 7 ; 9]: \mu_{8}=[3 ; 8 ; 10\right.$, $\sigma^{2}=[0,01 ; 1,9931 ; 5]$.

A partir destas informações iniciais e da especificação dos hiperparàmetros das densidades à priori, na próxima seção apresentamos os restultados do modelo de regressão com erros a partir da utilização dos algoritmos EM e Gibbs Sampling.

\subsection{Resultados}

Nesta seção apresentamos os resultados das análises Clássica e Bayesiana considerando os dados para padrões o pistões das Tabelas (2.5) e (2.6), respectivamente.

Na análise clássica do modelo de regressão com crros apresentamos as estimativas de máxima-verossimilhança obtida a partir do algoritmo EM c as respcctivas variâncias assintóticas. Possibilitando a contrução de intervalos de confiança. Na Baycsiana, apresentamos os sumários a posteriori a partir do algoritmo de Gibbs Sampling.

\subsubsection{Análise Clássica}

Na cstimação dos paràmetros envolvidos no modelo de regressão com erros através do algoritmo EM descuvolvido no capítulo 4, utilizamos os dados para peça e padrão transformados obtidos a partir do scgundo experimento c os valores iniciais estabolecidos na seção anterior. Aqui assimimos sempre um nívol de significância $\alpha=0,05$.

Nas Tabolas a seguir, apresentamos as aproximações das estimativas de máximaverossimilhança, desvio-padrão assintótico dado na seção 4.2 e o intervalo de confiança de $9 \tilde{3}$ 


\begin{tabular}{|c|c|c|c|}
\hline Parâmctro & EMV & DP & Int.Conf(95) \\
\hline$\beta_{\text {Pnd }}$ & 0,125 & 0,00746 & $(0,1103 ; 0,139)$ \\
\hline$\mu_{1}$ & 0 & 0,3448 & $(-0,675 ; 0,675)$ \\
\hline$\mu_{2}$ & 12,63 & 0,3535 & $(11,937 ; 13,323)$ \\
\hline$\mu_{3}$ & 3,55 & 0,3455 & $(2,872 ; 4,227)$ \\
\hline$\mu_{4}$ & 7,7 & 0,3481 & $(7,017 ; 8,382)$ \\
\hline$\mu_{5}$ & 7,2 & 0,3476 & $(6,518 ; 7,8814)$ \\
\hline$\mu_{6}$ & $-3,64$ & 0,345 & $(-4,317 ;-2,962)$ \\
\hline$\mu_{7}$ & 4,83 & 0,3461 & $(4,151 ; 5,508)$ \\
\hline$\mu_{8}$ & 5,94 & 0,3467 & $(5,26 ; 6,62)$ \\
\hline$\sigma_{V}^{2}$ & 0,005 & 0,0845 & $(0 ; 0,17)$ \\
\hline$\sigma^{2}$ & 0,071 & 0,0126 & $(0,0462 ; 0,0957)$ \\
\hline
\end{tabular}

Tabela 6.4: Resultados da análise clássica do modelo de regressão com erros para os dados para os padröes

\begin{tabular}{|c|c|c|c|}
\hline Parânetro & EMV & DP & Int.Conf(95) \\
\hline$\beta_{P_{\text {tst }}}$ & 0,269 & 0,0032 & $(0,2626 ; 0,2753)$ \\
\hline$\mu_{1}$ & 0 & 0,1069 & $(-0,209 ; 0,209)$ \\
\hline$\mu_{2}$ & 11,75 & 0,1078 & $(11,528 ; 11,951)$ \\
\hline$\mu_{3}$ & 4,46 & 0,107 & $(4,25 ; 4,66)$ \\
\hline$\mu_{4}$ & 6,8 & 0,10723 & $(6,58 ; 7,01)$ \\
\hline$\mu_{5}$ & 7,25 & 0,10727 & $(7,05 ; 7,47)$ \\
\hline$\mu_{6}$ & $-2,6$ & 0,10698 & $(-2,809 ;-2,3903)$ \\
\hline$\mu_{7}$ & 5,88 & 0,1071 & $(5,65 ; 6,08)$ \\
\hline$\mu_{8}$ & 8,62 & 0,1074 & $(8,41 ; 8,83)$ \\
\hline$\sigma_{V}^{2}$ & 0,67 & 0,0405 & $(0,59 ; 0,749)$ \\
\hline$\sigma^{2}$ & 0,35 & 0,0131 & $(0,324 ; 0,3757)$ \\
\hline
\end{tabular}

Tabela 6.5: Resultados da análise clássica do modelo de regressão com erros para os dados para os pistõcs. 
De posse das aproximações para as estimativas de máxima verossimilhança relativo ans parâmetros $\beta_{P a d}$ e $\beta_{P i s t}$, visualizamos o comportamento das equaçôcs estimadas junto ans gráficos de dispersão $(2.10)$ e (2.11) para os dados dlos padrões e dos pistões, respectivamente. 


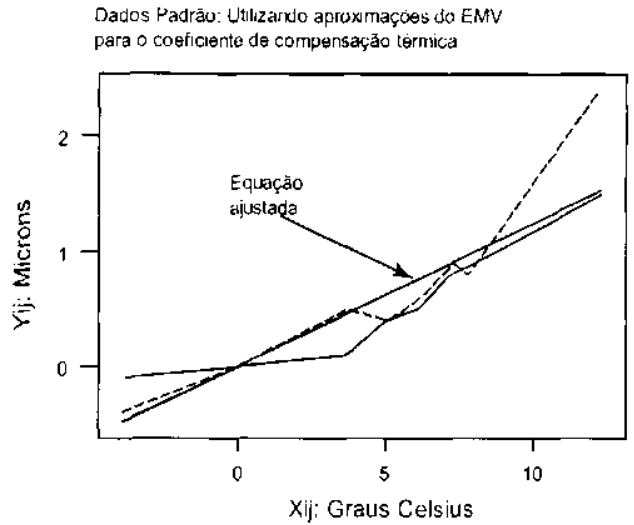

Figura 6.1: Fquação cstimadia - dados dos padrões

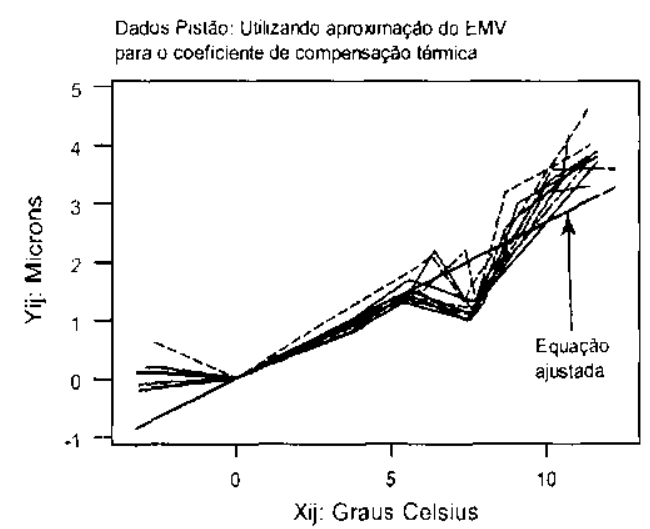

Figura 6.2: Equação estimada - daclos dos pistõos 
Note que, as equacoócs estimadas utilizando as aproximaçöes das estimativas de máxima verossimilhança ajustaram-se bem aos dados observados. Na próxima seçào, realizamos abordagem Bayesiana do modelo de regressão con crros proposto.

\subsubsection{Análise Bayesiana}

As Tabelas (6.6) e (6.7) nos mostram os resumos a postcriori dos parâmetros $\beta, \sigma_{V}^{2}$, $\mu_{1}, \mu_{2}, \mu_{3}, \mu_{4}, \mu_{5}, \mu_{6} \mathrm{c} \mu_{7}$ e $\mu_{8}$. Aprescntamos para cada parâmetro, a média, o desvio padrão, o intervalo de credibilidade (95) e o fator de redução e escala (GR) clo critério de convergência de Gelman e Rubin. Primeiro apresentamos os sumários associado aos dados dos padróes e depois os sumários para os pistónes

\begin{tabular}{|c|c|c|c|c|}
\hline Parânctro & Mćdia & DP & Int.Crcd(95) & GR \\
\hline$\beta_{P a d}$ & 0,20 & 0,0020469 & $(0,1946 ; 0,2097)$ & 1,0001 \\
\hline$\mu_{1}$ & $-0,42$ & 0,1461721 & $(-0,5862 ; 0,14013)$ & 1,0001 \\
\hline$\mu_{2}$ & 8,87 & 0,1461982 & $(8,5056 ; 9,4548)$ & 1,0001 \\
\hline$\mu_{3}$ & 2,87 & 0,1365543 & $(2,44129 ; 3,14269)$ & 1,0001 \\
\hline$\mu_{4}$ & 5,64 & 0,1481350 & $(4,90366 ; 6,25629)$ & 1,0001 \\
\hline$\mu_{5}$ & 6,99 & 0,1463323 & $(6,235955 ; 7,4793)$ & 1,0001 \\
\hline$\mu_{6}$ & $-2,518$ & 0,1462018 & $(-2,9098 ;-2,18146)$ & 1,0001 \\
\hline$\mu_{7}$ & 4,19 & 0,1881707 & $(3,86051 ; 4,44456)$ & 1,0001 \\
\hline$\mu_{8}$ & 5,28 & 0,1881707 & $(4,96051 ; 5,54456)$ & 1,0001 \\
\hline$\sigma_{v}^{2}$ & 3,15 & 0,523 & $(2,985 ; 3,7653)$ & 0,9998 \\
\hline$\sigma^{2}$ & 0,6007 & 0,0131 & $(0,532 ; 0,687)$ & 0,9998 \\
\hline
\end{tabular}

Tabcla 6.6: Sumários a posteriori do modelo de regressão com crros para os dados para os padröcs. 


\begin{tabular}{|c|c|c|c|c|}
\hline Parâmctro & Média & DP & Int.Cred(95) & GR \\
\hline$\beta_{\text {Pist }}$ & 0,58 & 0,008361973 & $(0,57245765 ; 0,596167434)$ & 1,0002 \\
\hline$\mu_{1}$ & $-0,18$ & 0,033523284 & $(-0,264360686 ; 0,06407953)$ & 1,0002 \\
\hline$\mu_{2}$ & 6,018 & 0,216760952 & $(6,003480992 ; 6,873095137)$ & 1,0003 \\
\hline$\mu_{3}$ & 1,73 & 0,092799802 & $(1,516180478 ; 1,883393641)$ & 1,0002 \\
\hline$\mu_{4}$ & 3,71 & 0,143479134 & $(3,449590494 ; 4,021644797)$ & 1,0001 \\
\hline$\mu_{5}$ & 3,2 & 0,155532249 & $(2,900450669 ; 3,513024714)$ & 1,0001 \\
\hline$\mu_{6}$ & $\cdots 0,7$ & 0,069788731 & $(-0,905542853 ;-0,528268536)$ & 1,0002 \\
\hline$\mu_{\tau}$ & 2,8 & 0,117766929 & $(2,608351657 ; 3,073732215)$ & 1,0001 \\
\hline$\mu_{8}$ & 4,06 & 0,158921357 & $(3,668513479 ; 4,592197149)$ & 1,0001 \\
\hline$\sigma_{V}^{2}$ & 0,7 & 0,057385313 & $(0,293126834 ; 0,915097725)$ & 0,9988 \\
\hline$\sigma^{2}$ & 0,3044 & 0,012402945 & $(0,198677104 ; 0,8743910351)$ & 0,9988 \\
\hline
\end{tabular}

Tabela 6.7: Sunários a posteriori do modelo de regressão com erros para os dados para os pistoros.

Da mesma forma que realizado na análise clássica, aqui também utilizamos as aproximaçoes para as estimativas de Bayos relativo aos parânetros $\beta_{p^{\prime} \text { ad }}$ e $\beta_{\text {pist }}$ c desta forma visualizamos o comportamento das efuações estimadas junto aus gráficos de dispersão $(2.10)$ e (2.11) para os dados dos padrões e dos pistões respectivamente. 


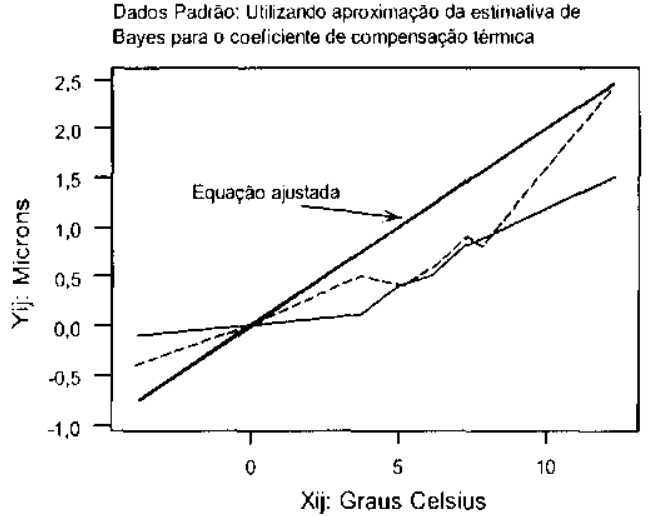

Figura 6.3: liquação estimada - dados dos padrões

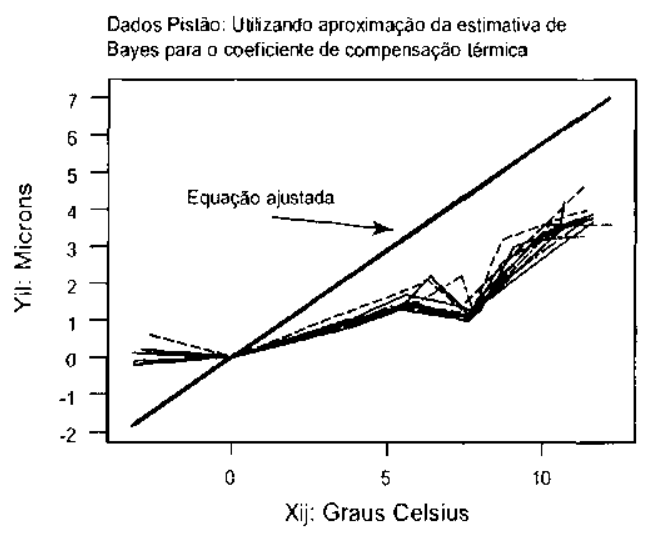

Figura 6.4: Hiquação estimada - dados dos pistóos 
Observalnos que o modelo de regressão com crros sob cnfoque Bayesiano nãa se ajustou de mancira satisfatória aus dados observados. Enquanto que a estratégia clássica de estimação proporcionon um melhor ajuste dos parâmetros do modelo de regressão com erros. Porém, se variarmos os valores de $\sigma_{\delta}^{2}$ tanto para os dados dos pistões e dos padrões, obtemos, as seguintes aproximações para as estimativas de Bayes

\begin{tabular}{|c|c|c|}
\hline$\sigma_{\delta}^{2}$ & $\widehat{\beta_{\text {Pist }}}$ & $\widehat{\beta_{\text {Pad }}}$ \\
\hline 0,1 & 0,3246 & 0,1512 \\
\hline 0,5625 & 0,58 & 0,2 \\
\hline 1,0 & 0.763 & 0,23 \\
\hline
\end{tabular}

Tabela 6.8: Estimativas Bayesianas para diferentes valores de $\sigma_{\delta}^{2}$.

Notamos que se a variabilidade do erro cometido pelo termômetro Fluke é pecuena, as cstimativas Baycsianas tornan-se próximas das estimativas de máxima vorossimilhança. Anteriormente, mostramos que as estimativas de máxima verossimuilhança referente ao parâmetro $\beta_{P i s t} C \beta_{\text {Pad }}$ aprescntaram bom desempenho quando comparado aos dados observados.

No processo de geração das cadeias, geramos várias cadeias com grande quantidade de pontos e selecionamos sistematicamente valores dentro da cadeia, formando novas anostras. Foram geradas 3 cadcias de 40000 para cada parâmetro. Para cada cadeia, desprezamos os 20000 valores iniciais e selecionamos os restantes: 1 em cada 20 valores, formando 3 amostras com 1000 valores.

Para todos os parâmetros tivemos que a convergência foi atingida pelo critćrio de Gelman e Rubin, pois os valores do fator de redução e escala se aproximam de 1. Outra forma de verificarmos a convergência dos parâmetros, ćatravés dos gráficos dados a seguir que mostram as trajetórias das cadcias ao longo das itcraçõos. Apresentamos apcnas gráfico associado ao parâmetro $\beta$. 


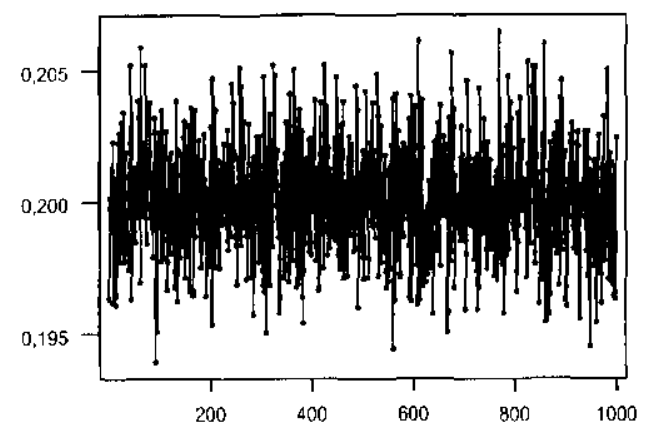

Figura 6.5: Itcrações para $\beta_{P a d}$

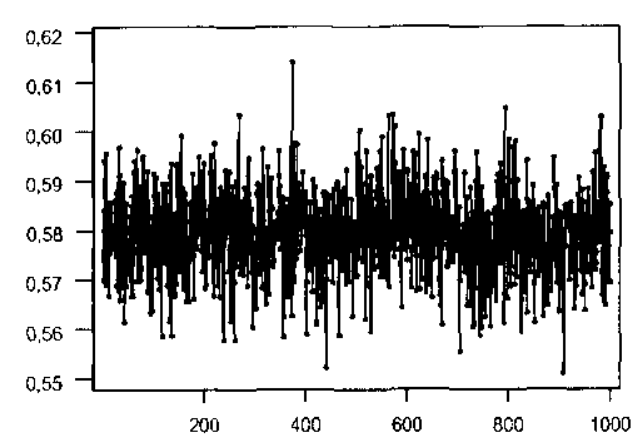

Figura 6.6: Iteraçôes para $\beta_{\text {pist }}$ 
$\Lambda$ seguir aprescntamos as Figuras 6.7 e 7.1 , que são histogramas referentes aos 1000 valores obtidos após selegão das amostras dos parámetros $\beta_{\text {fist }}$ c $\beta_{\Gamma^{2} a d}$. Esses histogramas representam aproximações das densidades a posteriori narginais desses parânetros.

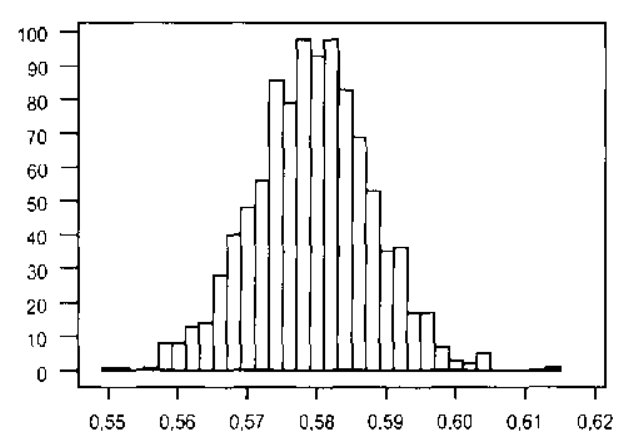

Figura 6.7: Aproximação da densidade a posteriori marginal de $\beta_{P i s t}$

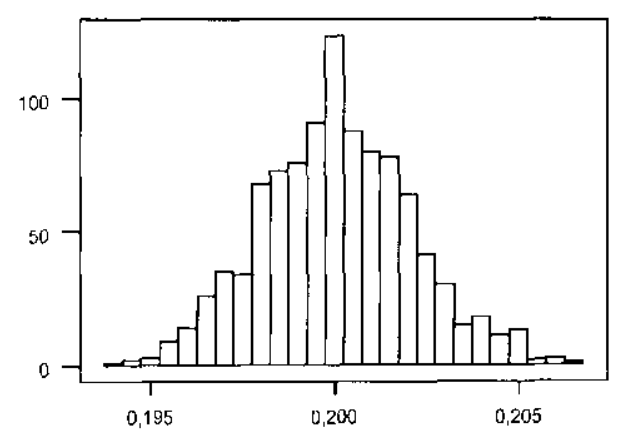

Figura 6.8: Aproximação da densidade a posteriori marginal do $\beta_{P a d}$ 


\subsection{Análise de Robustez}

De fundamental interesse na escolha da técnica de estimação a ser utilizada é o estudo de sua robustez. Na análise Bayesiana a robustez ć caracterizada pola influcheia dos hiperparâmetros $a_{0}, a_{3}, b_{3}, a_{2}$, e $b_{2}$ das densidades a priori dos parâmetros $\beta, \sigma^{2}$ e $\sigma_{v}^{2}$. Na análise clássica a robustez ć caracterizada pela influencia de diferentes valores iniciais utilizados no algoritmo EM. Primciro, aprescntamos a robuste do algoritmo $\mathrm{E}$. I o depois para o algoritmo Gibbs sampling.

\subsubsection{Robustez do Algoritmo EM}

Nesta análise, variamos os valores iniciais estabelccidos para os parâmetros $\beta, \sigma_{V}^{2}$ c $\sigma^{2}$ para padrăo c peça. Nas tabelas a seguir, apresentamos as aproximaçócs das cstinlativas de máxima verossimilhança para os três diferentes valores iniciais e os respectivos número de iterações.

$\Lambda$ coluna Parâmetros refere-se aos parâmetros analisados; a coluna Valores iniciais referc-se aos valores iniciais avaliados no algoritmo, as colunas R1,R2 e R3 são as aproximações das cstimativas de máxina verossimilhança obtidas a partir de cada valor inicial: as colunas IT1,IT2 e IT3 são as itcrações necessárias para que houvesse convergencia do algoritmo para cada valor inicial utilizado.

\begin{tabular}{|c|c|c|c|c|c|c|c|}
\hline Parâmetro & Valores Iniciais & $\mathrm{RI}$ & $\mathrm{R} 2$ & $\mathrm{R} 3$ & $\mathrm{IT} 1$ & $\mathrm{IT} 2$ & $\mathrm{IT} 3$ \\
\hline$\beta$ & 0,$1 ; 0,14 ; 5$ & 0,124 & 0,127 & 0,125 & 8 & 5 & 34 \\
\hline$\sigma_{v^{2}}^{2}$ & 0,$01 ; 0,44 ; 5$ & 0,007 & 0,004 & 0,005 & 12 & 7 & 21 \\
\hline$\sigma^{2}$ & 0,$01 ; 0,17 ; 5$ & 0,071 & 0,072 & 0,068 & 11 & 4 & 23 \\
\hline
\end{tabular}

Tabela 6.9: Análise de Robustez do algoritmo Exl para os dados dos padrócs. 


\begin{tabular}{|c|c|c|c|c|c|c|c|}
\hline Parâmotro & Valores Iniciais & R1 & R2 & R3 & I'l'1 & IT2 & IT3 \\
\hline$\beta$ & 0,$1 ; 0,24 ; 5$ & 0,273 & 0,267 & 0,298 & 10 & 3 & 22 \\
\hline$\sigma_{V}^{2}$ & 0,$01 ; 0,88 ; 5$ & 0,63 & 0,72 & 0,68 & 6 & 15 & 19 \\
\hline$\sigma^{2}$ & 0,$01 ; 1,99 ; 5$ & 0,36 & 0,34 & 0,38 & 7 & 5 & 18 \\
\hline
\end{tabular}

Tabela 6.10: Análise de Robustez do algoritmo EM para os dados clos pistões.

Observamos que para diferentes valores iniciais, o algoritmo EM atingiu convergencia. Porém, para valores iniciais distantes da solução numórica, a obtenção da convergencia exige um número maior de itcrações.

\subsubsection{Robustez das Estimativas Bayesianas}

$\mathrm{Na}$ Tabclas 6.11 e 6.12 , apresentamos as estimativas de monte carlo para três diferentes situações de valores dos hiperparâmetros das distribuições a prioris para os parâmetros $\beta, \sigma_{V}^{2}$ e $\sigma^{2}$ para parlião e peça.

A coluna Parâmetros refere-se aos parâmetros analisados; a coluna Hiperparâmetros refere-se aos hiperparanetros associados às distribuiçôes à priori especificadas; as colunas S1,S2 e S3 são as tres situações para os hiperparânetros; as colunas MCS1, MCS2 e MCS3 são as estimativas de Monte Carlo avaliadas para cada uma das três situaçooes.

\begin{tabular}{|c|c|c|c|c|c|c|c|}
\hline Parânctro & Hiperparâmotros & S1 & S2 & S3 & MCS1 & MCS2 & MCS3 \\
\hline$\beta$ & $a_{0}-$ & 0,1 & 0,14 & 0,5 & 0,21 & 0,204 & 0,1992 \\
& $b_{0}^{2}-$ & 0,01 & 0,06 & 1 & & & \\
\hline$\sigma_{v}^{2}$ & $a_{2} \cdots$ & 1 & 3,15 & 5 & 3,07 & 3,2 & 3,3 \\
& $b_{2} \cdots$ & 0,1 & 0,94 & 3 & & & \\
\hline$\sigma^{2}$ & $a_{3} \cdots$ & 1 & 3,54 & 8 & 0,61 & 0,57 & 0,65 \\
& $b_{3} \cdots$ & 0,01 & 0,42 & 3 & & & \\
\hline
\end{tabular}

Tabela 6.11: Análise de Robuste\% clas aproximações para as estimativas Bayesinas do molelo de regressão com orros para os dados dos padróos. 


\begin{tabular}{|c|c|c|c|c|c|c|c|}
\hline Parâmetro & Iliperparâmetros & S1 & S2 & S3 & MCS1 & MCS2 & MCS3 \\
\hline$\beta$ & $a_{0}=$ & 0,1 & 0,24 & 0,5 & 0,571 & 0,569 & 0,581 \\
& $b_{0}^{2}=$ & 0,001 & 0,018 & 1 & & & \\
\hline$\sigma_{V}^{2}$ & $a_{2}=$ & 1 & 2,27 & 3 & 0,65 & 0,72 & 0,82 \\
& $b_{2}=$ & 0,1 & 1,126 & 3 & & & \\
\hline$\sigma^{2}$ & $a_{3}=$ & 1 & 5,23 & 10 & 0,298 & 0,301 & 0,305 \\
& $b_{3}=$ & 4 & 8,44 & 12 & & & \\
\hline
\end{tabular}

Tabela 6.12: Análise do Robustcz das aproximações para as estimativas Baycsinas do modelo de regressão com crros para os dados dos pistões.

Após análisc das Tabelas acima, concluímos que as densidades à priori formuladas para os parâmetros produziram estimativas baycsianas robustas. Principalmente para os parâmetro de interesse $\beta$ útil nà Equação de Correção em 1.8 . 


\section{Capítulo 7}

\section{Discussão}

Para resolver o problema de compensação da medição do diâmetro do furo do pistão devido à variação térmica, estabelecemos uma estratégia de correção (ver equação 1.8). Porém, para que esta cquaçào funcione de forma adequada no dia a dia de trabalho, precisamos estimar os parâmetros $\beta_{P a d} \mathrm{c} \beta_{P i s t}$. Listes parâmetros representam a alteração ocorrida no diâmetro a partir da alteração de um grau da temperatura da peça.

A parte experimental deste problema necessitou de um grande período de tempo. No início dos primciros experimentos, chegamos a utilizar uma caixa de papelão com uma lâmpada para aquecer as peças c os padrões em 15 minutos de estabilização. Após análise do gráfico de dispersão dos daclos, percebemos que esta forma de execução do experimento não cra adequada. $\Lambda$ partir daí, uma estufa passou a scr utilizada nos experimentos. Mesmo com a utilização da estufa para aquecer as peças, foi necessário realizar outros experimentos para determinar um tempo adcquado para a estabilização da temperatura. Após alguns experimentos pilotos, proponos um tempo de estabilização de 2 horas para os pistões e de 3 horas para o padrão cm cada patamar de temperatura. A principal contribuição da estufa foi que a sua utilização permitiu realizar em curto prazo de tempo um experimento. Por outro lado a utilização da estufa cria uma situação artificial de variação da temperatura das peças e padrões. Alćm disso, ao retirarmos a peça da estufa para ser medida, temos una troca de calor entre a peça c o meio ambiente, que pode comprometer os dados. Desta forma, decidimos realizar um segundo experimento onde observamos o diâmetro do furo a partir da variaçäo natural da tempcratura do setor de 
realização do experimento e utilização do sistema de medição. Com este experinento, obtemos rcsultados satisfatórios.

Basicamente, os experimentos consistiram em variar a temperatura da peça e do padrão o imediatamente medirmos scus respectivos diâmetros do furo. No entanto. estas variáveis são medidas por cquipamentos do mediçào, o termônctro de contato na medição da temperatura e a cólula de medição na medição do diâmetro do furo. Como todo cquipamento de medição, cólula e termômetro, ambos medem com crro, consideramos modelos com cros nas variáveis mediante ao conhecimento prévio da variabilidade associada ao crro alcatório conetido pelo termónctro de contato (ver Relatório de Calibração apêndico). Adequadamentc, adotamos modelo de regressão com crros nas variávcis sem intercepto: relação ultracstrutural para modelar as modiçócs do diâmetro en função dia temperatura.

Para abordar este modelo, utilizamos análises Clássicas c Bayesianas. Na análisc clássica, não foi possivel cncontrar expressões fechadas para os estimadores de máxima verossimilhança. De forma análoga, na análise Bayesiana também não foi possível cstabelecer uma expressãa fechada para o estimador do Bayes. Diante disto, foi necestário introduzir para ambas abordagens a variável latente $\left(V_{i j}\right)$. Esta variável permitiu na análise Clássica, a utilização do algoritmo EM e na análiso Bayesiana a utilização do algoritmo de Gibbs Sampling. Após análise dos gráficos de dispersão (6.1), (6.2) para os coficientes cncontrados a partir da utilização do algoritmo EM c dos gráficos (6.3) e (6.4) utilizando os coeficientes encontrados a partir da estratégia Bayesiana, observanos que a abordagem Clássica, a partir da utilização do algoritmo EM, sc ajustou molhor aos dados observados.

Com as aproximações das estimativas dos cocficientes $\beta_{P i s t} \circ \beta_{P a d}$ obtidas a partir das estratégias Clássica o Bayesina, nos resta saber qual dupla produzem correções satisfatórias na modição do diânetro da peça no dia a dia do traballıo. Para validar estes coeficientes, adotamos uma estratégia em duas fases:

\section{Fase 1: Definindo valores de referência a $20^{\circ} \mathrm{C}$}

- Para isto, 10 peças, 2 padrões e uma Cćlula de medição foram cncaminhadas para 
uma sala climatizada a $20^{\circ} \mathrm{C}$ onde ficaram por 24 horas, para ostabilizar a temperatura;

- Logo após, cada peça foi medicla em sequencia aleatória realizando-se a medição do diametro de cada pega por 3 vezes.

- Calculamos a módia das 3 lcituras realizadas à $20^{\circ} \mathrm{C}$. Os dados estão na tabcla 7.1 .

\section{Fase 2: Obtenção de mediçōes em várias temperaturas}

- As mesinas 10 pecas, 2 padróes e Célula de medicão foran encaminhadas para o Chão de Fábrica.

- Durante scte vezes, un experimetador dirigiu-se ao local do experimento, anotandose a temperatura dos padróes o realizando o ajuste da Célula. Lin seguida, anotou-se peça e peça, a medição cla tomperatura e do diâmetro de cada peça.

$\Lambda$ Tabela abaixo, a primeira coluna refore-se a peça, as colunas R1, R2 e R3 referense a cada uma das réplicas e a última coluna a média das trôs réplicas

\begin{tabular}{|c|c|c|c|c|}
\hline & $R 1$ & $R 2$ & $R 3$ & MÉDIA \\
\hline$P 1$ & 20004,3 & $20004: 2$ & 20004,2 & 20004,2 \\
\hline$P 2$ & 20003 & 20003,3 & 20003,2 & 20003,1 \\
\hline$P 3$ & 20003,5 & 20003,6 & 20003,5 & 20003,5 \\
\hline$P^{\prime}$ & 20005,1 & 200005,2 & 20005,3 & 20005,2 \\
\hline$P 5$ & 200005 & 20005,1 & 20005 & 20005,03 \\
\hline$P 6$ & 20003,9 & 20003,9 & 20003,8 & 20003,8 \\
\hline$P 7$ & 20005,6 & 200005,6 & 20005,5 & 20005,5 \\
\hline$P_{8}$ & 20005,6 & 20005,7 & 20005,5 & 20005,6 \\
\hline$P 9$ & 20004,9 & 20005 & 20004,9 & 20004.9 \\
\hline$P 10$ & 20004,1 & 200004,3 & 20004,2 & 20004,2 \\
\hline
\end{tabular}

Tabcla 7.1: Valores de referencia obtidos a $200^{\circ} \mathrm{C}$ 
Portanto, utilizando os dados obtidos na scgunda fase (dados completos estão no apêndice) com os cocficientes $\beta_{P \text { ist }}$ e $\beta_{P_{a d}}$ obtidos nas análises Clássica o Bayesiana, realizannos as compensações nas medições do diâmetro devido a variação de temperatura. utilizando a equação (1.8). Com isto, comparamos estes valores com a medição de reforência obtido na temperatura de $20^{\circ} \mathrm{C}$ na primeira fase da validação. A comparação cntre as aproximaçôes os coeficientes de compensação térmica obtidas via análises Clássicas e Baycsinas ć aprosentado a scguir

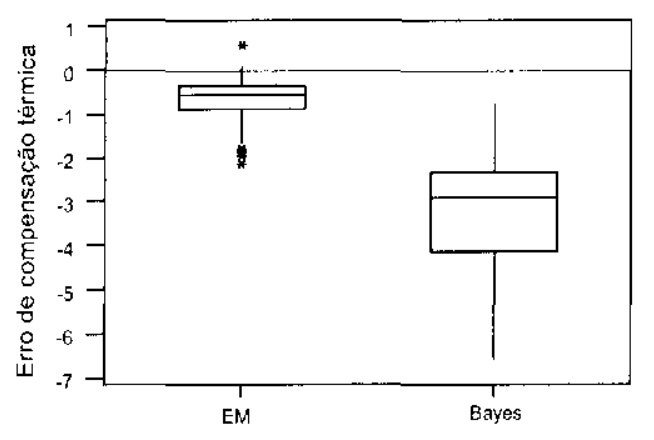

Figura 7.1: Frrros de compensação térmica

No gráfico acima, o primeiro Box-plot (E.H) refere-se ao cro cometido utilizandose os cocficientes obtidos a partir da análisc clássica. Enquanto que o segundo BoxPlot, refere-se aos crros de compensação térmica utilizando os cocficientes obtidos com abordagem Baycsiana.

Diante disto, decidimos escolher os coeficientes obtidos através da análise clássica para serem configurados em todas as Cólulas de medição da KS Pistóes. A partir da implantação destes coeficientes no dia primciro de setembro de 2003, avaliamos o rcfugo deviclo a caractcrística do diâmetro do furo durante todo o ano. O gráfico abaixo, mostra o impacto da implantação dos cocficientes no refugo. 


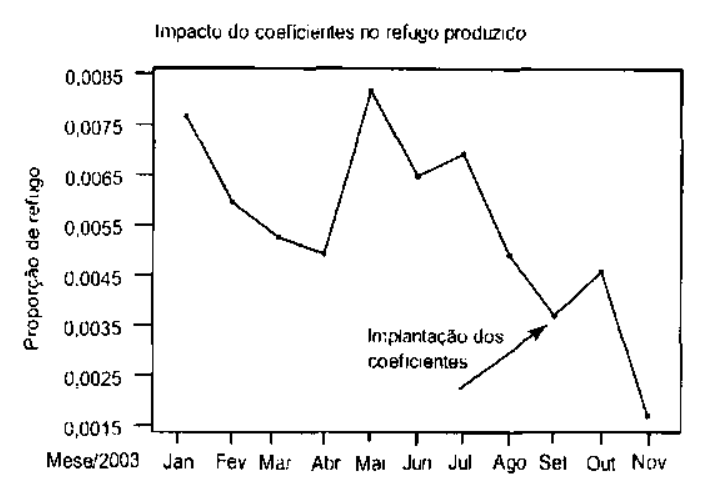

Figura 7.2: Impacto da implantação dos coefieientes obticlos via análise clássica

Com isso, mostramos que a estratégia de correção foi cficaz roduzindo substancialmente o refugo. 


\section{Capítulo 8}

\section{Propostas futuras}

Como perspectivas futuras, podemos sugerir para continuidade e melhoria deste trabalho:

1. Introduzir un cfeito aleatório para peça/padrão no modelo do regressão com crros

2. Considerar que os $V_{i j}^{r}$ possuem variâncias distintas em cada patamar de temperatura.

3. No contexto Bayesiano, pode-se formular outras prioris para o parânıctro $\beta$. 
Capítulo 9

\section{Apêndices}

9.1 Certificado de calibração

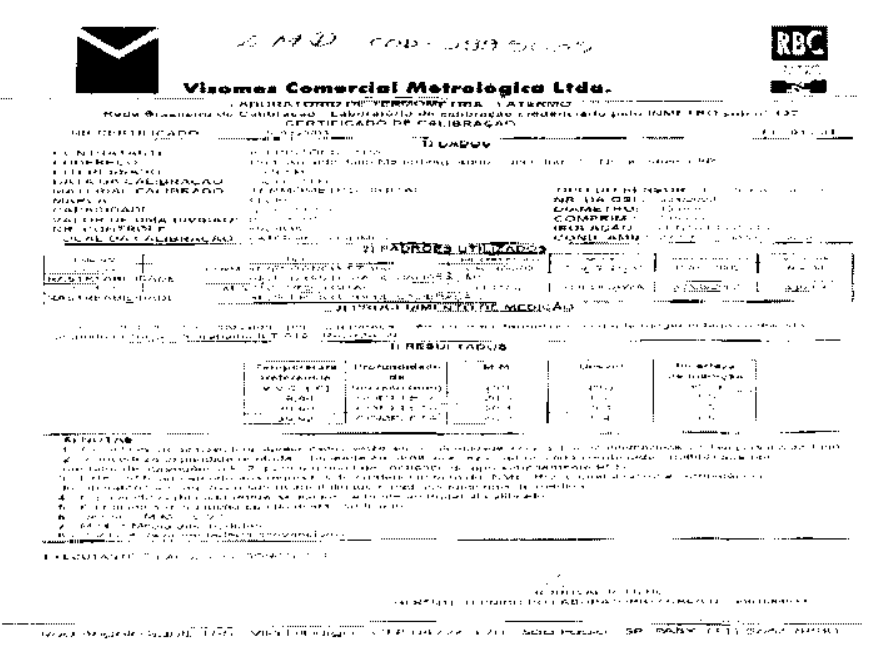

Figura 9.1: Certificado de calibração do temômotro Fluke 


\subsection{Algoritmo de Gibbs Sampling}

O algoritmo Gibbs Sampling foi introduzido formatnente por Gclman o Gelman (1981), propuseram un esquema de anostragem de distribuições explorando as distribuições condicionais completas, através de um algoritmo itcrativo que define uma Cadeia do Markov.

O algoritmo Gibbs Sampling ć essencialmente um cscunema jterativo de amostragem de uma cadeia de Markov eujo núcleo de transição é formado pelas distribuiçoes condicionais completas.

Descriçấo do método:

Suponha que a distribuição de interesse ć $\pi(\underline{0})$ onde $\underline{\theta}-\left(\theta_{1}, \theta_{2}, \ldots, \theta_{p}\right)$ e que as distribuicoues condicionais completas a posteriori $\pi\left(\theta_{i} / \theta_{1}, \theta_{2}, \ldots, \theta_{i-1}, \theta_{i+1}, \ldots, \theta_{p}\right), i=1, \ldots, p$. estão disponíveis sob forma padronizada. Podemos então gerar amostras atravós do seguinte procedimento:

Passo 1: iniciar o contador das itoraçoes, $j=1$, o atribuir valores iniciais $\underline{0}$ $\left(\theta_{1}^{(0)}: \theta_{2}^{(0)}, \ldots, \theta_{p}^{(0)}\right)$

Passo 2: obter um novo valor $\underline{Q}=\left(\theta_{1}^{(j)}, \theta_{2}^{(j)}, \ldots, \theta_{p}^{(j)}\right)$ através de sucessivas geracão de valores:

$$
\begin{gathered}
\theta_{1}^{(j)} \sim \pi\left(\theta_{1} / \theta_{2}^{(j-1)}, \ldots, \theta_{p}^{(j-1)}\right) \\
\theta_{2}^{(j)} \sim \pi\left(\theta_{2} / \theta_{1}^{(j)}, \theta_{3}^{(j-1)}, \ldots, \theta_{p}^{(j-1)}\right) \\
\cdot \\
\cdot \\
\theta_{p}^{(j)} \sim \pi\left(\theta_{p} / \theta_{1}^{(j)}, \theta_{2}^{(j)}, \ldots, \theta_{p-1}^{(j)}\right)
\end{gathered}
$$

Passo 3: mudamos o contador j para $j+1$ a retorlamos ao Passo 2 até a convergência. 
Gelman e Golman (1984) mostram que os valores geradus para $\theta_{i}, i=1, \ldots, p$, convergem cm distribuição para uma variável aleatória da distribuição $\pi(\theta) \operatorname{com} j \rightarrow \infty$. 


\subsection{Critério de convergência de Gelman e Rubin}

Tima forma simples de verificar convergência é a utilizaçào de várias cadeias $\mathrm{em} \mathrm{paralolo}$ começando por diferentes pontos iniciais. Com isso, evita-se que as cadeias se concentrem em regiõos em torno de modas locais.

A inspeção visual de similaridade entre as trajetórias clas várias cadeias após um certo número de iteraçòes é um forte indício de convergência. Gclman e Rubin (1992) formalizam essa idćia, de que as trajetórias das cadeias devem ser a mesma depois de convergirem, através do uso de tócnicas de análisc de variância. A idéia geral é testar so a dispersão intra-cadeias é maior do que a dispersão inter-cadeias. Isto equivale a dizer que: o histograna das cadcias cono um todo deve ser similar aos histogramas das cadeias tomadas individualnente.

Considerando $m$ cadcias que cvoluem cm paralclo e uma função real $t(\theta)$, tem-se m trajctórias $\left\{t_{i}^{0}, t_{i}^{1}, \ldots, t_{i}^{n}\right\}, i-1, \ldots, m$, para t. Portanto, podem scr obtidas a varianncia cntre as cadcias, B, e a variância dentro das cadcias, W. $\Lambda$ s fórmulas correspondentes são daclas por:

$B=\frac{n}{m-1} \sum_{i=1}^{m}\left(\ddot{t}_{i}-\bar{t}\right)^{2} \odot W=\frac{1}{m(n-1)} \sum_{i=1}^{m} \sum_{j=1}^{n}\left(t_{i}^{(j)}-t_{i}\right)^{2}$

onde $\bar{t}_{i}$ ć a módia das observaçôes da cadeia i e t́ é módia dessas módias, $i=1, \ldots, m$.

A variância de t pode ser estimada de forma não viciada por:

$\hat{V}(t(\theta))=\left(1-\frac{1}{n}\right) W+\left(\frac{1}{n}\right) B$

So as cadeias ainda não estiverem convergindo, cntäo ossa estimativa é maior que $\hat{V}(t(\theta))$ pois os valores iniciais ainda estão sendo influenciados pelos valores dos outros parametros da cadeia, de forma que a distribuição de equilíbrio ainda nâo foi atingida, indicando que eles foram escolhidos com dispersão maior que a da distribuição de equilíbrio. Por outro lado, W fornece cstimativas menores que $\hat{V}(t(\theta))$, pois cadeia não terá coberto toda a variabilidade de $t(\theta)$.

Um indicador de convergencicia é dado pela chamada redução potencial estimada 


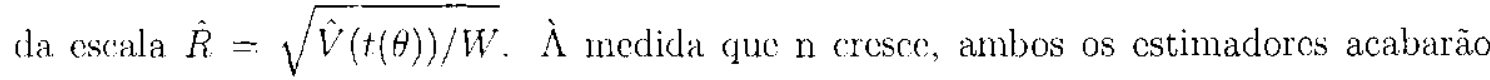
convergindo para $\hat{V}(t(\theta))$ o $R$ convergirá para 1 . $A$ ssim, $\hat{R}$ pode ser usado como indicador de convergência pela avaliação de sua proximidado a 1. 


\subsection{Dados do Pré e segundo experimentos}

Os dados obtidos a partir do pré-experimento foram realizados segundo procedimento experimental detalhado no capítulo 2. Para ambos os experincntos colctou-se informaçõcs amostrais para peça c partrão.

\section{Pré-experimento}

Aqui, temos as mediçooss do diâmetros e das temperaturas observadas de 10 peças c 2 padrôes foram submetidos a 6 condições de temperatura

\begin{tabular}{|c|c|c|c|}
\hline Patamar & Padrão & $D_{i j}$ & $T_{i j}$ \\
\hline 1 & 1 & 20000,1 & 24,3 \\
1 & 2 & 20008,6 & 24,3 \\
\hline 2 & 1 & 20001,6 & 30,6 \\
2 & 2 & 20010,0 & 30,7 \\
\hline 3 & 1 & 20001,9 & 34,1 \\
3 & 2 & 20009,8 & 35 \\
\hline 1 & 1 & 20002,5 & 40,9 \\
4 & 2 & 20011,9 & 42,3 \\
\hline 5 & 1 & 20002,6 & 45,9 \\
5 & 2 & 20012,2 & 46,8 \\
\hline 6 & 1 & 20004,1 & 50,2 \\
6 & 2 & 20013,1 & 51,5 \\
\hline
\end{tabular}

Tabcla 9.1: Dados referentes ao Diâmetro do Furo dos Padrões - Pré-experimento.

c os dados referentes às peças 


\begin{tabular}{|c|c|c|c||c|c|c|c|}
\hline Patamar & Peça & $D_{i j}$ & $T_{i j}$ & Pattamar & Pç̧a & $D_{i j}$ & $T_{i j}$ \\
\hline 1 & 1 & 20004,1 & 23,8 & 4 & 1 & 20009,0 & 40,6 \\
1 & 2 & 20005,3 & 23,7 & 4 & 2 & 200008,9 & 41,3 \\
1 & 3 & 20005,4 & 23,4 & 4 & 3 & 20009,9 & 42,4 \\
1 & 4 & 20004,8 & 23,4 & 4 & 4 & 20009,1 & 39,2 \\
1 & 5 & 20003,2 & 23,4 & 4 & 5 & 20007,2 & 41,8 \\
1 & 6 & 20004,8 & 23,2 & 4 & 6 & 20010,9 & 42,6 \\
1 & 7 & 20004,4 & 23,2 & 4 & 7 & 20007,8 & 38,4 \\
1 & 8 & 20004,2 & 23,1 & 4 & 8 & 200009,9 & 43,4 \\
1 & 9 & 20003,2 & 23,2 & 4 & 9 & 200008,8 & 41,1 \\
1 & 10 & 20004,4 & 23,5 & 4 & 10 & 20010,1 & 43,2 \\
\hline 2 & 1 & 20005,5 & 30,1 & 5 & 1 & 20010,8 & 47,2 \\
2 & 2 & 20006,9 & 29,8 & 5 & 2 & 20010,5 & 48,5 \\
2 & 3 & 20007,1 & 29,6 & 5 & 3 & 20007,6 & 48 \\
2 & 4 & 20006,1 & 29,9 & 5 & 4 & 20000,1 & 48,4 \\
2 & 5 & 20004,8 & 30 & 5 & 5 & 200004,6 & 48,5 \\
2 & 6 & 20006,5 & 30,5 & 5 & 6 & 20008,3 & 48,3 \\
2 & 7 & 20005,8 & 29,8 & 5 & 7 & 20008,4 & 47,4 \\
2 & 8 & 20005,7 & 29,8 & 5 & 8 & 20007 & 47,8 \\
2 & 9 & 20004,6 & 29,7 & 5 & 9 & 20007,9 & 46,6 \\
2 & 10 & 20005,8 & 30 & 5 & 10 & 20007,4 & 48,5 \\
\hline
\end{tabular}




\begin{tabular}{|c|c|c|c||c|c|c|c|}
\hline Patamar & Padrão & $D_{i j}$ & $T_{i j}$ & Patamar & Padrão & $D_{i j}$ & $T_{i, i}$ \\
\hline 3 & 1 & 20007 & 34,5 & 6 & 1 & 20013,9 & 55,3 \\
3 & 2 & 200008,7 & 36,4 & 6 & 2 & 20015,2 & 56,8 \\
3 & 3 & 20008,4 & 36,2 & 6 & 3 & 20013,7 & 56,4 \\
3 & 4 & 20007,7 & 34,5 & 6 & 4 & 20013,4 & 58,5 \\
3 & 5 & 20006 & 35,8 & 6 & 5 & 20010,7 & 60,6 \\
3 & 6 & 20007,6 & 35,1 & 6 & 6 & 20014,7 & 54,2 \\
3 & 7 & 20007,1 & 35,2 & 6 & 7 & 20013 & 57,8 \\
3 & 8 & 20007 & 35,7 & 6 & 8 & 20012,9 & 59,5 \\
3 & 9 & 20006,1 & 34,9 & 6 & 9 & 20013,9 & 55,3 \\
3 & 10 & 20007,1 & 35,5 & 6 & 10 & 20013,4 & 55,4 \\
\hline
\end{tabular}

Tabela 9.2: Dados referentes ao Jiâmetro do Furo dos Pistóes (Peças) - Pró-cxperimento.

Onde, para ambos peça c padrão:

- $D_{i j}$ : Diâmetro da j-ćsima peça obtida no i-ćsinno patamar do temperatura.

- $T_{i j}$ : Temperatura observada da j-ésima peça no i-ísimo patanar de temperatura. Medição obtida a partir do termômetro de contato Fluke. 


\section{Segundo-experimento}

Aqui, temos as mediçoes do diannetros e das temperaturas observadas de 10 peģas o 2 padröes foram submetidos a 8 condições de temperatura

\begin{tabular}{|c|c|c|c|}
\hline Patamar & Padrão & $D_{i j}$ & $T_{i j}$ \\
\hline 1 & 1 & 20000 & 20,9 \\
1 & 2 & 20009,1 & 20,9 \\
\hline 2 & 1 & 20001,5 & 33,2 \\
2 & 2 & 20011,5 & 33,1 \\
\hline 3 & 1 & 20000,1 & 24,6 \\
3 & 2 & 20009,6 & 21,6 \\
\hline 1 & 1 & 20000 & 28,9 \\
4 & 2 & 20009,6 & 28,7 \\
\hline 5 & 1 & 20000,8 & 28,1 \\
\hline 5 & 2 & 20010 & 28,3 \\
\hline 6 & 1 & 19999,9 & 17,1 \\
\hline 6 & 2 & 20008,7 & 17 \\
\hline 7 & 1 & 20000,4 & 25,9 \\
\hline 7 & 2 & 20009,5 & 26 \\
\hline 8 & 1 & 20000,5 & 27 \\
\hline 8 & 2 & 20009,7 & 27,1 \\
\hline
\end{tabular}

Tabela 9.3: Dados referentes ao Diâmetro do Furo dos Padròs - Segundo-experimento. 
c os dados referentes às peças

\begin{tabular}{|c|c|c|c||c|c|c|c|}
\hline Patamar & Pistão & $D_{i j}$ & $T_{i j}$ & Patamar & P'istão & $D_{i j}$ & $T_{i j}$ \\
\hline 1 & 1 & 20004,4 & 20,9 & 5 & 1 & 20005,6 & 28,5 \\
1 & 2 & 20003,9 & 20,9 & 5 & 2 & 20005,2 & 28,3 \\
1 & 3 & 20004,8 & 20,8 & 5 & 3 & 20005,9 & 28,5 \\
1 & 4 & 20004,8 & 20,8 & 5 & 4 & 20006 & 28,6 \\
1 & 5 & 20002,3 & 20,8 & 5 & 5 & 20003,3 & 28,3 \\
1 & 6 & 20005,6 & 20,8 & 5 & 6 & 20006,9 & 28,6 \\
1 & 7 & 20004 & 20,8 & 5 & 7 & 20005,1 & 28,4 \\
1 & 8 & 20004,6 & 20,8 & 5 & 8 & 20005,6 & 28,4 \\
1 & 9 & 20004,3 & 20,8 & 5 & 9 & 20005,5 & 28,5 \\
1 & 10 & 20005,1 & 20,9 & 5 & 10 & 20006,1 & 28,3 \\
\hline 2 & 1 & 20008,1 & 32,5 & 6 & 1 & 20004,5 & 17,7 \\
2 & 2 & 20008,5 & 32,2 & 6 & 2 & 20004,5 & 18,3 \\
2 & 3 & 20008,7 & 32,4 & 6 & 3 & 20004,6 & 17,9 \\
2 & 4 & 20008,5 & 32,1 & 6 & 4 & 20004,9 & 17,7 \\
2 & 5 & 20005,6 & 32,2 & 6 & 5 & 20002,1 & 17,7 \\
2 & 6 & 20009,4 & 32,1 & 6 & 6 & 20005,4 & 17,7 \\
2 & 7 & 20007,6 & 33 & 6 & 7 & 20004,2 & 18,2 \\
2 & 8 & 20008,4 & 32,4 & 6 & 8 & 20004,7 & 18,1 \\
\hline 2 & 9 & 20008,3 & 32,2 & 6 & 9 & 20004,5 & 17,9 \\
\hline 2 & 10 & 20009,3 & 31,6 & 6 & 10 & 20005 & 17,8 \\
\hline
\end{tabular}




\begin{tabular}{|c|c|c|c||c|c|c|c|}
\hline Patamar & Pistão & $D_{i j}$ & $T_{i j}$ & Patamar & Pistão & $D_{i j}$ & $T_{i j}$ \\
\hline 3 & 1 & 20005,7 & 28,7 & 7 & 1 & 20005,8 & 26,4 \\
3 & 2 & 20005,1 & 24,5 & 7 & 2 & 20005,7 & 26,4 \\
3 & 3 & 20005,6 & 24,5 & 7 & 3 & 20007,4 & 29,5 \\
3 & 4 & 20005,8 & 24,5 & 7 & 4 & 20006,2 & 26,6 \\
3 & 5 & 20003,1 & 24,6 & 7 & 5 & 20003,7 & 26,5 \\
3 & 6 & 20006,6 & 24,5 & 7 & 6 & 20007,3 & 26,4 \\
3 & 7 & 20004,9 & 24,5 & 7 & 7 & 20005,4 & 25,9 \\
3 & 8 & 20005,9 & 28,8 & 7 & 8 & 20005,9 & 26,2 \\
3 & 9 & $20000,5,2$ & 24,6 & 7 & 9 & 20005,7 & 26,3 \\
3 & 10 & 20006 & 24,6 & 7 & 10 & 20006,6 & 26,8 \\
\hline 4 & 1 & 20005,3 & 24,5 & 8 & 1 & 20006,6 & 27,3 \\
4 & 2 & 20005,4 & 28,4 & 8 & 2 & 20006 & 27,2 \\
4 & 3 & 20006,1 & 28,6 & 8 & 3 & 20006,3 & 26,4 \\
4 & 4 & 20006,3 & 28,7 & 8 & 4 & 20007 & 28,2 \\
4 & 5 & 20003,6 & 28,6 & 8 & 5 & 20005,5 & 30,8 \\
4 & 6 & 20007,2 & 28,7 & 8 & 6 & 20009 & 30,9 \\
4 & 7 & 20005,5 & 28,8 & 8 & 7 & 20007,6 & 31 \\
4 & 8 & 20005,4 & 24,6 & 8 & 8 & 20007,6 & 29,9 \\
4 & 9 & 20005,9 & 28,7 & 8 & 9 & 20007,5 & 29,5 \\
4 & 10 & 20006,5 & 28,9 & 8 & 10 & 20008,5 & 31,4 \\
\hline
\end{tabular}

Tabcla 9.4: Dados refurentes ao Diâmetro do Furo dos Pistões (Peçass) - Segundoexperimento.

Após a transformação que possibilita a utilização do modelo com intercepto nulo, obtcmos

e os dados transformados referentes às peças 


\begin{tabular}{|c|c|c|c|}
\hline Patamar & Padrão & $Y_{i j}$ & $X_{i_{3}}$ \\
\hline 1 & 1 & 0 & 0 \\
1 & 2 & 0 & 0 \\
\hline 2 & 1 & 1,5 & 12,3 \\
2 & 2 & 2,4 & 12,2 \\
\hline 3 & 1 & 0,1 & 3,7 \\
3 & 2 & 0,5 & 3,7 \\
\hline 4 & 1 & 0,9 & 8 \\
4 & 2 & 0,8 & 7,8 \\
\hline 5 & 1 & 0,8 & 7,2 \\
5 & 2 & 0,9 & 7,3 \\
\hline 6 & 1 & $-0,1$ & $-3,8$ \\
6 & 2 & $-0,4$ & $-3,9$ \\
\hline 7 & 1 & 0,4 & 5 \\
7 & 2 & 0,4 & 5,1 \\
\hline 8 & 1 & 0,5 & 6,1 \\
8 & 2 & 0.6 & 6,2 \\
\hline
\end{tabular}

Tabela 9.5: Dados referentes ao Diâmetro do Furo e temperatura dos Padrões transformados - Scgundo-cxperimento. 


\begin{tabular}{|c|c|c|c||c|c|c|c|}
\hline Patamar & Pistaño & $Y_{i j}$ & $X_{i j}$ & Patamar & Pistão & $Y_{i j}$ & $X_{i j}$ \\
\hline 1 & 1 & 0 & 0 & 5 & 1 & 1,2 & 7,6 \\
1 & 2 & 0 & 0 & 5 & 2 & 1,3 & 7,4 \\
1 & 3 & 0 & 0 & 5 & 3 & 1,1 & 7,7 \\
1 & 4 & 0 & 0 & 5 & 4 & 1,2 & 7,8 \\
1 & 5 & 0 & 0 & 5 & 5 & 1 & 7,5 \\
1 & 6 & 0 & 0 & 5 & 6 & 1,3 & 7,8 \\
1 & 7 & 0 & 0 & 5 & 7 & 1,1 & 7,6 \\
1 & 8 & 0 & 0 & 5 & 8 & 1 & 7,6 \\
1 & 9 & 0 & 0 & 5 & 9 & 1,2 & 7,7 \\
1 & 10 & 0 & 0 & 5 & 10 & 1 & 7,4 \\
\hline 2 & 1 & 3,7 & 11,6 & 6 & 1 & 0,1 & $-3,2$ \\
2 & 2 & 4,6 & 11,3 & 6 & 2 & 0,6 & $-2,6$ \\
2 & 3 & 3,9 & 11,6 & 6 & 3 & $-0,2$ & $-2,9$ \\
2 & 4 & 3,7 & 11,3 & 6 & 4 & 0,1 & $-3,1$ \\
2 & 5 & 3,3 & 11,4 & 6 & 5 & $-0,2$ & $-3,1$ \\
2 & 6 & 3,8 & 11,3 & 6 & 6 & $-0,2$ & $-3,1$ \\
2 & 7 & 3,6 & 12,2 & 6 & 7 & 0,2 & $-2,6$ \\
2 & 8 & 3,8 & 11,6 & 6 & 8 & 0,1 & $-2,7$ \\
2 & 9 & 4 & 11,1 & 6 & 9 & 0,2 & $-2,9$ \\
2 & 10 & 4,2 & 10,7 & 6 & 10 & $-0,1$ & $-3,1$ \\
\hline
\end{tabular}

\subsection{Dados da segunda fase da validação}




\begin{tabular}{|c|c|c|c||c|c|c|c|}
\hline Patamar & Pistão & $Y_{i j}$ & $X_{i j}$ & Patamar & Pistão & $Y_{i j}$ & $X_{i j}$ \\
\hline 3 & 1 & 1,3 & 7,8 & 7 & 1 & 1,4 & 5,5 \\
3 & 2 & 1,2 & 3,6 & 7 & 2 & 1,8 & 5,5 \\
3 & 3 & 0,8 & 3,7 & 7 & 3 & 2,6 & 8,7 \\
3 & 4 & 1 & 3,7 & 7 & 4 & 1,4 & 5,8 \\
3 & 5 & 0,8 & 3,8 & 7 & 5 & 1,4 & 5,7 \\
3 & 6 & 1 & 3,7 & 7 & 6 & 1,7 & 5.6 \\
3 & 7 & 0,9 & 3,7 & 7 & 7 & 1,4 & 5,1 \\
3 & 8 & 1,3 & 8 & 7 & 8 & 1,3 & 5,4 \\
3 & 9 & 0,9 & 3,8 & 7 & 9 & 1,4 & 5,5 \\
3 & 10 & 0,9 & 3,7 & 7 & 10 & 1,5 & 5,9 \\
\hline 4 & 1 & 0,9 & 3,6 & 8 & 1 & 2,2 & 6,4 \\
4 & 2 & 1,5 & 7,5 & 8 & 2 & 2,1 & 6,3 \\
4 & 3 & 1,3 & 7,8 & 8 & 3 & 1,5 & 5,6 \\
4 & 4 & 1,5 & 7,9 & 8 & 4 & 2,2 & 7,4 \\
4 & 5 & 1,3 & 7,8 & 8 & 5 & 3,2 & 10 \\
4 & 6 & 1,6 & 7,9 & 8 & 6 & 3,4 & 10,1 \\
4 & 7 & 1,5 & 8 & 8 & 7 & 3,6 & 10,2 \\
4 & 8 & 0,8 & 3,8 & 8 & 8 & 3 & 9,1 \\
4 & 9 & 1,6 & 7,9 & 8 & 9 & 3,2 & 8,7 \\
4 & 10 & 1,4 & 8 & 8 & 10 & 3,4 & 10,5 \\
\hline
\end{tabular}

Tabela 9.6: Dados referentes ao Diâmetro do Furo dos Pistōos Transformados (Peças) Segundo-experimento. 


\begin{tabular}{|c|c|c|c|c|c|c|c|c|}
\hline Peça & F1SC & TPistão & TPadrão & F1CEM & F1CB & $\mathrm{F} 120$ & DIFFlEM & DIFF $1 B$ \\
\hline$P 1$ & 20005,1 & 29,1 & 30.5 & 20003,81487 & 20004,23333 & $-0,42$ & 20001,922 & $-2,31$ \\
\hline$P 2$ & 20004,1 & 29,1 & 30.5 & 20002,81487 & 20003,16667 & $-0,35$ & 20000,922 & $-2,24$ \\
\hline$P 3$ & 20004,5 & 29,3 & 30,5 & 20003,16096 & 20003,53333 & $-0,37$ & 20001,206 & $-2,33$ \\
\hline$P 4$ & 20006,3 & 29,3 & 30,5 & 20004,96096 & 20005,2 & $-0,24$ & 20003,006 & $-2,19$ \\
\hline$P 5$ & 20006 & 28,9 & 30,5 & 20004,76879 & 20005,03333 & $-0,26$ & 20002,938 & $-2,10$ \\
\hline$P 6$ & 20004,9 & 29,1 & 30,5 & 20003,61487 & 20003.86667 & $-0,25$ & 20001,722 & $-2,14$ \\
\hline$P 7$ & 20006,4 & 29,1 & 30,5 & 20005,11487 & 20005,56667 & -0.45 & 20003,222 & -2.34 \\
\hline$P 8$ & 20006,4 & 29,1 & 30,5 & 20005,11487 & 20005,6 & $-0,49$ & 20003,222 & $-2,38$ \\
\hline$P 9$ & 20005,9 & 29,4 & 30,5 & 20004,534 & 20004,93333 & $-0,40$ & 20002,548 & $-2,39$ \\
\hline$P 10$ & 20005 & 29,6 & 30,5 & 20003 & 20004,2 & $-0,62$ & 20001,532 & $-2,67$ \\
\hline$P 1$ & 20004,7 & 25,9 & 23 & 200033,33999 & 20004,23333 & $-0,89$ & 20001,878 & $-2,36$ \\
\hline$P^{2}$ & 20004,2 & 26,2 & 23 & 20002,75912 & 20003,16667 & $-0,41$ & 20001,204 & $-1,96$ \\
\hline P3 & 20003,8 & 23.1 & 23 & 20003.19478 & 20003,53333 & $-0,34$ & 20002,602 & $-0,93$ \\
\hline$P_{4}$ & 20005,7 & 23.2 & 23 & 20005,06782 & $2000 \tilde{j}, 2$ & $-0,13$ & 200004,444 & $-0,76$ \\
\hline$P 5$ & 20005,7 & 24,6 & 23 & 20004,69042 & 20005,03333 & $-0,34$ & 20003,632 & $-1,40$ \\
\hline$P 6$ & 20001,1 & 23,4 & 23 & 20003,41391 & 20003,86667 & $-0,45$ & 20002,728 & $-1,14$ \\
\hline$P 7$ & 20005,4 & 22,9 & 23 & 20004,84869 & 20005,56667 & $-0,72$ & 20004,318 & -1.25 \\
\hline$P 8$ & 20005 & 21,5 & 23 & 20004,82608 & 20005,6 & $-0,77$ & 20004,73 & $-0,87$ \\
\hline$P 9$ & 20004,5 & 22,1 & 23 & 20004,16434 & 20004,93333 & $-0,77$ & 20003,882 & $-1,05$ \\
\hline$P 10$ & 20005,4 & 25,5 & 23 & 20004,14781 & 20004,2 & $-0,05$ & 20002,81 & $-1,39$ \\
\hline
\end{tabular}




\begin{tabular}{|c|c|c|c|c|c|c|c|c|}
\hline Peça & F1SC & TP'istãon & TPadrão & F1CEM & $\mathrm{F} 1 \mathrm{CB}$ & F120 & DIFF1EM & DIFF1B \\
\hline$P 1$ & 20004,5 & 29,5 & 31,1 & 20003,21955 & 20004,23333 & $-1,01$ & 20001,27 & $-2,96$ \\
\hline$P 2$ & 20003,6 & 30,9 & 31,1 & 20001,94215 & 20003,16667 & $-1,22$ & 19999,558 & $-3,61$ \\
\hline$P 3$ & 20004,5 & 31,2 & 31,4 & 20002.76128 & 20003,53333 & $-0,77$ & 20000,284 & $-3,25$ \\
\hline$P^{\prime} 4$ & 20006,8 & 32 & 31,4 & 20004,84563 & 20005,2 & $-0,35$ & 20002,12 & $-3,08$ \\
\hline$P 5$ & 20005,8 & 31,2 & 31,4 & 20004,06128 & 20005,03333 & $-0,97$ & 20001,584 & $-3,45$ \\
\hline$P 6$ & 20005,3 & 31,7 & 31,4 & 20003,4265 & 20003,866667 & 0,44 & 20000,794 & 3,07 \\
\hline$P 7$ & 20006,3 & 30,7 & 31,4 & 20004,69607 & 20005,56667 & $-0,87$ & 20002,374 & $-3,19$ \\
\hline$P 8$ & 20006,3 & 30,7 & 31,4 & 20004,69607 & 20005,6 & $-0,90$ & 20002,371 & $\ldots 3,23$ \\
\hline$P 9$ & 20005,6 & 29,7 & 31,4 & 20004,26503 & 20004,93333 & $-0,67$ & 20002.254 & $-2,68$ \\
\hline$P 10$ & 20005,2 & 30,6 & 31,4 & 20003,62302 & 200 & $-0,58$ & 20001,332 & $-2,87$ \\
\hline$P 1$ & 20005,3 & 38,2 & 46,2 & 20003,52431 & 20004,23333 & $-0,71$ & 19999,984 & $-4,25$ \\
\hline$P 2$ & 20004,5 & 38,9 & 46,2 & 20002,53562 & 20003,166667 & $-0,63$ & 19998,778 & $-4,39$ \\
\hline$P 3$ & 20004,7 & 38,2 & 46,2 & 20002,92431 & 20003,53333 & $-0,01$ & 19999,384 & $-4,15$ \\
\hline$P 4$ & 20007,9 & 39,5 & 46,2 & 20005.77388 & 20005,2 & 0.57 & 20001,83 & $-3,37$ \\
\hline$P 5$ & 20006,9 & 40,3 & 46,2 & 20004,55822 & 20005,03333 & $-0,48$ & 20000,366 & $-4,67$ \\
\hline$P 6$ & 20006,1 & 41 & 46,2 & 20003,56953 & 20003.86667 & $-0,30$ & 19999,16 & $-4,71$ \\
\hline$P 7$ & 20006,4 & 37,5 & 46,2 & 20004,81301 & 20005,56667 & $-0,75$ & 20001,49 & $-4,08$ \\
\hline$P 8$ & 20006,3 & 37,5 & 46,2 & 20004,71301 & 20005.6 & $-0,89$ & 20001,39 & $-4,21$ \\
\hline$P 9$ & 20007,1 & 40,2 & 46,2 & 20004,78518 & 20004,93333 & $-0,15$ & 20000,624 & $-4,31$ \\
\hline$P 10$ & 20004,2 & 36,2 & 46,2 & 20002,96345 & 20004,2 & $-1,24$ & 20000,044 & $-4,16$ \\
\hline
\end{tabular}




\begin{tabular}{|c|c|c|c|c|c|c|c|c|}
\hline Peça & F1SC & TPistão & TPadrão & F1CEM & $\mathrm{F} 1 \mathrm{CB}$ & $\mathrm{F} 120$ & DIFF1EM & DIFF1B \\
\hline$P 1$ & 20005 & 29,3 & 30,1 & 200003,61096 & 20004,23333 & $-0,62$ & 20001,626 & $-2,61$ \\
\hline$P 2$ & 20004 & 29,6 & 30,1 & 20002,530019 & 20003,16667 & $-0,64$ & 20000,452 & -2.71 \\
\hline$P 3$ & 20004,6 & 29,2 & 30,1 & 20003,23792 & 20003,53333 & $-0,30$ & 20001.284 & $-2,25$ \\
\hline$P 4$ & 20007 & 30,6 & 30,1 & 20005,26052 & 200005,2 & 0,06 & $20002: 872$ & $-2,33$ \\
\hline P5 & 20000,4 & 30,1 & 30). 1 & 200004.79531 & 20005,03333 & $-0,24$ & 20002,562 & $-2,47$ \\
\hline$P 6$ & 20005,7 & 30,7 & 30,1 & $200003: 93357$ & 20003,86667 & 0,07 & 20001,514 & $-2,35$ \\
\hline$P 7$ & 20006,4 & 29,2 & 30,1 & 20005,03792 & 20005,56667 & $-0,53$ & 20003,084 & $-2,48$ \\
\hline$P 8$ & 20000,5 & 30,2 & 30,1 & 20004,86835 & 20005,6 & $-0,73$ & 20002,604 & $-3,00$ \\
\hline$P 9$ & 20006,2 & 29,4 & 30,1 & 20004,781 & 20004,93333 & $-0,1 j$ & 200002,768 & $-2,17$ \\
\hline$P 10$ & 20005,6 & 30,9 & 30,1 & 20003,77965 & 20004,2 & $-0,42$ & 20001,298 & $-2,90$ \\
\hline$I^{\prime} 1$ & 20004,8 & 37,4 & 38,6 & 8997 & $20004,2:$ & $-1,94$ &, 428 & $-5,81$ \\
\hline$P 2$ & 20004 & 38,1 & 38,6 & 20001,30127 & 20003,16667 & $-1,87$ & 19997,222 & $-5,94$ \\
\hline$P 3$ & 20004,6 & 36,7 & 38,6 & 20002,27866 & 20003,53333 & $-1,25$ & 19998,634 & $-4,90$ \\
\hline$P 4$ & 20007,3 & 39,6 & 38,6 & 20004,19692 & 20005,2 & $-1,00$ & 19999,652 & $-5,55$ \\
\hline$P 5$ & 20005,9 & 39,2 & 38,6 & 20002,90475 & 20005,03333 & $-2,13$ & $19998,48.1$ & $-6,55$ \\
\hline$P_{6}$ & 20004,7 & 38,4 & 38,6 & 2000 & 20003,86667 & $-1,95$ & 19997,748 & $-6,12$ \\
\hline$P 7$ & 20006,1 & 36,7 & 38,6 & 200003,77866 & 20005,56667 & $-1,79$ & 200000,134 & $-5,43$ \\
\hline P8 & 20006,1 & 36,6 & 38,6 & 200013,80562 & 20005,6 & $-1,79$ & 20000,192 & $-5,41$ \\
\hline$P 9$ & 20006,5 & 39 & 38,6 & 20003,55866 & 20004,93333 & $-1,37$ & 19999,2 & $--5,73$ \\
\hline$P 10$ & 20004,9 & 36,8 & $38: 6$ & 20002,55171 & 20004,2 & $-1,65$ & 19998,876 & $-5,32$ \\
\hline
\end{tabular}




\begin{tabular}{|c|c|c|c||c|c|c|c|c|}
\hline Pcça & F1SC & TPistão & TPadrão & F1CEM & F1CB & F120 & DIFF1FM & I)II]1B \\
\hline$P 1$ & 20005,2 & 31,2 & 34,4 & 20003,83628 & 20004,23333 & $-0,40$ & 20001,584 & $-2,65$ \\
\hline$P 2$ & 20004,3 & 31,7 & 34,4 & 20002,8015 & 20003,16667 & $-0,37$ & 20000.394 & $-2,77$ \\
\hline$P 3$ & 20004,7 & 32 & 34,4 & 20003,12063 & 20003,53333 & $-0,41$ & 20000,62 & $-2,91$ \\
\hline$P 4$ & 20006,6 & 32,6 & 34,4 & 20004,85889 & 20005,2 & $-0,34$ & 20002,172 & $-3,03$ \\
\hline$P 5$ & 20006,2 & 32,2 & 34,4 & 20004,56672 & 20005,03333 & $-0,47$ & 20002,004 & $-3,03$ \\
\hline$P 6$ & 20005,1 & 32,4 & 34,4 & 20003,4128 & 20003,86667 & $-0,45$ & 20000,788 & $-3,08$ \\
\hline$P 7$ & 20006,4 & 31,5 & 34,4 & 20004,95541 & 20005,56667 & $-0,61$ & 20002,61 & $-2,96$ \\
\hline$P 8$ & 20006,4 & 31,3 & 34,4 & 20005,00933 & 20005,6 & $-0,59$ & 20002,726 & $-2,87$ \\
\hline$P 9$ & 20006,1 & 31,4 & 34,4 & 20004,68237 & 20004,93333 & $-0,25$ & 20002,368 & $-2,57$ \\
\hline$P 10$ & 20004,9 & 31,2 & 34,4 & 20003,53628 & 20004,2 & $-0,66$ & 20001,284 & $-2,92$ \\
\hline
\end{tabular}




\section{Bibliografia}

[1] Drapcr, N.R. \& Smith, H. Applicd Regression Analysis, Nova Iorque: John Wiley c Sons, 1998.

22. Dempster,A.P. \& Laird,N.M. \& and Rubin,D.B.1977. Maximum likelihood from incomplete data via the F.M algorithm, Jomal of the Royal Statistical Society, Series B, 39, 1-38.

[3] Gelman,A.E. \& Rubin,D. 1992. Inference from iterative sinulation using secquences, Statistical Science, vol 7, 457-511.

[4] Gelmanl,A.E. \& Gelman,D.1984. Stochastic Rclaxation, Gibbs Distribuitions and the Baycsian Restoration of Images. IEEE Transaction on Pattern Analysis and Machine Intelligenec,n.6,pg 721-711.

[5] Dolby,G.R.1976. 'The ultrastructural relation: A synthesis of the relations. Bimetrica, $63,1,39-50$

6) Box, G.E.P. \& N.R. Draper 1987. Empirical Model Building and Response Surface. Wiley, New York.

[7. Pranlab, K.S \& Singer, M.J. 1993. Large Sample Methods in Statistics. Chapman Hall/CRC.

[8. Graybill, F.A. 1976. Theory and Application of the Lincar Model, Pacific Grove, California.

[9] Graybill, F.A. 1983, Matrices with Applications in Statistics, $2^{0}$ edition. 
[10] Cheng, C.L. \& Van Ness, J.W. 1999. Statistical Regression with Measurement Error. Kendall's of Statistic 6. Arnold.

11] Fuller,W.A.1987. Measurcment Error Models, John Wilcy \& Sons.

[12] Pericchi, L.R. \& Smith, A.F.M 1992. Exact and Approximate Posterior Moments for a Normal Location Paramctcr. Journal Royal Statistical Socicty. B, 54, 3, 793-804.

13] Tanner, M.A. \& Wong, W.II. 1987. The calculation of Posteriori Distribuitions by Data Augmention. Journal of the Amarican Statistical Association, 82 (398), Theory and Methods, 528-540. 